\title{
Carbon-Based Composites as Electrocatalysts for Oxygen Evolution Reaction in Alkaline Media
}

\author{
Paweł Stelmachowski ${ }^{1, * \mathbb{D}}$, Joanna Duch ${ }^{2}$, David Sebastián ${ }^{3} \mathbb{D}$, María Jesús Lázaro ${ }^{3}$ (D) and Andrzej Kotarba ${ }^{1} \mathbb{D}$ \\ 1 Faculty of Chemistry, Jagiellonian University, Gronostajowa 2, 30-387 Krakow, Poland; ak@uj.edu.pl \\ 2 Department of Bioinorganic Chemistry, Faculty of Chemistry, University of Gdańsk, Wita Stwosza 63, \\ 80-308 Gdańsk, Poland; joanna.duch@ug.edu.pl \\ 3 Instituto de Carboquímica (CSIC), Miguel Luesma Castán 4, 50018 Zaragoza, Spain; \\ dsebastian@icb.csic.es (D.S.); mlazaro@icb.csic.es (M.J.L.) \\ * Correspondence: pawel.stelmachowski@uj.edu.pl
}

Citation: Stelmachowski, P.; Duch, J.; Sebastián, D.; Lázaro, M.J.; Kotarba, A. Carbon-Based Composites as Electrocatalysts for Oxygen Evolution Reaction in Alkaline Media. Materials 2021, 14, 4984. https://doi.org/ $10.3390 /$ ma14174984

Academic Editor: Salvatore Scirè

Received: 30 July 2021

Accepted: 24 August 2021

Published: 31 August 2021

Publisher's Note: MDPI stays neutral with regard to jurisdictional claims in published maps and institutional affiliations.

Copyright: (C) 2021 by the authors. Licensee MDPI, Basel, Switzerland. This article is an open access article distributed under the terms and conditions of the Creative Commons Attribution (CC BY) license (https:// creativecommons.org/licenses/by/ $4.0 /)$.
Abstract: This review paper presents the most recent research progress on carbon-based composite electrocatalysts for the oxygen evolution reaction (OER), which are of interest for application in low temperature water electrolyzers for hydrogen production. The reviewed materials are primarily investigated as active and stable replacements aimed at lowering the cost of the metal electrocatalysts in liquid alkaline electrolyzers as well as potential electrocatalysts for an emerging technology like alkaline exchange membrane (AEM) electrolyzers. Low temperature electrolyzer technologies are first briefly introduced and the challenges thereof are presented. The non-carbon electrocatalysts are briefly overviewed, with an emphasis on the modes of action of different active phases. The main part of the review focuses on the role of carbon-metal compound active phase interfaces with an emphasis on the synergistic and additive effects. The procedures of carbon oxidative pretreatment and an overview of metal-free carbon catalysts for OER are presented. Then, the successful synthesis protocols of composite materials are presented with a discussion on the specific catalytic activity of carbon composites with metal hydroxides/oxyhydroxides/oxides, chalcogenides, nitrides and phosphides. Finally, a summary and outlook on carbon-based composites for low temperature water electrolysis are presented.

Keywords: water electrolysis; hydrogen production; energy conversion; carbon composites

\section{Introduction}

The world economy is expanding continuously, and energy demand increases likewise. It is predicted that the energy consumption will double by 2050 and triple by 2100 compared to the year 2001 [1,2]. The concomitant increase in $\mathrm{CO}_{2}$ emissions makes the current situation critical, resulting in the increased implementation of new policies for environmental protection. In addition, the limited fossil fuel reserves and their uneven distribution on the Earth call for a more distributed way of energy conversion and storage. Therefore, one of the greatest challenges for humanity in the 21st century is the development of renewable energy systems [1]. Within this area, the aspects of efficient conversion and energy storage in a safe, effective, and scalable way hold the key to commercial applications [3-6].

Currently, large amounts of energy are stored through the pumped hydro energy storage systems. However, its biggest disadvantage is its dependence on specific geographical features for installation and political environment [4]. In the meantime, hydrogen is considered one of the energy vectors that will play a key role in future mobile energy conversion devices [6-9]. Hydrogen is very abundant in nature but is bound in the form of $\mathrm{H}_{2} \mathrm{O}$ or $\mathrm{C}_{\mathrm{x}} \mathrm{H}_{\mathrm{y}}$. To become a sustainable energy carrier, the production process of hydrogen has to use renewable energy sources (sun, wind, hydropower) and the substrate itself has to be renewable $\left(\mathrm{H}_{2} \mathrm{O}\right)$. 
Water electrolysis using renewable energy sources and water as a substrate may be an answer to the problem of sustainable hydrogen production. It is also a fascinating subject for studies from the fundamental point of view as the reaction itself is very complex, as are the reaction conditions. The oxidation of oxygen atoms from water releases the protons and electrons required for the formation of hydrogen gas. However, water oxidation, whether in acidic or alkaline conditions, suffers from the kinetic limitations of the oxygen evolution reaction (OER) at the anode rather than by the limitations associated with the hydrogen evolution reaction (HER) at the cathode. The reason is mostly due to the four-electron transfer process of the OER compared to the two-electron transfer step of the HER [7]. At the same time, for practical applications, the architecture of the electrode interface plays an equally important role, since a triple-phase boundary of gas, liquid electrolyte, and solid electrocatalyst is the scene where the water electrolysis takes place [10].

The equilibrium redox potential $\left(E_{\mathrm{r}}\right)$ for the splitting of a water molecule is $1.23 \mathrm{~V}$. For practical yields in electrolysis cells, a higher voltage is required. This additional voltage, above $1.23 \mathrm{~V}$, is called the overpotential $(\eta)$. From the mechanistic point of view, the most popular proposed reaction schemes involve the coupling of electron and proton transfer in every step. If this coupling was always present in the oxygen evolution reaction pathway, it would put severe limitations on the optimization of the catalysts. In such a case, the energy barrier for each of the electron transfer steps would be different, and thus at least one would be higher than $1.23 \mathrm{~V}$ and the thermodynamic potential of the overall reaction could not be attained (Figure 1). However, highly active OER catalysts can be designed as multi-component materials, where the proposed linear correlation of the binding energies of intermediates (scaling relations) are valid no more, and other mechanisms may come into play [11]. Nonetheless, high catalytic activity is only one of the requirements for a practical application of an OER catalyst in water splitting devices since the catalytic materials are also required to exhibit long-term stability.

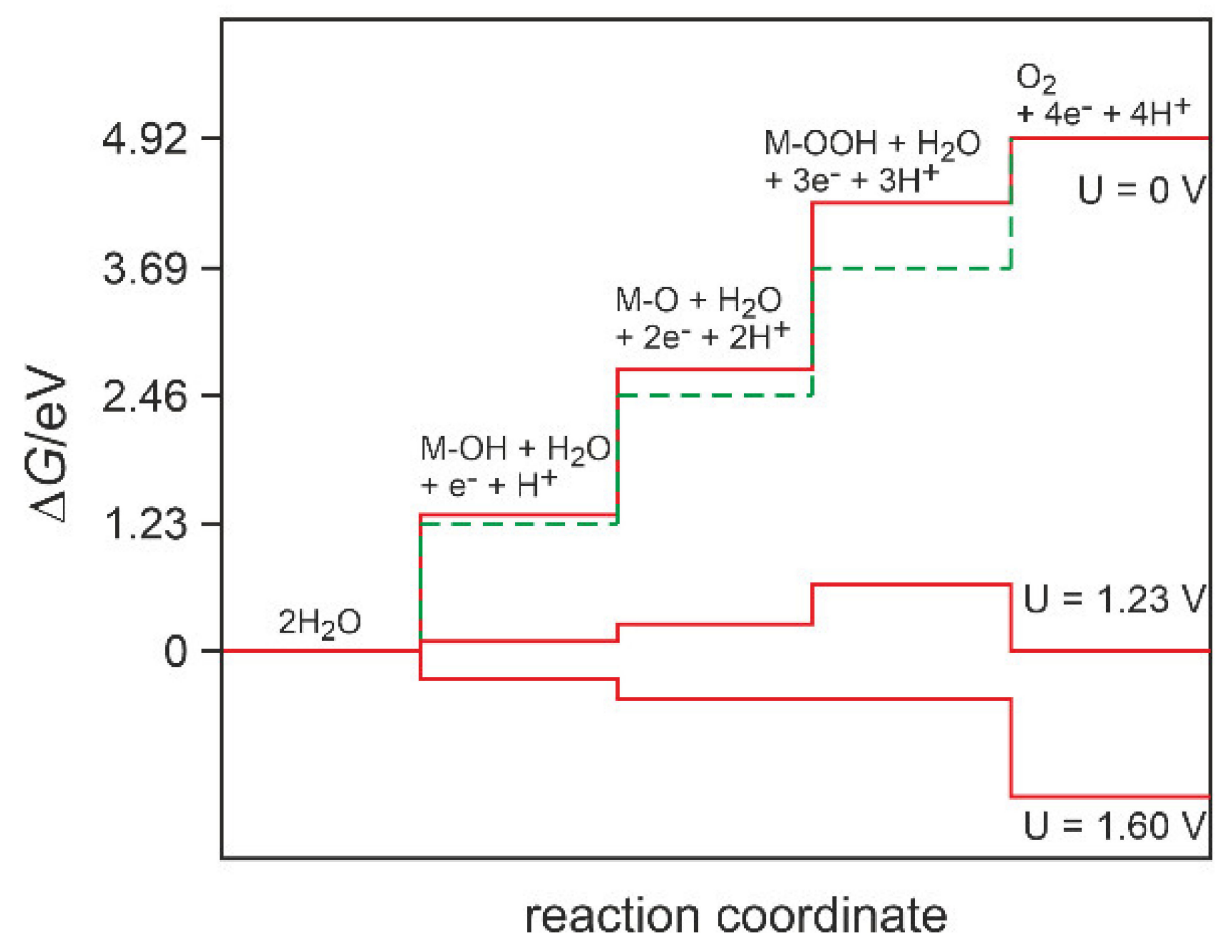

Figure 1. Energetics of OER over $\mathrm{RuO}_{2}$. Red, solid lines depict the Gibbs free energies of the reaction intermediates at three different external potentials $U=0 \mathrm{~V}, U=1.23 \mathrm{~V}$, and $U=1.60 \mathrm{~V}$. Only at $1.60 \mathrm{~V}$ are all the reaction steps thermodynamically favorable. Green, dashed line depicts the ideal $1.23 \mathrm{~V}$ barrier for all of the reaction steps. Figure adapted from [12]. 
From a scientific point of view, catalytic water electrolysis has attracted considerably increased attention in the last two decades (Figure 2).

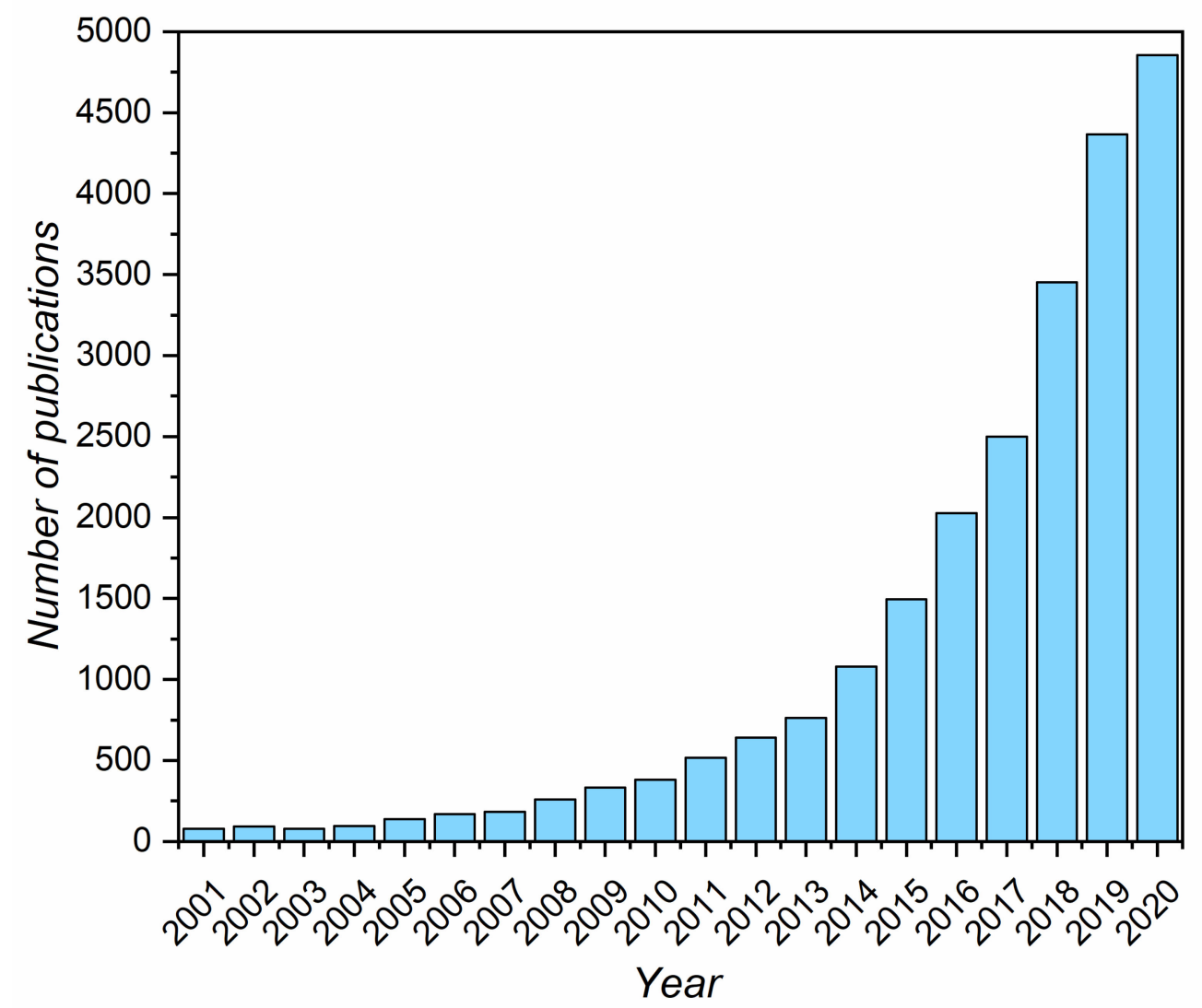

Figure 2. Scopus search results on TITLE-ABS-KEY ((“water splitting” OR (water AND electrolysis) OR “oxygen evolution" OR oer OR “water oxidation") AND (catalyst OR catalytic OR electrocatalyst OR electrocatalytic)), July 2021.

Three main water splitting processes are studied to the largest extent: liquid alkaline water electrolysis (AWE), proton exchange membrane (PEM) electrolysis, and anion exchange membrane (AEM) electrolysis. Two former ones are already commercial technologies, the liquid alkaline with an over 50-year history [13], while the AEM is still an emerging technology [9]. Electrode reactions taking place in liquid alkaline and anion exchange membrane electrolyzers can be written as:

$$
\begin{aligned}
& \text { Anode: } 4 \mathrm{OH}^{-} \rightleftharpoons 2 \mathrm{H}_{2} \mathrm{O}+\mathrm{O}_{2}+4 \mathrm{e}^{-} \\
& \text {Cathode: } 4 \mathrm{H}_{2} \mathrm{O}+4 \mathrm{e}^{-} \rightleftharpoons 2 \mathrm{H}_{2}+4 \mathrm{OH}^{-}
\end{aligned}
$$

For PEM electrolyzers, the electrode reactions are:

$$
\begin{gathered}
\text { Anode: } 2 \mathrm{H}_{2} \mathrm{O} \rightleftharpoons \mathrm{O}_{2}+4 \mathrm{H}^{+}+4 \mathrm{e}^{-} \\
\text {Cathode: } 4 \mathrm{H}^{+}+4 \mathrm{e}^{-} \rightleftharpoons 2 \mathrm{H}_{2}
\end{gathered}
$$

Other related popular research areas include solid oxide electrolysis (SOE) [14] and direct photoelectrocatalytic (PEC) water splitting [15]. Oxygen evolution is an important reaction not only in the water electrolysis application, but also in reversible fuel cells, and metal-air batteries, and thus it is anticipated that OER will play a vital role in the design of efficient energy conversion and storage devices [16]. 


\section{Water Splitting Systems}

There are many excellent review papers on hydrogen generation through water splitting, which the reader is encouraged to read. These reports include recent progress reports on low-cost hydrogen production with anion exchange membrane electrolyzers [17], including hydroxide exchange membranes, with a tentative cost analysis [18]. The advances in alkaline water electrolyzers are described in [4], while solar-to-hydrogen energy conversion based on water splitting is covered in [19].

Due to the high abundance of original research papers related to the topic of water splitting (Figure 2), the presented state-of-the-art knowledge is mostly based on recent publications, and the description is not intended to be comprehensive. The conditions for water splitting systems, and thus the most active phases, differ between liquid alkaline water, proton exchange membrane, and anion exchange membrane electrolysis. Alkaline electrolyzers are characterized by a robust performance, long lifetime, and low cost of the electrode materials, especially anodic, which consist mainly of abundant transition metals ( $\mathrm{Fe}, \mathrm{Ni}, \mathrm{Co}, \mathrm{Cu}$, and $\mathrm{Mn}$ oxides) and carbon-based materials (nitrogen-doped carbons). AWEs have been commercially employed for a long time now, and they represent a mature technology. In their application, however, the parts of the electrolyzer systems, such as separators and catalysts, that were developed many years ago are still used, while novel alternatives are already present. The main obstacle to be overcome to improve the longterm durability is the high overpotential of the anodic reaction, which causes corrosion of the active phase and support materials. Alkaline water electrolyzers comprise a set of electrodes separated by a diaphragm immersed in an alkaline solution, usually $6 \mathrm{M}$ potassium hydroxide (25 to $30 \mathrm{wt}$ \%) (Figure 3) [7]. Currently, the biggest challenges for AWEs include increasing porosity of the electrodes and catalytic layer to enhance reagent diffusion and gas bubble removal to decrease the ohmic fall, modification of the Ni cathode to increase its durability against the formation of hydride, which results in decreased mechanical stability (hydrogen embrittlement), and improvement of the separators to obtain gasses with greater purity [4].
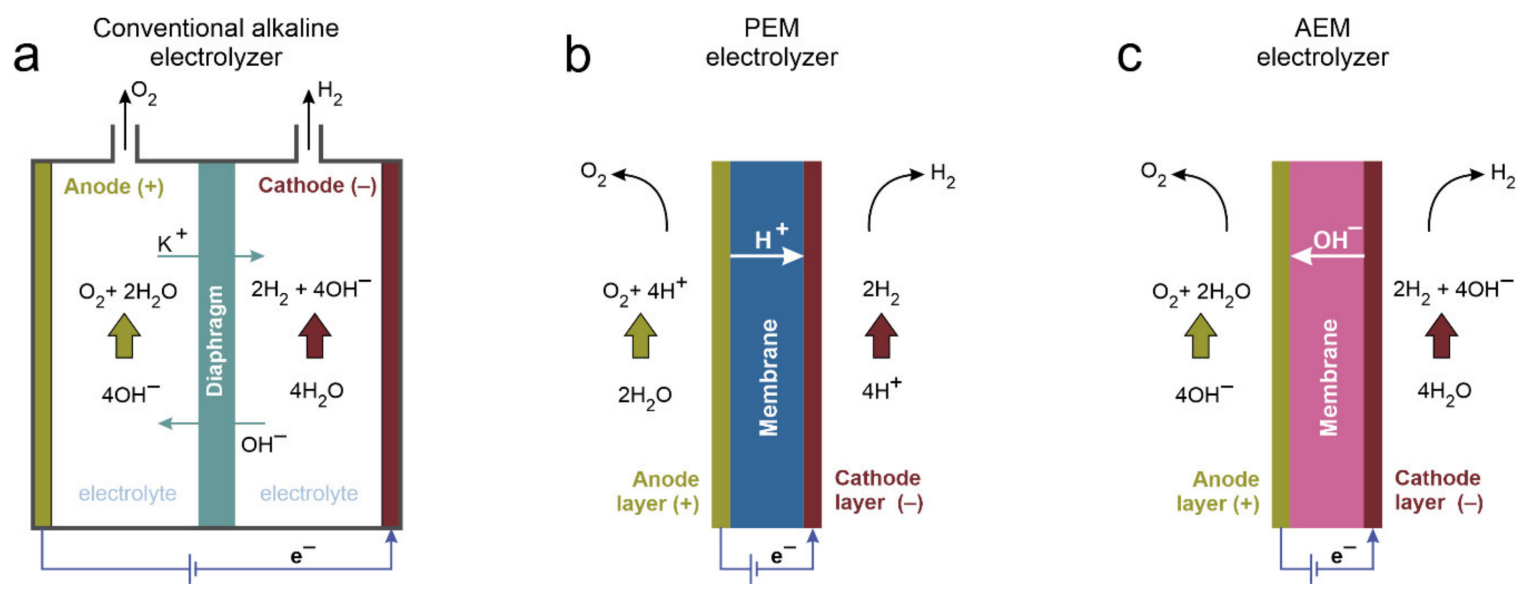

Figure 3. Schematic diagrams of electrolyzers for low temperature water splitting. Commercially available technologies: (a) liquid $\mathrm{KOH}$ and (b) proton exchange membrane (PEM) electrolyzers. Development stage technology: (c) anion exchange membrane (AEM) electrolysis.

\subsection{Proton Exchange Membrane Electrolyzers}

PEM electrolyzers, in comparison to AEM systems, are beneficial in terms of lower ohmic losses, higher purity of produced gases, lower overpotentials, higher operating current density, swifter responsiveness, larger range of partial load, and a more compact electrolyzer device. The main disadvantages of proton exchange electrolyzers are due to restrictions as to the anode catalysts, and also other device parts such as separator plates 
and current collectors since the heavily corrosive environment in combination with high electrode potentials requires high durability of the materials [11]. The development of more robust PEM electrolyzers can be enabled through the designing of more chemically and thermomechanically durable solid polymeric electrolyte membranes, resolving the issue of degradation of anodic collector bipolar plates, developing catalysts to replace $\mathrm{Ir}$ (or other noble metals), increasing the purity through decreasing the diffusivity in the solid phase of membranes [4]. The corrosive environment in the PEM cells requires the anodic catalysts to be based on the noble metals, electrochemically oxidized, for which the general trend of activity follows the order $\mathrm{Ru}>\mathrm{Ir}>\mathrm{Rh}>\mathrm{Pt}>\mathrm{Au}$ [11]. The catalysts' development focuses on the optimal utilization of noble metals, preferably with atomic efficiency, although Mn-based oxides were recently reported to exhibit promising stability at low potentials [20,21].

\subsection{Alkaline Exchange Membrane Electrolyzers}

AEM electrolysis is an emerging technology. The development of polymeric anion exchange membranes has gained momentum due to their application in alkaline fuel cells. However, they can also be used in water electrolysis systems, offering several benefits such as the use of catalysts based on transition metals instead of noble metal-based materials, use of distilled water (or low concentration alkaline solution) instead of high concentration $\mathrm{KOH}$ solution, cheaper substrates for the membrane production (quaternary ammonium ion-exchange-group-containing compounds) in comparison with the Nafion ${ }^{\circledR}$-based membranes, decreased degradation through to interaction with $\mathrm{CO}_{2}$ due to lack of metal ions in the AEM structure, and more versatility of the device engineering due to the absence of a corrosive liquid electrolyte. To develop this technology for commercial applications some important issues have to be addressed, such as improving the anionic conductivity of polymers for the membranes, developing improved hydroxyl ion conductivity in ionomers, developing the OER and HER catalysts, deeper characterization of the membrane electrode assemblies from the physical and electrochemical standpoint, and commercialization and industrialization of AEM electrolysis [17].

Recently, Park et al. reported on a Ni/C catalyst alloyed with Co and supported on carbon cloth for an AEM water electrolyzer [22]. The electrocatalyst was applied as the cathode in stack cell (five-cell), demonstrating a performance of $740 \mathrm{~mA} \mathrm{~cm}^{-2}$ at $9.25 \mathrm{~V}$ stack and almost $70 \%$ efficiency at $440 \mathrm{~mA} \mathrm{~cm}^{-2}(150 \mathrm{~h})$. Lindquist et al. investigated an AEM electrolyzer consisting of commercially available electrocatalytic materials (carbon paper as a component of the cathode) that performed below $2 \mathrm{~V}$ at $1 \mathrm{~A} \mathrm{~cm}^{-2}$ in pure water [23]. More recent examples of the application of carbon-based materials for AEM electrolyzers can be found in $[24,25]$ Despite a growing number of articles devoted to alkaline exchange membrane electrolyzers, only a small portion of studies show cell performance results [26]. Nevertheless, the available data points to the increasing progress of cell performance achieved in the last decade, giving hope for the development of commercial AEM systems. Nowadays, one of the leading companies working on commercial AEM electrolyzers is Enapter. According to Enapter, their modular devices, using AEM water electrolysis, enable the production of $500 \mathrm{NL} \mathrm{h}^{-1}$ of green $\mathrm{H}_{2}$ (99.9\% purity) [27]. Furthermore, the expansion of AEM technology can be accelerated by the international HydroGEN consortium, which works on the development of advanced water-splitting technologies [24].

Both alkaline water and alkaline exchange membrane electrolyzers can benefit from advancements of similar catalysts for higher efficiency. However, it has to be remembered that the typical results obtained with the rotating disc electrode in a three-electrode cell may be ill-suited to evaluate the catalysts' oxygen-evolution activity for AEM systems. While the $\mathrm{NiFeO}_{\mathrm{x}} \mathrm{H}_{\mathrm{y}}$ oxyhydroxides are among the best oxygen evolution reaction catalysts in alkaline electrolytes, they perform poorly in AEM electrolyzers, where pure water is used in combination with the solid alkaline electrolyte. Under AEM electrolyzer conditions, the $\mathrm{NiCoO}_{\mathrm{x}}$-based catalysts are among the best performing materials. Therefore, different 
catalysts' compositions have to be tested in relevant conditions to determine their structureactivity relationships [28].

\subsection{A Brief Overview of Carbon-Free Catalytic Materials for Oxygen Evolution Reaction in Alkaline Media}

In this section, a non-exhaustive review of carbon-free OER catalysts is given to illustrate the most important approaches to date. In Table 1, as well as in subsequent tables, the activity results are reported in terms of overpotential, that is, the deviation of potential from equilibrium ( $E_{\mathrm{r}}=1.23 \mathrm{~V}$ vs. reversible hydrogen electrode, $\mathrm{RHE}$ ) required to cause a given current density $\left(10 \mathrm{~mA} \mathrm{~cm}{ }^{-2}\right)$. Another important parameter is the Tafel slope, representing the variation in overpotential with the logarithmic increase of current, i.e., as well as overpotential, the lower the better. Tafel slope is an indication of the reaction mechanism since it is related to the rate-determining step. In the oxygen evolution, the reaction mechanism in alkaline medium can be described as a series of steps assuming a single-site mechanism (* denotes an active site), as follows (Equations (5)-(9)):

$$
\begin{aligned}
& { }^{*}+\mathrm{OH}^{-} \rightleftharpoons{ }^{*} \mathrm{OH}+\mathrm{e}^{-} \\
& { }^{*} \mathrm{OH}+\mathrm{OH}^{-} \rightleftharpoons{ }^{*} \mathrm{O}+\mathrm{H}_{2} \mathrm{O}+\mathrm{e}^{-} \\
& { }^{*} \mathrm{O}+\mathrm{OH}^{-} \rightleftharpoons{ }^{*} \mathrm{OOH}+\mathrm{e}^{-} \\
& { }^{*} \mathrm{OOH}+\mathrm{OH}^{-} \rightleftharpoons{ }^{*} \mathrm{OO}^{-}+\mathrm{H}_{2} \mathrm{O} \\
& { }^{*} \mathrm{OO}^{-} \rightleftharpoons{ }^{*}+\mathrm{O}_{2}+\mathrm{e}^{-}
\end{aligned}
$$$$
\begin{gathered}
\text { Tafel slope }=120 \mathrm{mV} \mathrm{dec}^{-1} \\
\text { Tafel slope }=30 \mathrm{mV} \mathrm{dec}^{-1} \\
\text { Tafel slope }=40 \mathrm{mV} \mathrm{dec}^{-1} \\
\text { Tafel slope }=30 \mathrm{mV} \mathrm{dec}^{-1} \\
\text { Tafel slope }=22 \text { or } 40 \mathrm{mV} \mathrm{dec}^{-1}
\end{gathered}
$$

\begin{tabular}{|c|c|c|c|c|c|c|}
\hline Electrocatalyst & КОН Concentration & Substrate & Loading/mg cm ${ }^{-2}$ & $\begin{array}{l}\text { Overpotential at } \\
10 \mathrm{~mA} \mathrm{~cm}-2 / \mathrm{mV}\end{array}$ & Tafel Slope/mV dec ${ }^{-1}$ & Ref. \\
\hline G-FeCoW & $1 \mathrm{M}$ & GCE* & 0.21 & 223 & 37 & [29] \\
\hline$\alpha-\mathrm{Co} 4 \mathrm{Fe}(\mathrm{OH})_{x}$ & $1 \mathrm{M}$ & GCE & 0.28 & 295 & 52 & [30] \\
\hline$(\mathrm{Ni}, \mathrm{Fe}) \mathrm{OOH}$ & $1 \mathrm{M}$ & $\mathrm{NF}^{*}$ & 4.0 & 154 & 41.5 & [31] \\
\hline $\mathrm{Co}_{3} \mathrm{O}_{4} \mathrm{C}-\mathrm{NA}$ & $0.1 \mathrm{M}$ & $\mathrm{Cu}$ foil & 0.2 & 290 & 70 & [32] \\
\hline $\mathrm{CoO}-\mathrm{MoO}_{2}$ & $1 \mathrm{M}$ & NF & $\mathrm{N} / \mathrm{A}$ & 270 & 36.5 & [33] \\
\hline Core-shell NiFeCu & $1 \mathrm{M}$ & NF & 10.2 & 180 & 33 & [34] \\
\hline $\mathrm{Ni}_{3} \mathrm{~S}_{2}$ nanorods & $0.1 \mathrm{M}$ & NF & 37 & 187 & 159 & [35] \\
\hline $\mathrm{Fe}_{7} \mathrm{~S}_{8}$ nanosheets & $1 \mathrm{M}$ & GCE & 0.143 & 270 & 43 & [36] \\
\hline $\mathrm{CoSe}_{2}$ nanosheet & $0.1 \mathrm{M}$ & GCE & 0.142 & 320 & 44 & [37] \\
\hline $\mathrm{CoTe}_{2}$ nanofleeces & $0.1 \mathrm{M}$ & GCE & 0.25 & 357 & 32 & [38] \\
\hline $\mathrm{Co}_{4} \mathrm{~N}$ nanowire & $1 \mathrm{M}$ & carbon cloth & 0.82 & 257 & 44 & [39] \\
\hline $\mathrm{FeP} / \mathrm{Ni}_{2} \mathrm{P}$ & $1 \mathrm{M}$ & NF & 8 & 154 & 22.7 & [40] \\
\hline
\end{tabular}

Table 1. Comparison of the OER performance of the best representative electrocatalysts in alkaline electrolytes.

${ }^{*}$ GCE—glassy carbon electrode; NF-nickel foam.

The Tafel slope depends on the reaction determining the overall rate (i.e., the ratedetermining step), which is a factor relying on the catalyst formulation and the overpotential. Together with each reaction (Equations (1)-(5)), we indicate the Tafel slope for overpotentials between 100 and $400 \mathrm{mV}$ according to the work of Shinagawa and coworkers [41]. An ideal catalyst should provide a catalytic pathway with the rate-determining step being associated with the lowest Tafel slope and towards four electrons for efficient oxygen formation. It is important to point out that a catalyst formulation may present active sites with different natures (presence of defects, different facets, etc.), which can lead to intermediate values of Tafel slopes as a result of the contribution from single active sites to the overall activity. For more details on the theoretical considerations of Tafel slopes in OER, the work of Shinagawa and coworkers is recommended [41].

\subsubsection{Metal Hydroxides/Oxyhydroxides}

Identification of the active phase in the OER in the case of crystalline metal hydroxides, which is crucial for understanding the reaction mechanism, and a rational design of 
catalysts are often impeded by the presence of at least two polymorphs, $\alpha$-phase and $\beta$ phase, as in the case of $\mathrm{Ni}(\mathrm{OH})_{2}$ and $\mathrm{Co}(\mathrm{OH})_{2}$. On the other hand, mixed-metal hydroxide phases have the advantage of a more flexible electron configuration. The addition of a different metallic element to a chosen hydroxide phase allows for the tuning of the electronic structure of the material and hence influences the adsorption energy of the reaction intermediates. Thus, it is one of the most common ways to enhance the reactivity of hydroxide-based materials [42,43]. Oxyhydroxides composed of Ni-Fe and Co-Fe are reported as the most active electrocatalyst for OER in the liquid alkaline electrolytes [44]. It is postulated that the iron dispersed in the matrix of $\mathrm{NiOOH}$ or $\mathrm{CoOOH}$ forms the actual active sites. Since $\mathrm{FeOOH}$ could not serve as a standalone catalytic material due to its electrical insulating properties, the nickel and cobalt oxyhydroxides provide electrical conductivity and chemical stability [45]. Recently, by comparison of Co-rich and Ni-rich (oxy)hydroxide nanosheets, it was found that the increased strength of $\mathrm{M}-\mathrm{O}$ bonds and porosity at the nanoscale substantially enhance the electrocatalyst stability during the electrochemical reaction [46].

\subsubsection{Metal Oxides}

Similarly to hydroxide electrocatalysts, first-row transition metal oxides (especially of $\mathrm{Ni}, \mathrm{Co}$, and $\mathrm{Fe}$ ) are the most popular metal oxide materials researched for oxygen evolution reaction in alkaline electrolytes. In particular, spinel- and perovskite-type oxide materials have been extensively studied [47-53]. For example, in $\mathrm{Co}_{3} \mathrm{O}_{4}$ the generation of oxygen vacancies enhances conductivity, and interactions with the support of or by doping with heteroatoms stabilizes $\mathrm{Co}^{4+}[54]$, which leads to the enhancement of electrocatalytic activity $[42,43]$. In general, stabilization of high oxidation states, as well as $\mathrm{Fe}^{4+}$ and $\mathrm{Ni}^{4+}$ in oxide matrices (spinel, perovskite), leads to better OER reactivity $[42,55,56]$. It has to be noted that the structural evolution taking place during electrochemical anodic reaction undergoes a remarkable structural transformation of the metal oxide catalysts under very high potential yields and results in the formation of the oxyhydroxide phase overlayer at the catalyst surface [57].

\subsubsection{Metal Chalcogenides}

Similarly to metal hydroxides and oxides, in the case of transition metal chalcogenides (TMCs) the most promising catalysts are $\mathrm{Fe}, \mathrm{Co}$, and Ni-based materials, including metal sulfides, selenides, and tellurides [42,43]. While TMCs have been broadly investigated in the electrocatalytic hydrogen evolution reaction, there is still room for their optimization towards OER.

\subsubsection{Metal Nitrides and Phosphides}

The high electrical conductivity of metal nitrides renders them ideal candidates for electrocatalytic materials, including oxygen evolution reaction. Similarly to oxide and oxyhydroxide electrocatalysts, mixed metal nitrides (bi- or trimetallic) exhibit a great potential due to the possibility of tuning their electronic properties [42,43]. Although phosphides may exhibit semiconducting or even insulating properties, for a particular atomic ratio of phosphorus and transition metal and suitable electronegativity difference the phosphides may exhibit metallic character, and for some metal-rich compounds superconductivity has been observed $[58,59]$. Exceptional conductivity of some bi- and trimetallic phosphides is reflected in the similar electronic structure to respective purely metallic materials [60]. As reported in Table $1, \mathrm{FeP} / \mathrm{Ni}_{2} \mathrm{P}$ hybrid electrocatalyst supported 3D Ni foam proved ex aequo the best OER reactivity in alkaline conditions. Moreover, it presented very high HER activity, allowing it to act as a bifunctional catalyst for overall water splitting in the same alkaline electrolyte [40]. Thermodynamically, under oxidizing conditions, metal sulfides are less stable than their respective metal oxides, while metal nitrides and phosphides are less stable than sulfides and phosphides, respectively. During strongly oxidative conditions of OER in water, it may be anticipated that metal nitrides and phosphides (and also sulfides, 
selenides) can easily undergo surface oxidation to the corresponding metal hydroxides or oxides [61,62]. Importantly, oxidation of electrocatalysts, such as cobalt and nickel phosphides in an alkaline environment can be used as an activation process for the oxygen evolution reaction in a neutral solution [63].

\section{Introduction to Carbon-Based Composite Materials}

Compared with traditional carbon materials, nanocarbons always exhibit higher electrical conductivity, larger surface area, tunable structural hierarchy, ultra-thin graphitic layer, and low dimensional properties. These unique features endow nanocarbons with multifunctionalities to strongly couple with other catalytically active components, resulting in significantly enhanced performances [64]. In recent years, transition metal/carbon (TM/C) composites have surfaced as a new class of effective catalysts for electrochemical oxygen and hydrogen evolution reactions. These composites usually exhibit the reactivity characteristics of their components (metal compound or carbon); however, the synergetic and interfacial effects are sought for and designed to endorse the material with enhanced electrocatalytic activities. A combination of cheap components, i.e., carbon and $\mathrm{Fe}-\mathrm{Co}-$, $\mathrm{Ni}$-phases and promising reactivities render them perfect candidates for the replacement of precious metal-based electrodes. Thus, new material formulations of the TM/C type, such as hierarchically porous carbon-supported TMs, carbon network supported TMs or carbon encapsulated TMs, are being developed to explore the possibility of deriving new functionalities. Parallel to developing new carbon morphologies, carbon doping, especially with $\mathrm{S}$ and $\mathrm{N}$, is used to obtain enhanced properties of the hybrid materials.

The oxygen evolution reactivities of spinel compounds, which are amongst the most active phases in the OER, are reported to be enhanced by dispersed deposition of spinel oxide phase onto structured carbon substrates such as graphene, single-walled carbon nanotubes (SWCNTs), and carbon nanosheets (CNS). Such a case was reported for the $\mathrm{CoCr}_{2} \mathrm{O}_{4}$, deposited onto carbon nanosheets or $\mathrm{Co}_{3} \mathrm{O}_{4}$ deposited onto carbon porous nanowire array, which displayed excellent OER activities, even outperforming the benchmark $\mathrm{RuO}_{2}$ [57]. Another highly active phase in the OER, NiFe hydroxide, was deposited in the form of nanoplates onto different nanocarbon-type materials to improve their electrical conductivity. Various classes of carbon materials were studied, ranging from graphene with different oxidation degrees to amorphous carbons nanoparticles (i.e., Vulcan XC-72R or Ketjen Black) to carbon nanotubes and carbon quantum dots. The composite materials formed with carbon black or carbon nanomaterials usually exhibit higher OER activity than single material type catalysts [65].

The transition metal alloys (TMAs) encapsulated in N-doped graphene are promising hybrid electrocatalysts for water splitting. The enhanced electron transfer at the interface of the TM core and the graphene shell is the main advantage for improved OER reactivity. Moreover, by changing the chemical composition of the transition metal core or thickness of the graphene shell, the electrocatalytic activity may be further tuned to improve the water-splitting activity. Transition metal sulfide (TMS) nanoparticles and nanosheets could be downsized to expose more highly active sulfur edges by a nano-confinement effect of carbon nanomaterials, resulting in the enhanced reactivity of TMSs. Such materials combined into TMS/carbon hybrids can be further enhanced by the rational introduction of another heteroatom, such as nitrogen, or defects into the composite materials. It is anticipated that the TMS/carbon composite materials may be good alternatives to precious metals, even for oxygen evolution reaction in acidic media. In the case of transition metal phosphides (TMPs), TMP/carbon composites are proven to be very effective for water splitting. Similar to other composite materials, the heterointerfaces with carbon are crucial in providing their high OER reactivity. The enhancement of active site exposition and acceleration of mass transport can be obtained in all cases by constructing composite structures based on hierarchically porous carbons, which may allow further improvement of the performance of all TM-phase carbon composites for water splitting $[43,47,66,67]$. 
A combination of two types of nanostructured carbon building blocks into nanocomposite structures has also been reported for electrochemical applications in lithium-ion batteries, metal-air batteries as oxygen reduction catalysts and bifunctional catalysts (OER and ORR), and as hydrogen evolving catalysts [67-72]. The carbon components are usually 1D structures (e.g., nanotubes) interconnecting 2D or 3D carbons doped with nitrogen to improve their electronic conductivity. In such materials, the carbon/carbon structure acts as a support for well-dispersed, non-noble, metal-based nanoparticles. The enhanced electrocatalytic activity of these materials is ascribed to the optimized surface chemical composition and distribution of the active phase, large specific surface area, and hierarchically porous microstructure resulting in improved electron and mass transport abilities [71-73].

The utilization of nanocarbons for high-efficiency hybrid electrocatalysts is based on the following effects: acceleration of the electron and mass transport; modification of the morphologies and properties of active components during the composite/hybrid fabrication; manipulation of the electronic structure through the interfacial charge transfer; generation of confinement effects resulting in (1) spatial restriction to hamper the sintering of nanoparticles, (2) significant electronic interaction to modify the property and activity of carbon shells, and (3) physical isolation of embedded nanoparticles from hostile operating conditions; and supporting electrocatalysts into 3D free-standing electrodes [64].

\section{Synthesis of Carbon-Based Nanocomposites}

In this section, the most popular strategies to prepare carbon-based composites are presented with the details of the synthetic procedures. The preparation of the composites starts with the surface functionalization of carbon components to increase their reactivity. Therefore, the pre-treatment routes of carbons are presented first, followed by a detailed description of the most successful approaches to form composites of carbon with transition metal compounds.

\subsection{Pre-Treatment of Carbons}

Recently, novel synthesis routes for the fabrication of new carbon structures have been extensively explored. The obtained materials can be additionally pre-treated before using as catalysts or supports to enhance their electrochemical performance during the OER process. Pre-treatment of carbons is instrumental in increasing specific surface area, introducing heteroatoms, tuning the electronic structure, improving conductivity, and developing porosity. Herein, common pre-treatment methods of previously fabricated carbon materials, as well as procedures for obtaining hetero-doped structures, will be presented rather than synthesis routes of bare carbons (Figure 4).

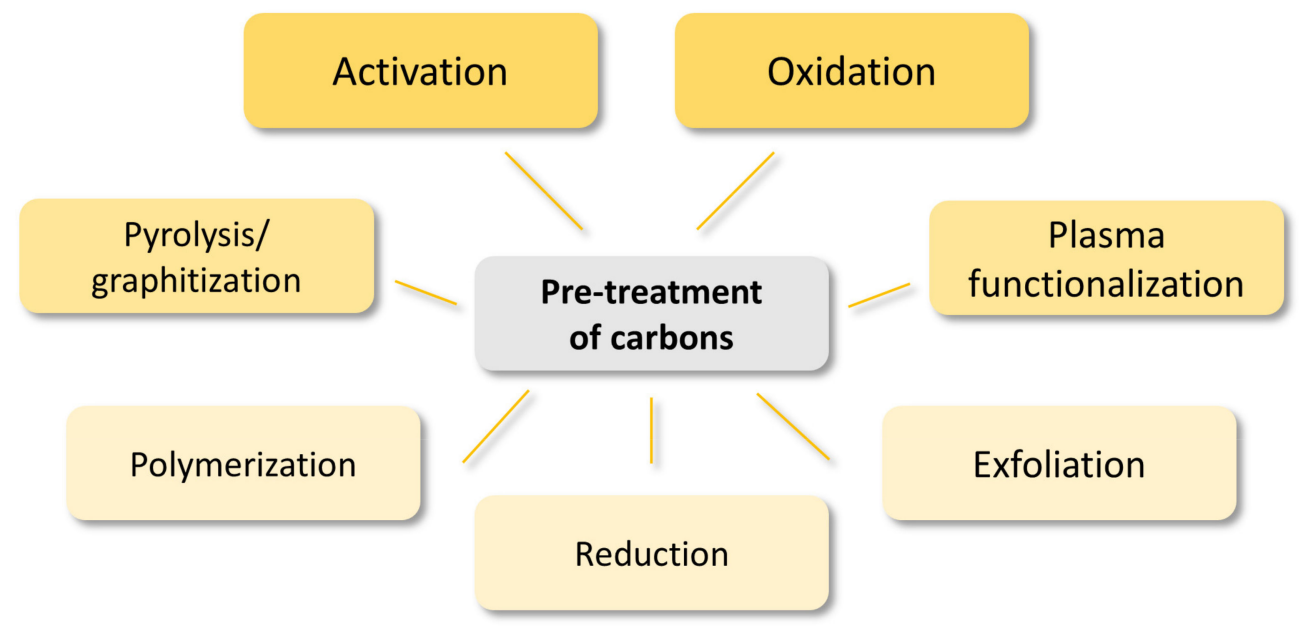

Figure 4. Graphical summary of typical pre-treatment strategies of carbon materials. 


\section{- Pyrolysis/graphitization}

To synthesize a composite consisting of carbon and red phosphorous, the sugar powder and red phosphorous were ground together. The mixture was reacted with a concentrated sulfuric acid to form foam-like carbon. Such obtained material was transformed into a tube furnace and pyrolyzed at $900{ }^{\circ} \mathrm{C}(3 \mathrm{~h})$ under a flow of argon [74]. As-synthesized ordered mesoporous carbons (SBA-15 silica as a template and a furan resin/acetone mixture as carbon precursor) were subjected to further modifications to enhance the formation of a crystalline carbon framework while maintaining the mesoporous structure. To meet the goal, ordered mesoporous carbons were graphitized at $1500^{\circ} \mathrm{C}$ for $1 \mathrm{~h}$ under continuous Ar flow [75,76].

\section{- Polymerization}

The N-doped hollow flower-shaped porous carbon materials (named N-HCNFs) were obtained in a three-step process. Firstly, cyanuric chloride was covalently linked onto mesocrystals of melamine-cyanuric acid (MCA) via a nucleophilic substitution reaction and as a result a covalent triazine framework (CTF) on the MCA surface was formed. Next, by adding piperazine (PP) three complexes with different ratios of CTF:MCA (1:4, 1:2, 1:1) were prepared. In the last stage, CTF-PP@MCA precursors were carbonized at temperatures $800-1000{ }^{\circ} \mathrm{C}$ for $2 \mathrm{~h}$ under an inert atmosphere of nitrogen [77].

A mesoporous carbon nitride material was synthesized through polymerization of guanidine hydrochloride as a source of carbon-nitrogen inside the organized mesopore channels of a previously prepared mesoporous SBA15 silica template with a $9.15 \mathrm{~nm}$ pore size [78]. The latter was impregnated and stirred with the ultrasonicated solution of guanidine hydrochloride for a few hours. The obtained homogenized mixture was firstly heated in an oven at $100^{\circ} \mathrm{C} \mathrm{h}(6 \mathrm{~h})$ and then at $160^{\circ} \mathrm{C}(6 \mathrm{~h})$. As a result, the dried nanocomposite material was carbonized in a furnace at $500{ }^{\circ} \mathrm{C}(4 \mathrm{~h})$ under nitrogen flow. To remove the SBA15 silica template, the carbonized sample was stirred in an aqueous solution of hydrogen fluoride. In the last step, a mesoporous carbon nitride material was repeatedly washed with ethanol and dried at $100^{\circ} \mathrm{C}$.

\section{- Plasma functionalization}

$\mathrm{B}$ and $\mathrm{N}$-co-doped carbon catalysts were fabricated through a plasma-assisted synthesis route. The mixtures of boric acid and quinoline with various concentrations (up to $10 \mathrm{mM}$ ) were sonicated and plasma discharged. To obtain conductive B,N-co-doped carbon powders, the discharged solution was filtered, dried overnight at $80^{\circ} \mathrm{C}$, and eventually heated to $800{ }^{\circ} \mathrm{C}$ in an $\mathrm{N}_{2}$ atmosphere for $1 \mathrm{~h}$ [79]. Tsounis et al. synthesized vertical graphene (VG) on a carbon fiber paper without using any catalyst in a plasma-enhanced chemical vapor deposition process using $\mathrm{Ar}, \mathrm{CH}_{4}$, and $\mathrm{H}_{2}\left(1000 \mathrm{~W}, 10 \mathrm{~min}, 400{ }^{\circ} \mathrm{C}\right)$. To modify pristine vertical graphene, directly after the growth of the material, the plasma chamber was degassed and pumped down to $\sim 10^{-3} \mathrm{~Pa}$. Argon was introduced again to the hot chamber and the VG was post-treated for $5 \mathrm{~min}$. As a result, edge-rich vertical graphene was produced as support for the electrochemically active phase [80]. To form a nanoarray-structurization and $\mathrm{N}$-doping before use as a support for NiFe-P particles, commercial carbon paper was cleaned in ethanol, acetone, and water. Then, the washed pieces of material were dried at room temperature and modified in the $\mathrm{N}_{2}$ plasma reactor for $30 \mathrm{~min}$ [81].

\section{- Exfoliation}

Graphene oxide (GO) is usually synthesized from natural flake graphite powder via chemical exfoliation-modified Hummers' method [82,83]. An acid-assisted liquid exfoliation of bulk graphitic carbon nitride $\left(\mathrm{g}-\mathrm{C}_{3} \mathrm{~N}_{4}\right)$ results in nanosheets of carboxylfunctionalized g- $\mathrm{C}_{3} \mathrm{~N}_{4}$, which then can be used as part of composite electrocatalysts. In the typical synthesis protocol, powder of bulk g- $\mathrm{C}_{3} \mathrm{~N}_{4}$ is mixed with $65 \mathrm{wt} . \% \mathrm{HNO}_{3}$ and refluxed at $80{ }^{\circ} \mathrm{C}$ for $3 \mathrm{~h}$. The precipitates are collected by centrifugation and washed with water. After overnight drying in a vacuum at $60^{\circ} \mathrm{C}$, a powder g- $\mathrm{C}_{3} \mathrm{~N}_{4}$ nanosheet is 
obtained [84]. The exfoliated graphite flakes have been used as a support for iron-nitrogen coordinated carbon nanofiber electrocatalysts. The electrochemical exfoliation of graphite was performed in a two-electrode system using $\mathrm{Pt}$ and a graphite flake as counter and working electrodes, respectively, as well as $0.1 \mathrm{M}$ aqueous solution of $\left(\mathrm{NH}_{4}\right)_{2} \mathrm{SO}_{4}$ as an electrolyte. A direct current voltage was applied to the graphite electrode for $3 \mathrm{~min}$. After the complete process, to remove any residual salts, the exfoliated graphite flake was washed with Milli-Q water. Finally, the received material was dried in the oven [85].

\section{- Reduction}

Reduced graphene oxide (rGO) was synthesized using previously prepared graphene oxide (GO) via a modified Hummers method [86]. The hydrazine was mixed with a GO aqueous solution at an ultrasound bath. The dispersion was refluxed for $12 \mathrm{~h}$ and the resultant material was thoroughly washed with Milli-Q water. Then, the rGO was transferred to an oven and heated at $60^{\circ} \mathrm{C}$ for $24 \mathrm{~h}$ to obtain a powder. The percentage yield of the graphene oxide reduction was nearly $90 \%$.

\section{- Oxidation}

Multi-walled carbon nanotubes, MWCNTs, were produced by ethylene chemical vapor deposition in a presence of a Fe-Co catalyst, which then was removed by treatment in boiling $\mathrm{HCl}$ solution. The obtained MWCNTs were functionalized with oxygen species through heating under reflux in 68 vol.\% nitric acid aqueous solution for $2 \mathrm{~h}$ at $120^{\circ} \mathrm{C}$. Such nanotubes were washed, dried and used as a support for metal oxides ( $\mathrm{M}=\mathrm{Mn}, \mathrm{Ni}, \mathrm{Fe})$ [87]. $\mathrm{Li}$ et al. refluxed pristine carbon nanotubes (CNTs) in a mixture of $65 \mathrm{wt} . \% \mathrm{HNO}_{3}$ and $98 \mathrm{wt} . \% \mathrm{H}_{2} \mathrm{SO}_{4}(1: 3)$ at $70{ }^{\circ} \mathrm{C}$ for $30 \mathrm{~min}$ to remove metal residues and introduced surface oxygen moieties that played the role of anchors for $\mathrm{Mn}_{3} \mathrm{O}_{4}$ adsorption [88]. Similarly, carbon fiber paper has been oxidized in $\mathrm{HNO}_{3}$ by heating at reflux. The precipitates were washed with water until they reached $\mathrm{pH} 7$ and then freeze-dried them to obtain the final oxidized powder [89]. Nickel nitride nanoparticles were supported on 2D graphene oxide, which was previously doped with boron. The as-prepared graphene oxide via the modified Hummer method was mixed and ultrasonicated for $2 \mathrm{~h}$ with boric acid in deionized water at the following weight ratios $\mathrm{H}_{3} \mathrm{BO}_{3}: \mathrm{GO}=1: 1,3: 1$ and 5:1. Afterwards, the mixture was dried at $60^{\circ} \mathrm{C}$ and heated at $800{ }^{\circ} \mathrm{C}$ for $3 \mathrm{~h}$ in an $\mathrm{Ar}$ atmosphere [90]. Before the integration of carbon fiber paper (CFP) with a Co-engineered FeOOH catalyst, the commercial carbon material was pretreated. Firstly, CFP was cleaned by ultrasonication in the following liquids: acetone, ethanol, and deionized water. After that, the CFP was modified in concentrated $\mathrm{HNO}_{3}\left(65 \%\right.$, aqueous solution) at $115{ }^{\circ} \mathrm{C}$ for $3 \mathrm{~h}$ in a roundbottom flask equipped with a condenser. The resultant material was washed with water and allowed to dry overnight at room temperature [91].

\section{- Activation}

Cauliflower leaves were repeatedly washed in Milli-Q water, dried, and were ground into a form of powder. Such carbon precursor was pre-carbonized in a tube furnace $\left(400{ }^{\circ} \mathrm{C}\right.$, $2 \mathrm{~h}, \mathrm{~N}_{2}$ flow). Then, the obtained material was mixed with $\mathrm{KOH}$ at the mass ratio of 1:3 and pyrolyzed $\left(800{ }^{\circ} \mathrm{C}, 1 \mathrm{~h}, \mathrm{~N}_{2}\right.$ flow). To get the biomass-derived activated carbon, the product of pyrolysis was washed with $1 \mathrm{M} \mathrm{HCl}$ solution, MilliQ water, and dried overnight $\left(70{ }^{\circ} \mathrm{C}\right)$ [92]. A similar procedure was applied to obtain nanoporous activated carbon sheets that were synthesized from food waste that was high in carbohydrates [93]. Briefly, the food waste material was ground and the resulting powder was heated at $450{ }^{\circ} \mathrm{C}$ for $2 \mathrm{~h}$ under an inert atmosphere of nitrogen. In the next step, the carbon material was activated with $\mathrm{KOH}$ at $750{ }^{\circ} \mathrm{C}$ for $3 \mathrm{~h}$ (ratio of $\mathrm{KOH}: \mathrm{C}$ was 1:3). Finally, the obtained activated carbon was washed with water to neutral $\mathrm{pH}$, collected by centrifugation, and dried at $60^{\circ} \mathrm{C}$ for $12 \mathrm{~h}$.

The electrochemical technique was proposed to activate carbon cloth, which was used as a support for Co-based films. In a typical procedure, a piece of carbon cloth was immersed in acetone, ethanol, and water, respectively. The activation process was carried 
out in the two-electrode system in the aqueous solution of $0.1 \mathrm{M}\left(\mathrm{NH}_{4}\right)_{2} \mathrm{SO}_{4}$ and $2 \mathrm{M}$ $\mathrm{NH}_{4} \mathrm{OH}$ using carbon cloth as the anode and carbon rod as the cathode (a DC voltage of $10 \mathrm{~V}, 2 \mathrm{~min}$ ). After the activation, the carbon cloth was thoroughly washed with water [94]. Another activation method of carbon cloth included mild chemical oxidation of raw carbon cloth pieces in an aqueous solution of $98 \% \mathrm{H}_{2} \mathrm{SO}_{4}$ and $70 \% \mathrm{HNO}_{3}$ acids at $70{ }^{\circ} \mathrm{C}$ for $24 \mathrm{~h}$. After washing with copious amounts of water and drying, the carbon cloth pieces were transferred to a muffle furnace and calcined at $500{ }^{\circ} \mathrm{C}$ for $2 \mathrm{~h}$ under an air atmosphere [95].

\subsection{Synthesis of Carbon-Metal Hydroxides/Oxyhydroxides/Oxides}

The great abundance of the hydroxide/oxide carbon materials results from the relative ease of the preparation of the structured catalysts (Figure 5). The synthesis procedures usually do not require high temperature treatments and a variety of precursors can be used. Among the reported synthesis methods, by far the most popular is the hydrothermal treatment of pretreated carbon with metal salt in the Teflon-lined autoclave placed in a conventional oven/dryer.

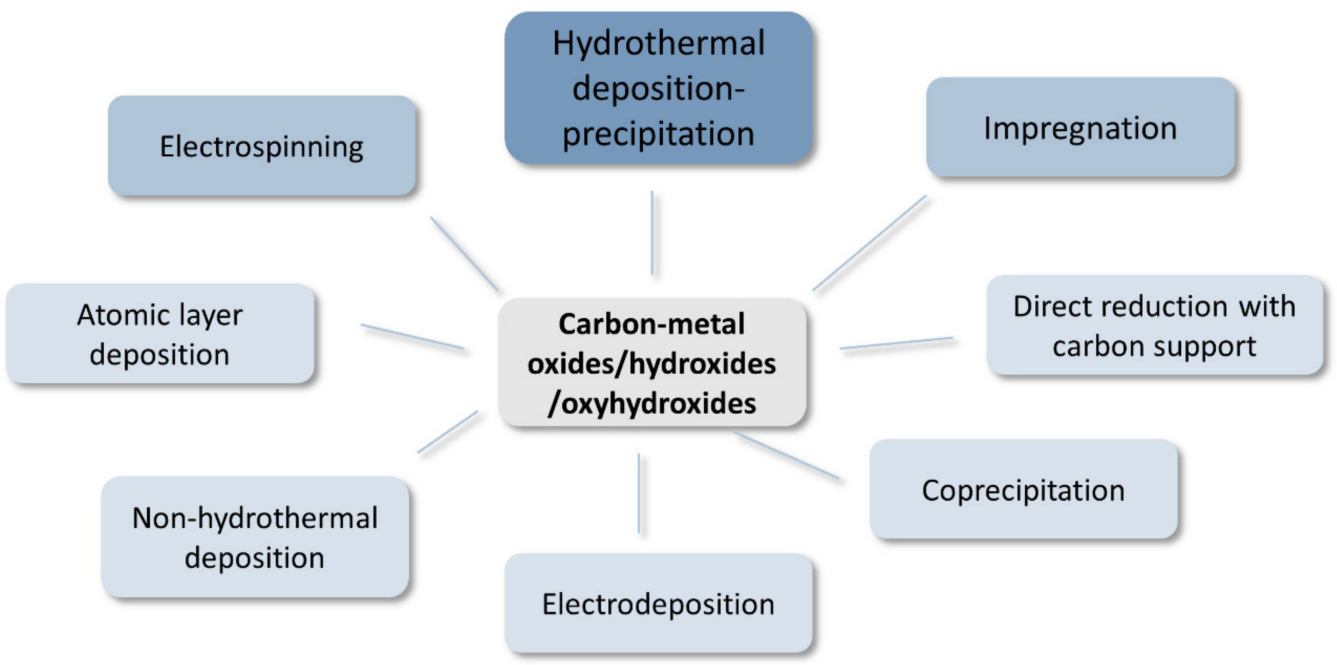

Figure 5. Graphical summary of synthesis methods of carbon-metal hydroxides/oxyhydroxides/oxides.

- Hydrothermal treatment of the oxide hydroxide precursors with carbon (hydrothermal deposition-precipitation)

Hydrothermal deposition-precipitation is one of the most popular ways to combine carbons with the hydroxide/oxide phase [96,97]. To combine nitrogen and sulfur co-doped mesoporous carbon spheres obtained by pyrolysis of thiourea with manganese and cobalt spinel oxides, a hydrothermal treatment was implemented. The S,N-doped carbon spheres were added into ultrasonicated anhydrous ethanol to obtain a homogeneous suspension, whereupon metal nitrate solutions were slowly added. After further homogenization of the suspension with stirring, ammonium hydroxide solution was added. The obtained suspension was aged at $85^{\circ} \mathrm{C}$ under stirring and further transferred into an autoclave and heated at $180{ }^{\circ} \mathrm{C}$ to complete the hydrothermal reaction. The obtained precipitate was recovered by centrifugation, washed with water and ethanol and dried in a vacuum oven at $85{ }^{\circ} \mathrm{C}$ [98].

Composite catalysts- $-\mathrm{Co}_{3} \mathrm{O}_{4}$ at nitrogen-doped hollow carbon nanospheres were synthesized through a facile, modified hydrothermal process, where desired amounts of presynthesized nitrogen-doped hollow carbon nanospheres and cobalt acetate were added into absolute ethanol and dispersed under ultrasonication, followed by the addition of $\mathrm{NH}_{4} \mathrm{OH}$ aqueous solution under stirring. After stirring at $80^{\circ} \mathrm{C}$, the mixture was loaded into a Teflon-lined stainless-steel autoclave. The hydrothermal process was carried out at $150{ }^{\circ} \mathrm{C}$. After allowing the autoclave to cool down to room temperature, the sample was 
centrifuged and washed with water and dried at $80^{\circ} \mathrm{C}$ overnight. The final product was obtained after annealing the above-resulting powder at $500{ }^{\circ} \mathrm{C}$ [99].

To obtain $\mathrm{Mn}_{\mathrm{x}} \mathrm{Co}_{3-\mathrm{x}} \mathrm{O}_{4}$ nanocrystals decorated on carbon nanotubes, the CNTs were preoxidized in nitric acid by heating at $110^{\circ} \mathrm{C}$ with reflux. Then, they were dispersed in ethanol in a round-bottomed flask and sonicated to ensure uniform dispersion and metal acetates were added. Then ammonia solution was added and the solution was then heated to $80{ }^{\circ} \mathrm{C}(20 \mathrm{~h})$. Finally, the reaction mixture was transferred to a $100 \mathrm{~mL}$ Teflon-lined autoclave for a solvothermal reaction at $150{ }^{\circ} \mathrm{C}$ for $3 \mathrm{~h}$. The product was collected by centrifugation, washed with deionized water several times, and freeze-dried to obtain the final product, MCO@NCNTs [89].

$\mathrm{Ni} / \mathrm{rGO}$ nanoplate composite was prepared via a one-step process with nickel chloride, aluminum chloride, urea, and graphene oxide (GO) suspension as precursors. This mixture was heated to $120^{\circ} \mathrm{C}$ and refluxed in nitrogen for $12 \mathrm{~h}$ under stirring to obtain a composite of Ni-Al layered double hydroxide (LDH) with GO. The Ni-Al LDH-GO precipitates were repeatedly washed with water and ethanol and then was dried at $60^{\circ} \mathrm{C}$ for $8 \mathrm{~h}$ in a vacuum. The following reduction reaction was carried in a Teflon-lined autoclave with hydrazine and Ni-Al LDH-GO redispersed in deionized water. After stirring for $30 \mathrm{~min}$, the autoclave was heated to $120{ }^{\circ} \mathrm{C}$ for $12 \mathrm{~h}$. The precipitate was washed with deionized water and ethanol a few times and then dried at $60^{\circ} \mathrm{C}$. Then the precipitate was purified by a $\mathrm{NaOH}$ solution in another hydrothermal process at $120^{\circ} \mathrm{C}$ for $6 \mathrm{~h}$. The black product was washed with water and ethanol and dried [100].

Carbon nanotubes were dispersed in water by continuous ultrasonication. Then, metal nitrates, $\mathrm{NH}_{4} \mathrm{~F}$, and urea were added to the above solution. The obtained homogenate was transferred into a stainless-steel autoclave and heated to $180^{\circ} \mathrm{C}$. After the reaction, the autoclave was allowed to cool naturally. The black products were collected and fully washed with water and anhydrous ethanol. Afterwards, the products were vacuum dried at $80^{\circ} \mathrm{C}$ and annealed at $500{ }^{\circ} \mathrm{C}$ for $2 \mathrm{~h}$ under an Ar atmosphere. Next, the products were annealed at $500{ }^{\circ} \mathrm{C}$ for $1 \mathrm{~h}$ under an $\mathrm{Ar} / \mathrm{NH}_{3}$ mixed atmosphere and cooled under an $\mathrm{Ar}$ atmosphere to obtain final products [101].

\section{- Non-hydrothermal deposition}

In the deposition-precipitation process, a NCNT/CNT forest was immersed in a solution of precursors containing cobalt acetate, $\mathrm{KOH}$, and $\mathrm{H}_{2} \mathrm{O}_{2}$ for 30 min for sufficient infiltration of the material by the reactants. Then, the temperature of the precursor solution was elevated to $45^{\circ} \mathrm{C}$ and maintained for $90 \mathrm{~min}$. The resultant cobalt hydroxide coated NCNT/CNT forest was moved to deionized water for rinsing. The residual water trapped in the hybrid catalyst forest was removed by rapid vacuum drying to maintain the vertical forest morphology. As prepared amorphous cobalt hydroxide coated NCNT forest was $400{ }^{\circ} \mathrm{C}$ rapid heat-treated to get amorphous cobalt oxide coated NCNTs, and $700{ }^{\circ} \mathrm{C}$ rapid heat-treated to get crystalline cobalt oxide anchored NCNTs (CoO-NCNTs) [102].

In the direct combination of metal oxide with carbon material, $\mathrm{Mn}_{3} \mathrm{O}_{4}-\mathrm{rGO}-\mathrm{x}$ was obtained by coating GO nanosheets on hydroxyl-modified multishell $\mathrm{Mn}_{3} \mathrm{O}_{4}$ hollow spheres and the subsequent reduction of graphene oxide through thermal treatment. The multishell $\mathrm{Mn}_{3} \mathrm{O}_{4}$ hollow spheres were dispersed in water containing ammonium hydroxide to obtain hydroxyl-modified multishelled $\mathrm{Mn}_{3} \mathrm{O}_{4}$ hollow spheres. The washed product was redispersed in water and combined with the suspension of GO and stirred. The obtained solid was recovered by centrifugation and annealed at $400^{\circ} \mathrm{C}$ in an $\mathrm{Ar}$ atmosphere to obtain $\mathrm{rGO}$. This procedure utilizes the affinity of the $\mathrm{OH}$ groups for the surface oxygen vacancy sites on the $\mathrm{Mn}_{3} \mathrm{O}_{4}$ phase. The oxygen functional groups on the GO surface act as the oxidation sites, enabling strong bonding between manganese spinel and graphene, which results in a uniform dispersion of multishell $\mathrm{Mn}_{3} \mathrm{O}_{4}$ spheres encapsulated in graphene. This specific interaction of manganese with carbon through the oxygen atom (Mn-O-C) combined with abundant oxygen vacancies on the $\mathrm{Mn}_{3} \mathrm{O}_{4}$ surface results in a coupling effect, which produces a high density of active sites and improved electron transfer properties [103]. 


\section{- Electrospinning of precursors}

Electrospun $\mathrm{NiMn}_{2} \mathrm{O}_{4}$ and $\mathrm{NiCo}_{2} \mathrm{O}_{4}$ spinel oxides supported on carbon nanofibers from metal acetates and polyacrylonitrile (PAN) as metal oxides and carbon nanofiber precursors in dimethylformamide (DMF). The electrospun layer was subjected to an initial stabilization thermal treatment at $270{ }^{\circ} \mathrm{C}$ in air and subsequent carbonization at $900{ }^{\circ} \mathrm{C}$ under helium flow. Finally, an oxidation thermal treatment was carried out at $350{ }^{\circ} \mathrm{C}$ in static air to obtain the composite materials [104].

PVP and metal nitrates are added to DMF and stirred at ambient conditions. Afterwards, the homogeneous solution was filled into a plastic syringe equipped with a 22-gauge needle tip and a DC voltage of $20 \mathrm{kV}$ was applied to the electrospinning set up. The as-obtained nanofiber membrane was initially stabilized at $250{ }^{\circ} \mathrm{C}$ for $3 \mathrm{~h}$ in the open air, and subsequently by annealing at $600{ }^{\circ} \mathrm{C}$ for carbonization for $3 \mathrm{~h}$ in $\mathrm{N}_{2}$ atmosphere to synthesize the final hollow- $\mathrm{Co}_{3} \mathrm{O}_{4} / \mathrm{CeO}_{2} @ \mathrm{~N}-\mathrm{CNFs}$ [105].

\section{- Impregnation}

To obtain a mixed transition metal $(\mathrm{Fe}, \mathrm{Co}, \mathrm{Ni})$ oxide, nanoparticles supported on oxidized multi-walled carbon nanotubes, MWCNT were mildly oxidized in concentrated $\mathrm{HNO}_{3}$, washed with water, and dried in air to obtain oxygen functionalized nanotubes. Preparation of $\mathrm{Fe}, \mathrm{Co}, \mathrm{Ni}$, and mixed $\mathrm{Fe}-\mathrm{Ni}-\mathrm{Co}$ oxide/MWCNT catalysts was performed by incipient wet impregnation of oxygen functionalized MWCNT with aqueous solutions of metal nitrates. The impregnated samples were dried at $110{ }^{\circ} \mathrm{C}$ and subsequently annealed at $350^{\circ} \mathrm{C}$ under argon flow. The concentration of $\mathrm{Fe}, \mathrm{Co}$, and Ni nitrates in the impregnation solutions was varied to obtain composite samples containing different metal ratios while keeping the total metal loading at about $14 \mathrm{wt} . \%$ [106].

For a typical synthesis of $\mathrm{Ni} / \mathrm{NiO} / \mathrm{N}$-doped active carbon hybrids, the as-prepared active carbon and nickel nitrate were added into ethanol, and after ultrasonic treatment, the mixture was kept to $80^{\circ} \mathrm{C}$ under vigorous stirring to evaporate the ethanol. The resultant solid was transferred into a tube furnace in an $\mathrm{N}_{2}$ environment and annealed at $400-600{ }^{\circ} \mathrm{C}$ for $2 \mathrm{~h}$ to obtain the final product [92].

\section{- Direct reduction with carbon support}

Reduced carbon layers, differing in lateral dimension, were used as a reduction agent for iron(II) salts, resulting in the decoration of the carbon framework by iron oxide nanoparticles. Depending on the choice of the carbon starting material, the average size of the formed nanoparticles was situated between $3-50 \mathrm{~nm}$. To obtain the composite material, graphenide solutions from different graphite starting materials have been used directly as a reduction agent for iron chloride dissolved in absolute tetrahydrofuran (THF) inside an argon-filled glove box. After the aggregation and precipitation occurred, the respective dispersion was further stirred, and afterwards, the dispersion was centrifuged in the glove box and the supernatant was removed. The samples have been redispersed in THF followed by another centrifugation step. Afterwards, the samples were removed from the glove box and water was added. The sample has been mixed with cyclohexane and has been extracted three times with water in a separation funnel. The final material was collected via filtration ( $0.2 \mu \mathrm{m}$ filter membranes) and dried in a vacuum [107].

\section{- Electrodeposition}

Mixed Ni-Fe hydroxides were electrochemically deposited on graphene, $\mathrm{Ni}$-foam, $\mathrm{Cu}$ foam, and graphene paper in an aqueous-based solution with metal nitrate. Potentiostatic electrodeposition was sustained for $100 \mathrm{~s}$ with an applied potential of $1.1 \mathrm{~V} v \mathrm{vs} . \mathrm{Ag} / \mathrm{AgCl}$ using a graphite rod counter electrode. After electrodeposition, the samples were washed thoroughly in water and ethanol [80].

\section{- Coprecipitation}

The ternary NiFeMn-Prussian blue analogues/polyvinylpyrrolidone (NiFeMn-PBA/PVP) hybrid precursors were prepared by a modified coprecipitation method. Metal acetates 
and PVP were dissolved in alcohol. $\mathrm{K}_{3}\left[\mathrm{Fe}(\mathrm{CN})_{6}\right]$ was dissolved in water to form another solution, which was added dropwise into the solution with acetates and PVP under intense stirring at room temperature. The resulting aqueous solution was aged for $2 \mathrm{~h}$, and the precipitate was obtained by centrifugation without washing. Afterwards, the precipitate was dried at $80^{\circ} \mathrm{C}$. The above was calcined under Ar atmosphere at $700{ }^{\circ} \mathrm{C}$ [108].

\section{- Atomic layer deposition}

Bis(1,4-diiso-propyl-1,4-diazabuta-diene) cobalt precursor (Co(dpdab) 2$)$ was used for the deposition of $\mathrm{CoO}_{\mathrm{x}}$. Ozone was selected as the oxidant for the atomic layer deposition (ALD) reaction. Before deposition, carbon paper (CP) was ultrasonically cleaned with acetone, methanol, and deionized water. The chamber pressure was maintained at 0.1 Torr using a rotary pump. The chamber and cobalt precursor were heated to 200 and $112.5^{\circ} \mathrm{C}$, respectively. During the deposition, high-purity nitrogen gas was allowed to flow through the chamber to purge by-products and excess chemicals. One cycle of ALD-CoO ${ }_{x}$ on $\mathrm{CP}$ consisted of $\mathrm{N}_{2}$ pulse/Co(dpdab) 2 pulse/ $\mathrm{N}_{2}$ purge $/ \mathrm{O}_{3}$ pulse. The growth rate of ALD-CoO ${ }_{x}$ was $0.4 \mathrm{~A} /$ cycle. The deposition of ALD-CoO $\mathrm{C}_{\mathrm{x}}$ was carried out with different numbers of cycles $(50,100,350$, and 700) [109].

\subsection{Synthesis of Carbon-Metal Chalcogenides}

Although from a thermodynamical point of view, metal sulfides are less stable than metal oxides under oxidizing potentials and metal nitrides and phosphides are less stable than sulfides and so on, an abundance of such electrocatalytic systems has been reported in recent years also for the OER. It can thus be anticipated that metal chalcogenides, nitrides, and phosphides would be readily oxidized, at least on the surface, to the respective metal oxides/hydroxides in the strongly oxidative environments of OER [61]. Therefore, care must be taken when characterizing such systems and particular attention should be paid to the spent catalysts. Most popular preparation methods are summarized in Figure 6.

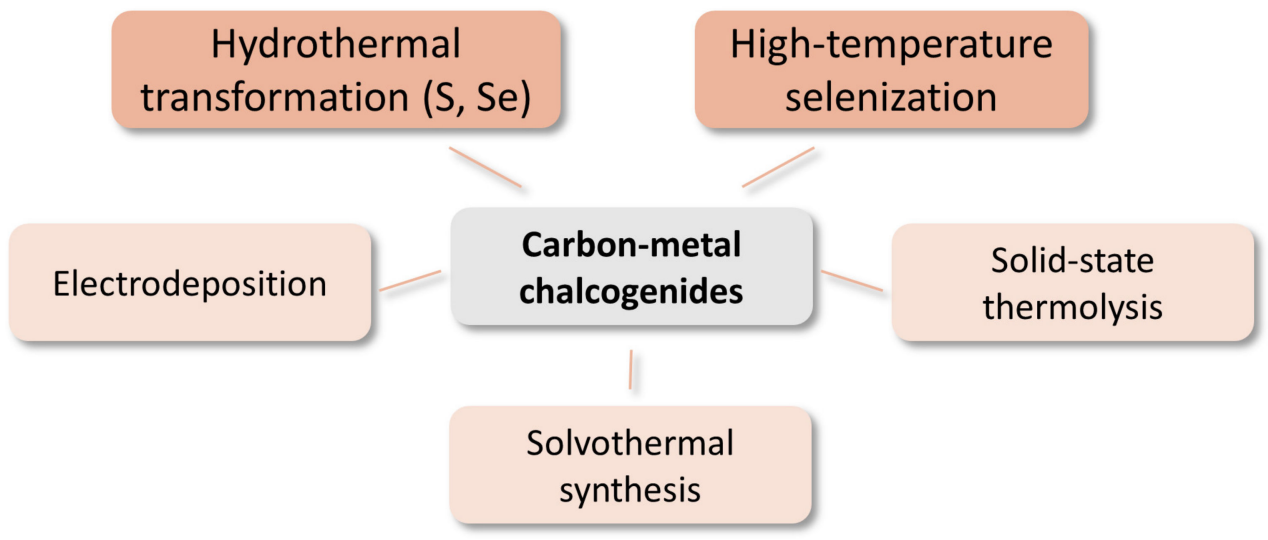

Figure 6. Graphical summary of synthesis methods of carbon-metal chalcogenides.

\section{- Hydrothermal transformation}

Hydrothermal treatment is frequently used to convert metal precursors to respective metal sulfides or selenides. Usually, pre-oxidized carbon materials and metal nitrates, acetates, or chlorides and chalcogenide sources are used in a Teflon-lined autoclave to carry out the reaction at temperatures from 120 to $200{ }^{\circ} \mathrm{C}$ for $2-20 \mathrm{~h}$. Initially, the metal precursor hydrolyses on the surface of oxidized carbon support and then is converted into metal sulfide. Selenides can be obtained with the use of selenide powder and an additional reducing agent.

The Co@NC@MoS 2 catalyst was synthesized using a hydrothermal treatment of the Co@NC nanoparticles, where Co@NC nanoparticles were dispersed in deionized water and sonicated for $1 \mathrm{~h}$. Afterwards $\left(\mathrm{NH}_{4}\right)_{6}-\mathrm{Mo}_{7} \mathrm{O}_{24} \cdot 4 \mathrm{H}_{2} \mathrm{O}$ and L-cysteine were added to the Co@NC dispersion and again sonicated for $1 \mathrm{~h}$. The obtained dispersion was transferred 
into a Teflon-lined autoclave and heated at $200{ }^{\circ} \mathrm{C}$ for $20 \mathrm{~h}$. The cooled-down precipitate was recovered by centrifugation, washed with ethanol and water, and dried in a vacuum dryer [110]. A Cog $\mathrm{S}_{8} /$ graphene composite was obtained with sodium sulfide $\left(\mathrm{Na}_{2} \mathrm{~S}\right)$ solution mixed with a graphene dispersion followed by ultrasonication and transferred to an autoclave where subsequently cobalt nitrate solution was poured in with gentle stirring whereupon a black gel was formed. The hydrothermal reaction was carried out at $120^{\circ} \mathrm{C}$ for $3 \mathrm{~h}$, the precipitate was washed with water and ethanol, and the product was collected after lyophilisation [111]. In a synthesis of $\mathrm{NiCo}_{2} \mathrm{~S}_{4} / \mathrm{N}-\mathrm{CNT}$, mildly oxidized CNTs were ultrasonically dispersed in ethanol and deionized water mixture. Then, stoichiometric amounts of $\mathrm{Co}(\mathrm{AC})_{2} \cdot 4 \mathrm{H}_{2} \mathrm{O}$ and $\mathrm{Ni}(\mathrm{AC})_{2} \cdot 4 \mathrm{H}_{2} \mathrm{O}$ were dissolved in this suspension and stirred at $80{ }^{\circ} \mathrm{C}$ for $2 \mathrm{~h}$ in a water bath, followed by the addition of $\mathrm{NH}_{3} \cdot \mathrm{H}_{2} \mathrm{O}$. After further stirring, thiourea was added and after continuous stirring for $20 \mathrm{~h}$, the reaction mixture was transferred to an autoclave for solvothermal reaction at $170^{\circ} \mathrm{C}$ for $3 \mathrm{~h}$. The precipitate was washed with water and ethanol and the product was collected after lyophilisation [112].

Carbon nitride-nickel selenide material was prepared from the graphitic $\mathrm{C}_{3} \mathrm{~N}_{4}$, nickel chloride and Se powder as precursors in an aqueous solution with $\mathrm{NaBH}_{4}$ as a reducing agent. Se $/ \mathrm{NaBH}_{4}$ solution and g- $\mathrm{C}_{3} \mathrm{~N}_{4} / \mathrm{Ni}^{2+}$ suspension were mixed, stirred for $1 \mathrm{~h}$, and transferred into a Teflon-lined autoclave for hydrothermal treatment at $160^{\circ} \mathrm{C}$ for $12 \mathrm{~h}$. The resulting product was collected by filtration, washed with deionized water and ethanol, and then dried at $60{ }^{\circ} \mathrm{C}$ overnight [113]. $\mathrm{Ni} / \mathrm{Co} / \mathrm{CoO} / \mathrm{NiCo}_{2} \mathrm{O}_{4}-\mathrm{g}-\mathrm{C}_{3} \mathrm{~N}_{4}$ prepared by thermal decomposition was used as a precursor for a $\mathrm{CoSe}_{2} / \mathrm{Ni}_{3} \mathrm{Se}_{4} @ \mathrm{~N}$-doped carbon nanosheets/ketjen black carbon composite electrocatalyst. The precursor, carbon support, and $\mathrm{SeO}_{2}$ were dispersed in dimethylformamide aqueous solution and were transferred into a Teflon-lined stainless steel autoclave and kept at $200{ }^{\circ} \mathrm{C}$ for $20 \mathrm{~h}$. The obtained precipitate was collected by centrifugation, washed with water, and dried in a vacuum at $80^{\circ} \mathrm{C}$. However, to obtain complete selenization, an additional pyrolysis step at $700{ }^{\circ} \mathrm{C}$ in an inert atmosphere was needed [114]. A similar two-step procedure, with thiourea as $\mathrm{S}$ precursor and nitrates as metal precursors and an additional pyrolysis step at $900{ }^{\circ} \mathrm{C}$, was used to obtain $\mathrm{NiCo}_{2} \mathrm{~S}_{4} /$ carbon-nitrogen nanosheet composites [84].

Other selenium precursors for autoclave selenization can be used, such as Se powder dissolved in a solution of ethylenediamine and ethylene glycol [115] or diphenyl diselenide dispersed in ethanol [116]. The latter was also used in combination with sulfourea to obtain $\mathrm{Co}\left(\mathrm{S}_{\mathrm{x}} \mathrm{Se}_{1-\mathrm{x}}\right)_{2} @ \mathrm{C}$ materials.

\section{- High temperature selenization}

This method is most frequently applied for direct selenization of the metal precursor and is usually carried out in a tubular furnace where Se powder (but also $\mathrm{S}$ or Te) is placed in a crucible in the upstream side of the tube and the metal/carbon precursor downstream. The furnace is purged with an inert gas, usually argon, and kept between 350 and $500{ }^{\circ} \mathrm{C}$ (usually $450{ }^{\circ} \mathrm{C}$ ) for $2-3 \mathrm{~h}$. The precursor is frequently in the form of a Prussian blue analogue (PBA) $[117,118]$ or a zeolitic imidazolate framework (ZIF) type metal-organic framework (MOF) compound where the metal is reduced before selenization $[119,120]$.

In one typical synthetic procedure, the as-prepared PBA metal precursor deposited onto the carbon support and Se powder were put at two separate positions of a quartz boat with Se powder at the upstream side of the tube furnace. Then, the samples were annealed at $350{ }^{\circ} \mathrm{C}$ for $2 \mathrm{~h}$ in $\mathrm{N}_{2}$ atmosphere with a heating rate of $2{ }^{\circ} \mathrm{C} \mathrm{min}^{-1}$ to obtain $\mathrm{Ni}-\mathrm{Fe}-$ $\mathrm{Se} / \mathrm{N}-\mathrm{CNTs}$ [117]. Another bimetallic NiFe PBAs as MOF precursors were electrodeposited on carbon fiber paper (CFP) and were put inside a tube furnace with the Se powder in a typical arrangement. The temperature was increased up to $450{ }^{\circ} \mathrm{C}$ at a ramping rate of $5^{\circ} \mathrm{C} \mathrm{min}^{-1}$ and kept there for $30 \mathrm{~min}$ in Ar atmosphere to obtain NiFe-Se/CFP [118]. Synthesis protocols involving ZIF compounds as metal precursors follow a similar scheme. A decomposed and reduced MOF material, previously deposited onto a $\mathrm{N}$ co-doped carbon nanopolyhedra/nanotubes support, Co@NC-CNTs, and the Se powder were placed in quartz boats in a vacuum tube furnace with flowing nitrogen and annealed at $500{ }^{\circ} \mathrm{C}$ for $3 \mathrm{~h}$ with a heating rate of $5^{\circ} \mathrm{C} \mathrm{min}^{-1}$ [119]. Carbon nanotubes grafted 3D core-shell 
$\mathrm{CoSe}_{2} @ \mathrm{C}$ composites were obtained by grinding together the synthesized ZIF material and commercial selenium powder and heating under Ar flow to $450{ }^{\circ} \mathrm{C}$ with $5{ }^{\circ} \mathrm{C} \mathrm{min}{ }^{-1}$ heating rate and annealing for $2 \mathrm{~h}$ [120]. ZIF precursor can also be used to obtain a sulfide electrocatalyst by using a three-stage heating procedure. To obtain the CoS deposited on carbon fiber (CF), a piece of cotton cloth with a deposited ZIF-L was put in the high temperature area of a tube furnace, and the excess $\mathrm{S}$ powder was placed in the upstream of a quartz tube in a porcelain crucible. With argon flowing, the temperature was raised to $350{ }^{\circ} \mathrm{C}$ at a heating rate of $2{ }^{\circ} \mathrm{C} \mathrm{min}-1$ and maintained for $30 \mathrm{~min}$. Then, still with argon, the temperature was further raised to $800^{\circ} \mathrm{C}$ at a heating rate of $5^{\circ} \mathrm{C} \mathrm{min}^{-1}$ and kept for $90 \mathrm{~min}$. Next, the Ar flushed furnace was cooled down to $200^{\circ} \mathrm{C}$ at a rate of $5^{\circ} \mathrm{C} \mathrm{min}{ }^{-1}$ and held for $2 \mathrm{~h}$ to remove residual S powder [121]. Also, a different type of MOF, such as MOF-74, can be used as both metal and carbon precursor to obtain a $\mathrm{CoSe}_{2} / \mathrm{FeSe}_{2}$ carbon nanorods electrocatalyst. As-synthesized MOF-74-Co/Fe precursor was fully mixed with commercial selenium powder in the mass ratio of $1: 2$ by grinding and then was transferred into a quartz boat. The temperature of the furnace was risen to $450{ }^{\circ} \mathrm{C}$ with a heating rate of $2{ }^{\circ} \mathrm{C} \min ^{-1}$ under an argon atmosphere and maintained for $2 \mathrm{~h} \mathrm{[122].}$

\section{- Other methods}

Other methods for chalcogenide-carbon composite synthesis include solid-state thermolysis, solvothermal synthesis, electrodeposition, and vulcanization. In the solid-state thermolysis method, carbon and chalcogenide components are obtained simultaneously during the high temperature treatment of precursors. In a simple synthesis, cobalt nitrate as a metal precursor and thioamide as sulfur precursor mixed uniformly can be pyrolyzed at $900{ }^{\circ} \mathrm{C}$ under Ar flow to yield $\mathrm{Co} / \mathrm{Co}_{9} \mathrm{~S}_{8} / \mathrm{CNT}$ [123]. Similarly, a metal precursor, such as Co-based Prussian blue analogue, can be ground together with the elemental chalcogenide (S, Se, Te) powder and placed inside a closed stainless steel tube. The reaction is carried out for $3 \mathrm{~h}$ at $500{ }^{\circ} \mathrm{C}$ and the products comprised of only one phase chalcogenide product [124]. Solvothermal synthesis with non-aqueous solvent is carried out in a typical Teflon-lined autoclave reactor where the carbon support is previously covered with metal compounds, e.g., by electrochemical deposition and with an addition of a reductor, e.g., $\mathrm{NaBH}_{4}$ and usually Se powder. Care is taken to remove the dissolved oxygen by purging the solution with inert gas before sealing it in the autoclave. In this type of synthesis, ethanol was used as a solvent to obtain NiSe/CFs [125], and N, N-dimethylformamide to obtain trimetallic $\mathrm{NiFeCoSe}_{x} / \mathrm{CF}$ cloth materials [126]. In the electrodeposition method, the chalcogenide compound on carbon support is directly obtained during the electrochemical reaction. The chronoamperometric method was used to obtain cobalt-sulfide sheets on carbon paper/carbon tubes material (CP/CT). A CP/CT electrode was subjected to a constant potential of $-0.9 \mathrm{~V}$ vs. $\mathrm{Ag} / \mathrm{AgCl}_{2}$ in a cobalt nitrate, thiourea in ethanol-water solution for $8 \mathrm{~min}$. After drying and annealing under Ar atmosphere at $300^{\circ} \mathrm{C}$ for $1 \mathrm{~h}$, the Co-S sheets on the CP/CTs were obtained [127].

\subsection{Synthesis of Carbon-Nitrides and -Phosphides}

Recent reviews describing the properties and electrochemical applications of metal phosphides are presented in $[60,128]$, while metal nitrides are reviewed in [129,130]. Carbon composite materials can be obtained by a procedure involving a direct combination of components, e.g., ultrasonication of $\mathrm{Ni}_{12} \mathrm{P}_{5}$ and oxidized MWCNTs can be used [131]. However, most of the described methods involve the preparation of a precursor that is then high temperature treated to obtain the final material (Figure 7). 


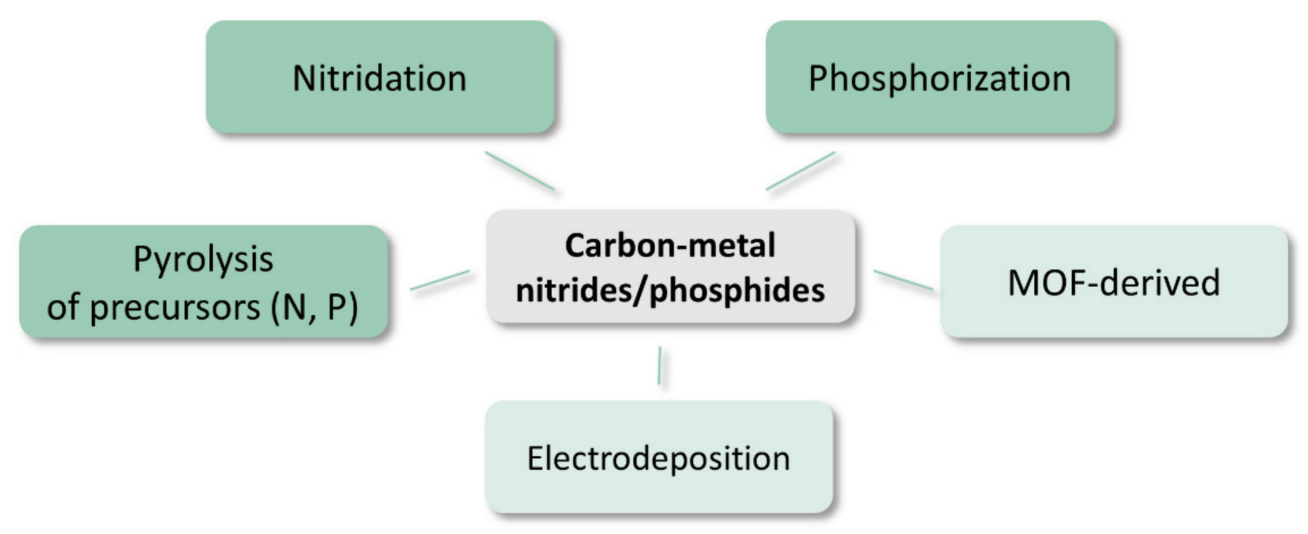

Figure 7. Graphical summary of synthesis methods of carbon-metal nitrides and phosphides.

\section{- Pyrolysis of precursors}

Pyrolysis can be used to obtain both carbon-nitride and carbon-phosphide composite materials. Using a general strategy combining sol-gel and carbonization-assisted route phosphides of $\mathrm{Co}, \mathrm{Mo}, \mathrm{Fe}, \mathrm{Ni}$, and their combinations can be coupled with an amorphous carbon matrix in a one-step carbon composite formation. In this procedure, metal chlorides, $\mathrm{NH}_{4} \mathrm{H}_{2} \mathrm{PO}_{4}$, citric acid, and deionized water were mixed to form a homogeneous aqueous solution, which was refluxed at $80^{\circ} \mathrm{C}$ for $20 \mathrm{~min}$ to form a sol. Then, the sol was dried at $140{ }^{\circ} \mathrm{C}$ to obtain gel ash. The gel ash was collected and heated at $900{ }^{\circ} \mathrm{C}$ in an $\mathrm{H}_{2} / \mathrm{Ar}$ atmosphere to obtain carbon-metal phosphide nanoparticle materials [132]. Another recently reported method to prepare supported transition-metal phosphide catalysts is the so-called carbothermal hydrogen route (carbothermal hydrogen reduction method). Cobalt nitrate and carbon black powder with ultrapure water were mixed with a solution of the phosphorus precursor, $\left(\mathrm{NH}_{4}\right)_{2} \mathrm{HPO}_{4}$, and sonicated to form a well-dispersed metal phosphate $\left(\mathrm{M}_{\mathrm{x}}\left(\mathrm{PO}_{4}\right)_{\mathrm{y}}\right)$ on carbon black. Then, the sample was dried, ground and pyrolyzed in $\mathrm{H}_{2} / \mathrm{N}_{2}$ atmosphere at $1000{ }^{\circ} \mathrm{C}$ to obtain $40 \mathrm{wt} . \% \mathrm{Co}_{2} \mathrm{P}$ on carbon black [133]. Phosphide and nitride carbon composites can also be prepared by electrospinning and subsequent pyrolysis, such as in the procedure where DNA, PAN, and cobalt acetate were used as substrates for electrospinning. The electrospun precursor was then dried in air at $270{ }^{\circ} \mathrm{C}$ and pyrolyzed at $900^{\circ} \mathrm{C}$ in $\mathrm{N}_{2}$ atmosphere to derive a $\mathrm{Co}_{2} \mathrm{P} / \mathrm{Co}_{2} \mathrm{~N}$ core-shell nanostructure embedded in N-doped carbon nanofiber [134].

\section{- Nitridation of metal precursors deposited on the carbon matrix}

Metal salts can be hydrolyzed on the surface of the pre-treated carbon materials with subsequent conditioning in hydrothermal conditions. In the case of nitride materials, the nitridation in the $\mathrm{NH}_{3}$ atmosphere at elevated temperatures completes the preparation procedure. Usually, carbon matrix, metal salt (acetate, nitrate), and hydrolyzing agent (hexamethylenetetramine, dimethylamine) are put into Teflon-lined autoclaves and heated at about $120-160{ }^{\circ} \mathrm{C}$ for several hours (e.g., 6-12 h). The obtained hydroxides/carbon hybrids are further annealed under ammonia flow, usually at $400-500{ }^{\circ} \mathrm{C}$ for $2 \mathrm{~h}[135,136]$. An alternative way of preparing a precursor for nitridation may involve heating the carbon matrix and metal salt (e.g., chloride) with the precipitating agent in the form of trisodium citrate in an oil bath at $90^{\circ} \mathrm{C}$ [137]. The following nitridation is the same as above. If the carbon material already contains metal, such as $\mathrm{Ni}$, the addition of iron salt results in a galvanic replacement mediated method to obtain iron-nickel nitride active phase on a carbon support [137]. Tannic acid can also be used to precipitate precursors onto carbon support at room temperature [138]. In this case, nitridation was carried out at $750{ }^{\circ} \mathrm{C}$ with an $\mathrm{N}_{2}: \mathrm{NH}_{3}$ ratio of $3: 1$ for $1 \mathrm{~h}$.

\section{- Phosphorization of metal precursors with $\mathrm{NaH}_{2} \mathrm{PO}_{2}$}

Similar to precursors for nitridation, the hydrothermal process can be used to obtain hydroxides for subsequent phosphorization. Usually, a carbon matrix, metal salt, and a 
hydrolyzing agent (hexamethylenetetramine, urea) are put into Teflon-lined autoclaves and heated at about $120^{\circ} \mathrm{C}$ for several hours (i.e., 6-12 h). Afterwards, the precursor and excess of $\mathrm{NaH}_{2} \mathrm{PO}_{2}$ are put into a quartz boat at different positions with the latter at the upstream side and heated at $300-350{ }^{\circ} \mathrm{C}$ for $2 \mathrm{~h}$ in an inert atmosphere [139-141]. Deposition in a chronoamperometry mode can also be used to prepare precursors for phosphorization, as in the deposition of polyaniline on carbon cloth followed by deposition of $\mathrm{Ni}$ at $-10 \mathrm{~mA} \mathrm{~cm}^{-2}$. In this case, however, the final phosphide electrocatalyst required additional annealing at $800{ }^{\circ} \mathrm{C}$ after the typical phosphorization procedure [142].

\section{- Electrodeposition of phosphide phase}

This method stands out among the reported procedures because it can be a one-step synthesis. The electrodeposition process can be used to deposit amorphous phosphide precursors on carbon electrodes, which may or may not be further annealed. Usually, a solution with metal salt (nitrate, chloride), trisodium citrate, and $\mathrm{NaH}_{2} \mathrm{PO}_{2}$ is used in a three-electrode system. Cyclic voltammetry ( 20 cycles at $5 \mathrm{mV} \mathrm{s}^{-1}$ from -1.3 to $-0.3 \mathrm{~V}$ vs. $\mathrm{Ag} / \mathrm{AgCl})$ or chronopotentiometry ( $-1.2 \mathrm{~V}$ vs. saturated calomel electrode) modes can be used for deposition of metal phosphide phase [81,143].

\section{- Metal-organic framework-derived}

Zeolitic imidazolate framework (ZIF) materials are often used to obtain carbon-metal composites, especially combined with carbon cloth. Usually, Co-ZIF material is synthesized in the presence of carbon cloth with a reaction time of up to $5 \mathrm{~h}$. Afterwards, the precursor may be directly subjected to a nitridation process at $400{ }^{\circ} \mathrm{C}$ [144], or firstly decomposed at $800^{\circ} \mathrm{C}$ in a reducing atmosphere and then nitride [145]. A phosphide electrocatalyst can be achieved by simultaneous annealing and phosphating of a metal-rich metal-organic frameworks precursor. The as-synthesized MOF and $\mathrm{NaH}_{2} \mathrm{PO}_{2}$ are used as in the typical phosphorization procedure but at a higher annealing temperature of $650{ }^{\circ} \mathrm{C}$ [146].

\section{- Phosphides and nitrides with protective carbon shell}

A protective carbon layer over metal phosphides is used to prevent the leaching of metal ions during oxidative reactions. A simple procedure involves covering the phosphide material with glucose in a Teflon-lined autoclave in a hydrothermal process with subsequent carbonization at $400{ }^{\circ} \mathrm{C}$ for $2 \mathrm{~h}$ in an inert atmosphere [147]. Alternatively, a precursor in form of 1,2-bis-diphenylphosphinoethane dichloronickel (II) can be pyrolyzed in a reducing atmosphere at 400 to $600{ }^{\circ} \mathrm{C}$ for $2 \mathrm{~h}$ to obtain carbon-encapsulated nickel phosphide nanoparticles [148]. For nitride materials with carbon shell, $\mathrm{Co}_{3}\left[\mathrm{Co}(\mathrm{CN})_{6}\right]_{2}-$ Prussian blue analogue precursors were subjected to calcination and nitridation in the $\mathrm{N}_{2} / \mathrm{NH}_{3}$ atmosphere at temperatures of $450-650^{\circ} \mathrm{C}$ for $2 \mathrm{~h}$ to synthesize cobalt nitrides, $\mathrm{Co}_{3} \mathrm{~N}, \mathrm{Co}_{3} \mathrm{~N} / \mathrm{Co}_{4} \mathrm{~N}$, and $\mathrm{Co}_{4} \mathrm{~N}[149]$.

\section{Reactivity of Carbon-Based Composite Materials}

In this review, the carbon-based electrocatalysts are classified according to their composition into four categories: (i) metal-free carbon composites (ii) composites of carbon with metal hydroxides/oxyhydroxides/oxides, (iii) composites of carbon with metal nitrides/phosphides, and (iv) carbon-metal chalcogenides. Density functional theory (DFT) calculations are frequently used to rationalize the observed reactivity trends, and such results are also often presented here. The full review of the theoretical methods, however, is beyond the scope of the present article.

From the point of view of the carbon component, the highest reported activities in OER are, in general, obtained for the composites with graphene or reduced graphene oxide [80,100], and $\mathrm{N}$ or S,N-co-doped graphene materials [96,150-152]. Interestingly, similarly high reactivities can be obtained with composites built with amorphous carbons without [147,153], or with alien atom doping [139,154]. Heteroatom doping of carbon materials results in improved oxygen evolution activity. A straightforward comparison of the classes of the electrocatalysts is difficult and ambiguous due to the limited database of 
explored materials. Nonetheless, the average overpotential for the 5 best electrocatalysts studied in $1 \mathrm{M}$ electrolyte, in each class reported in this review, may be a useful first approximation to evaluate the carbon-based composites in OER (Figure 8). The average overpotential values are: (i) 316, (ii) 283, (iii) 259, and (iv) $247 \mathrm{mV}$ at $10 \mathrm{~mA} \mathrm{~cm}{ }^{-2}$, for metal-free carbons, oxides, nitrides/phosphides and chalcogenides, respectively. Thus, in terms of a generalized trend in OER reactivity, the most active catalysts are found in the chalcogenide category, followed by the metal nitrides/phosphides. The least active composites are formed without the addition of metal compounds. In the following sections, the most active OER electrocatalysts are presented in detail, with discussions on the possible origins of the observed reactivity.

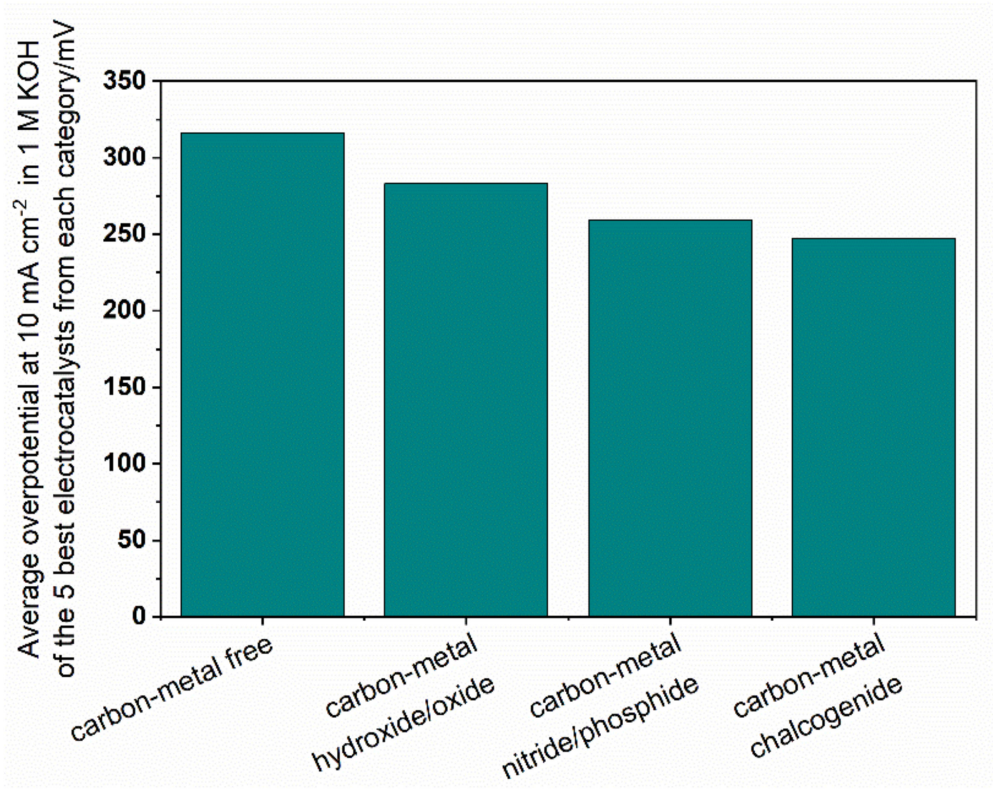

Figure 8. Average overpotentials at $10 \mathrm{~mA} \mathrm{~cm}{ }^{-2}$ of the five best carbon-based electrocatalysts reviewed from each category in $1 \mathrm{M} \mathrm{KOH}$.

\subsection{Metal-Free Carbon Composite Electrocatalysts}

One of the ongoing issues concerning the production of the highly active and stable catalysts for water splitting is the cost of the metal active phase. Among metal-free alternatives, carbon-based electrodes have recently attracted great attention due to their relatively low price and robustness (mechanical strength, electrical conductivity) which is of paramount importance while designing OER electrocatalysts for large-scale application. A broad family of carbon-based nanomaterials can be fabricated offering various structures and dimensionalities: 0D (fullerenes, carbon dots), 1D (nanotubes, nanofibers), 2D (graphene and graphemic materials, such as few-layer graphenes, graphene nanoribbons), or 3D (capsules, spheres, nanoporous structures). Such structural diversity has an immediate impact on the physicochemical properties of the materials and hence OER activity. The characteristic reactivity parameters of the metal-free carbon electrocatalysts are summarized in Table 2. Pristine carbon-based materials, mostly carbon nanotubes (CNTs), have recently been investigated as OER catalysts. Cheng et al. revealed that pristine CNTs with specific characteristics, namely an outer diameter of 2-5 nm and the number of concentric tubes of 2-7, exhibit an excellent electrocatalytic activity toward OER in alkaline medium, which follows the volcano-type dependence on the number of walls of CNTs (Figure 9) [155]. 
Table 2. Selection-comparison of metal-free carbon electrocatalysts.

\begin{tabular}{|c|c|c|c|c|}
\hline Catalyst & Electrolyte & $\begin{array}{l}\text { Overpotential at } \\
10 \mathrm{~mA} \mathrm{~cm}^{-2} / \mathrm{mV}\end{array}$ & Tafel Slope/mV dec -1 & Ref. \\
\hline ANGS (activated S, N co-doped graphene) & $1 \mathrm{M} \mathrm{KOH}$ & 281 & 109 & [150] \\
\hline SNG@GF (N and S-doped graphene on graphite foam) & $1 \mathrm{M} \mathrm{KOH}$ & 330 & 149 & [151] \\
\hline GNP (N, P, and O-doped carbon) & $1 \mathrm{M} \mathrm{KOH}$ & 299 & 127 & [154] \\
\hline N-GRW (N-doped graphene nanoribbons) & $1 \mathrm{M} \mathrm{KOH}$ & 360 & 47 & [156] \\
\hline PAN-CCC (N-doped cotton cloth) & $1 \mathrm{M} \mathrm{NaOH}$ & 351 & 88 & [157] \\
\hline NMWNT (N-doped multi-walled carbon nanotubes) & $1 \mathrm{M} \mathrm{NaOH}$ & 320 & 68 & [158] \\
\hline $\begin{array}{l}\text { G-BNG (stacked nanofilm of graphene on } \\
\text { B,N-codoped graphene) }\end{array}$ & $0.1 \mathrm{M} \mathrm{KOH}$ & 580 & 143 & [159] \\
\hline OCC (oxidized carbon cloth) & $0.1 \mathrm{M} \mathrm{KOH}$ & 477 & 82 & [160] \\
\hline
\end{tabular}

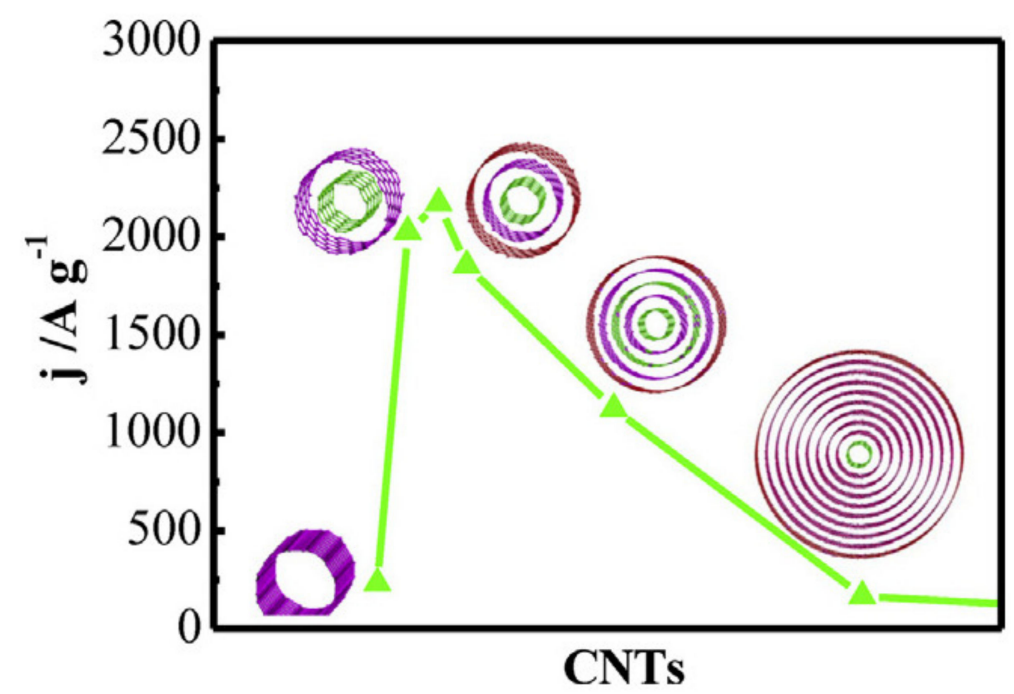

Figure 9. A plot of the activity of CNTs for the OER in $1 \mathrm{M} \mathrm{KOH}$ solutions as a function of the number of walls. The mass-specific activity was measured at $1.8 \mathrm{~V}$ (vs. RHE) at a scan rate of $1 \mathrm{mV} \mathrm{s}^{-1}$ and rotating rate of $2000 \mathrm{rpm}$ with CNTs loading of $0.025 \mathrm{mg} \mathrm{cm}^{-2}$. Reprinted from Applied Catalysis B: Environmental, 163, Yi Cheng, Changwei Xu, Lichao Jia, Julian D. Gale, Lili Zhang, Chang Liu, Pei Kang Shen, San Ping Jiang, Pristine carbon nanotubes as non-metal electrocatalysts for oxygen evolution reaction of water splitting, 96-104. Copyright (2015), with permission from Elsevier [155].

The current density of triple-walled nanotubes is $\sim 56 \mathrm{~mA} \mathrm{~cm}^{-2}$ at $1.8 \mathrm{~V}$ in $1 \mathrm{M} \mathrm{KOH}$, whereas the values measured for SWCNTs and MWCNTs are around 10 and 35 times smaller, respectively. An excellent activity of nanotubes with the specific number of walls at high polarization potentials, much better even than for $50 \% \mathrm{Pt} / \mathrm{C}\left(5.6 \mathrm{~mA} \mathrm{~cm}^{-2}\right)$, can be explained by the reactive sites on the outer wall for adsorption/dissociation of $-\mathrm{OH}^{-}$and $-\mathrm{OOH}^{*}$ species and by the electron tunnelling between the outer wall and inner tubes. As a result, OER, which is a charge transfer dependent process, is promoted at the surface of the outer wall of the carbon nanotubes. Such improvement of the activity is impossible for SWCNTs, whereas reduced driving force across the walls of MWCNT leads to decreased effective electron tunnelling between the outer wall and inner tubes. Moreover, Cheng et al. conducted experiments that excluded the importance of trace metal impurities in differences of the activities between nanotubes with various numbers of walls. A similar conclusion was drawn by Ali et al. [161], who observed that the onset potential of CNTs (four concentric tubes without any post-treatment) for the OER process in $3 \mathrm{M} \mathrm{NaOH}$ is reduced $(1.60 \mathrm{~V})$ compared to a Pt-based electrode $(1.72 \mathrm{~V})$. The overpotential of materials decreases with an increased concentration of the electrolyte.

The susceptibility of carbon materials to chemical reactions is linked to topological and edge defects. Nevertheless, to boost intrinsic OER activity, pristine materials usually require surface and/or structural modifications that at present are often realized by the 
introduction of heteroatoms, such as $\mathrm{O}, \mathrm{N}, \mathrm{S}, \mathrm{F}, \mathrm{B}$, and the formation of stable surfacespecific functional groups. Furthermore, doping leads to changes in the charge distribution and electronic properties as well as the formation of additional defects, besides the intrinsic ones, enhancing the electrocatalytic performance of carbons. The extent of possible modifications depends on the electronegativity and size of the doping atoms.

An important aspect of doped catalysts is their stability in harsh reaction conditions (high OER potential and corrosive environment), since the oxidation of carbon, or heteroatom, is thermodynamically favorable. From a practical point of view, stability is even more important than the initial reactivity of the novel heteroatom-doped carbon material. Finally, the purity of the heteroatom-doped concerning trace metals should be carefully evaluated. The functionalization procedures may lead to the unintentional introduction of traces of metals that may be responsible for the significant improvement of the electrocatalytic performance.

Yang et al. reported that nitrogen-doped 3D graphene nanoribbon exhibited excellent OER activity with an overpotential of $360 \mathrm{mV}$ at $10 \mathrm{~mA} \mathrm{~cm}^{-2}$ in $1 \mathrm{M} \mathrm{KOH}$ and Tafel slope of $47 \mathrm{mV} \mathrm{dec}{ }^{-1}$. Authors experimentally proved thorough X-ray absorption near-edge structure (XANES) spectroscopic measurements that the electron-withdrawing pyridinic $\mathrm{N}$ groups play a role as active sites for OER [156]. Such groups provide p-type doping effects, accepting electrons from adjacent $\mathrm{C}$ atoms and facilitating the adsorption of $\mathrm{OH}^{-} / \mathrm{OOH}^{-}$water oxidation intermediates. Davodi et al. demonstrated excellent activity of N-doped MWCNTs towards both OER and HER. The electrode required an overpotential of $360 \mathrm{mV}$ and $340 \mathrm{mV}$ toward OER and HER respectively, to achieve $10 \mathrm{~mA} \mathrm{~cm}^{-2}$ in $0.1 \mathrm{M}$ $\mathrm{NaOH}$ [158]. Jiang et al. presented nitrogen-doped ultrathin carbon sheets with a high surface area $\left(1793 \mathrm{~m}^{2} \mathrm{~g}^{-1}\right)$ and rich edge defects. Such materials can be used as a trifunctional electrode for OER, ORR, and HER with high performance and durability. DFT calculations revealed that the carbon atoms located at the armchair edge and adjacent to the graphitic $\mathrm{N}$ dopants act as the active site for the electrocatalytic reactions [162]. N-doped cotton cloth requires a low overpotential of $351 \mathrm{mV}$ to deliver $10 \mathrm{~mA} \mathrm{~cm}^{-2}$ of current density with a Tafel slope of $88 \mathrm{mV} \mathrm{dec}{ }^{-1}$ during the OER test, while the parental material exhibited

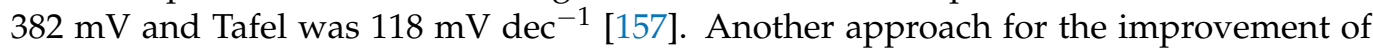
catalytic activity toward OER and catalysts stability consists in surface oxidation of the raw carbons. Introduction of oxygen-containing functional groups into carbon cloth surface $(\mathrm{O} / \mathrm{C}$ ratio of 0.051$)$ allowed the reaching of an overpotential of $477 \mathrm{mV}$, giving a current density of $10 \mathrm{~mA} \mathrm{~cm}^{-2}$ with a Tafel slope of $82 \mathrm{mV} \mathrm{dec}^{-1}$ and long-term durability (at least $24,000 \mathrm{~s}$ ) during $\mathrm{OER}$ tests in $0.1 \mathrm{M} \mathrm{KOH} \mathrm{[160].} \mathrm{Under} \mathrm{alkaline} \mathrm{conditions,} \mathrm{ketonic}-\mathrm{C}=\mathrm{O}$ sites make substantial contributions to the OER activity of carbon-based electrodes since by altering the electronic distribution of the surrounding carbon atoms they facilitate the electron transfer and adsorption of water oxidation intermediates $[160,163]$.

Furthermore, the OER activity of the N-doped carbons can be enhanced by the synergistic effect of the introduced multiple heteroatoms. Incorporation of boron was reported to decrease the onset potential by $100 \mathrm{mV}$ vs. RHE and overpotential by $61 \mathrm{mV}$ at current densities of $10 \mathrm{~mA} \mathrm{~cm}^{-2}$ in alkaline media compared with the corresponding $\mathrm{N}$-doped catalyst. DFT verified that chemisorption energy of $-\mathrm{OH}^{*}$ on B,N-co-doped catalyst was $0.281 \mathrm{eV}$ less [79]. Similarly, Paul et al. documented an improved performance of graphene/BNgraphene stacked nanofilms toward OER due to the modified $\pi$-bonding environment in the top graphenic layer by doped $\mathrm{B}$ and $\mathrm{N}$ atoms. As a result, the electron transfer during OER tests was facilitated. The material reached an onset potential of $1.6 \mathrm{~V}$ vs. RHE and Tafel slope of $143.22 \mathrm{mV} \mathrm{dec}^{-1}$ [159]. Li et al. fabricated $\mathrm{N}$ and $\mathrm{P}$ dual-doped graphene/carbon nanosheet (N,P-GCNS) composites that exhibited an OER onset potential of $1.32 \mathrm{~V}$, whereas for $\mathrm{RuO}_{2}$, which is one of the most popular OER electrocatalysts, the value was $1.39 \mathrm{~V}$. The current densities at $1.9 \mathrm{~V}$ were 70.75 and $32.41 \mathrm{~mA} \mathrm{~cm}^{-2}$ for N,P-GCNS and $\mathrm{RuO}_{2}$, respectively [164].

Besides co-doping, one important strategy to enhance the electrocatalytic kinetics is microstructure engineering of the non-metal carbonaceous catalysts. In the case of $2 \mathrm{D}$ 
graphenic-based catalysts, the electron transfer can be diminished due to the susceptibility of these materials to stacking together that results in shielding of the active sites. Thus, 3D carbon materials, such as carbon hydrogels, foams, and hierarchical porous carbons are commonly used as electrode materials or supports for energy storage and conversion devices [165-167]. The porous structure allows for the increase in the utilization efficiency of the catalytically active centers, providing access to the sites to the electrolyte and reactants. Guo et al. revealed that immobilization of the nitrogen and sulfur co-doped graphene flakes on the interconnected conductive graphite foam facilities electron transfer and decreases electrolyte/electrode interface resistance during the OER process [151]. Such composite material can act as a free-standing electrode that exhibits an initial overpotential of $330 \mathrm{mV}$ vs. RHE at $10 \mathrm{~mA} \mathrm{~cm}{ }^{-2}$ in $1 \mathrm{M} \mathrm{KOH}$ with a Tafel slope of $149 \mathrm{mV} \mathrm{dec}^{-1}$. The synergistic effect of nitrogen and sulfur as co-dopants, as well as the importance of the 3D nanoarchitecture to provide a high density of the OER active sites and promote the electrolyte and electron transports, was confirmed by Li et al. The activation of the synthesized S, N co-doped graphene (NGS) by $\mathrm{KOH}$ allowed for the obtaining of a porous structure (ANSG), which introduced abundant structural defects into the carbon matrix. The ANSG catalyst ( $281 \mathrm{mV}$ vs. RHE) showed a considerably lower overpotential at $10 \mathrm{~mA} \mathrm{~cm}^{-2}$ in $1 \mathrm{M} \mathrm{KOH}$ than NSG (452 mV vs. RHE). Similarly, significant differences were observed for electrochemical kinetics during the OER test; the Tafel slopes for ANGS and NGS were 108.9 and $172.1 \mathrm{mV} \mathrm{dec}^{-1}$, respectively [150].

One of the materials that has recently attracted significant attention in electrocatalytic applications is graphitic carbon nitride $\left(\mathrm{g}-\mathrm{C}_{3} \mathrm{~N}_{4}\right)$, mostly due to its tailorable structure and high nitrogen content (pyridinic and pyrrolic $\mathrm{N}$ ) in the carbon framework [168-170]. Nevertheless, the catalytic activity of bulk g- $\mathrm{C}_{3} \mathrm{~N}_{4}$ suffers from low surface area and insufficient electronic conductivity. Doping with heteroatoms, designing nanostructures, and composite materials seem to be promising solutions for improving the electrocatalytic performance of carbon nitride. Wahab et al. reported the OER catalytic parameters for mesoporous g- $\mathrm{C}_{3} \mathrm{~N}_{4}$ with high nitrogen content (48 wt.\%); an onset potential of $1.51 \mathrm{~V}$ and a Tafel slope of $52.4 \mathrm{mV} \mathrm{dec}^{-1}$ in $1 \mathrm{M} \mathrm{KOH}$, indicating favorable OER kinetics [78]. Furthermore, the high stability of the electrode was proven by the chronoamperometric response of mesoporous graphitic carbon nitride, which displays an attenuation of only $1.6 \%$ after $24 \mathrm{~h}$. Ma et al. proposed the synthesis of a composite material consisting of self-assembly of g- $\mathrm{C}_{3} \mathrm{~N}_{4}$ nanosheets and carbon nanotubes. The latter provided improved electron transfer and thus the catalyst generated a current density of $10 \mathrm{~mA} \mathrm{~cm}{ }^{-2}$ at $1.60 \mathrm{~V}[72]$.

\subsection{Carbon-Metal Hydroxides/Oxyhydroxides/Oxides}

Metal oxide-hydroxide composites with carbons are being increasingly used to improve the electrocatalytic performance of the transition metal active phase. Such a combination promotes electron transport to the current collector by decreasing the thickness of the poorly conductive oxyhydroxide phase. In addition, the application of the porous carbons offers the benefits of enhanced access of the liquid phase reactants to the surface of the solid electrocatalyst. The formation of such composite materials enables an efficient way to reach the state-of-the-art OER activities (compare with Table 1). Representative recent reports are summarized below, with a special emphasis on the effects of carbon support on the transition metal phase reactivity. The characteristic parameters of the electrocatalysts are summarized in Table 3. 
Table 3. Selection-comparison of carbon-metal hydroxides/oxyhydroxides/oxides.

\begin{tabular}{|c|c|c|c|c|}
\hline Catalyst & $\begin{array}{l}\text { KOH Electrolyte } \\
\text { Concentration }\end{array}$ & $\begin{array}{l}\text { Overpotential at } \\
10 \mathrm{~mA} \mathrm{~cm}^{-2} / \mathrm{mV}\end{array}$ & Tafel Slope/mV dec -1 & Ref. \\
\hline Ni-Fe Hydroxide/edge-rich vertical graphene & $1 \mathrm{M}$ & 276 & 38 & [80] \\
\hline $\mathrm{Ni} / \mathrm{NiO} / \mathrm{N}$-doped activated carbon & $0.1 \mathrm{M}$ & 346 & 70 & [92] \\
\hline N-rGO/NiCo-NiO-CoO & $1 \mathrm{M}$ & 260 & 72 & [96] \\
\hline $\mathrm{N}-\mathrm{rGO} / \mathrm{CoFe}-\mathrm{CoFe}_{2} \mathrm{O}_{4}$ & $1 \mathrm{M}$ & 320 & 54 & [96] \\
\hline $\mathrm{Co}_{0.5} \mathrm{Fe}_{0.5} \mathrm{WO}_{4} / \mathrm{CNT}$ & $1 \mathrm{M}$ & 290 & 42 & [97] \\
\hline Ni nanoplates/rGO & $1 \mathrm{M}$ & 330 & 68 & [100] \\
\hline $\mathrm{Ni@Pt} \mathrm{core-shell} \mathrm{nanoplates/rGO}$ & $1 \mathrm{M}$ & 290 & 52 & [100] \\
\hline $\mathrm{Ni}-\mathrm{NiFe}_{2} \mathrm{O}_{4} / \mathrm{N}-\mathrm{CNT}$ & $1 \mathrm{M}$ & 340 & $51 *$ & [101] \\
\hline $\mathrm{Co}(\mathrm{OH})_{\mathrm{X}} / \mathrm{N}-\mathrm{CNT}$ & $1 \mathrm{M}$ & 350 & 36 & [102] \\
\hline $\begin{array}{l}\text { Hollow } \mathrm{Co}_{3} \mathrm{O}_{4} / \mathrm{CeO}_{2} \text {-heterostructure/ } \\
\text { N-doped carbon nanofibers }\end{array}$ & $0.1 \mathrm{M}$ & 310 & 85 & [105] \\
\hline $\begin{array}{c}\mathrm{Ni}_{0.36} \mathrm{Fe}_{0.64} / \mathrm{MnOx} / \mathrm{N} \text {-doped graphitic carbon, } \\
\mathrm{Mn} / \mathrm{Ni}=0.2\end{array}$ & $1 \mathrm{M}$ & 300 & 43 & [108] \\
\hline $\mathrm{CoO}_{\mathrm{x}} /$ carbon fiber paper & $1 \mathrm{M}$ & 343 & 74 & [109] \\
\hline $\mathrm{CoO}_{\mathrm{x}} / \mathrm{NrGO}$ & $0.1 \mathrm{M}$ & 392 & 72 & [171] \\
\hline $\mathrm{TaO}_{\mathrm{x}} / \mathrm{CNF}$ & $0.1 \mathrm{M}$ & 405 & 72 & [172] \\
\hline $\mathrm{CoO}-\mathrm{Co} / \mathrm{CNF}$ & $1 \mathrm{M}$ & 437 & 140 & [173] \\
\hline NiCo-loaded CNF & $1 \mathrm{M}$ & 408 & 140 & [174] \\
\hline $\mathrm{Co}_{3} \mathrm{O}_{4} / \mathrm{CNF}$ & $1 \mathrm{M}$ & 416 & 108 & [175] \\
\hline $\mathrm{NiCO}_{2} \mathrm{O}_{4} / \mathrm{CNF}$ & $6 \mathrm{M}$ & 223 & 174 & [176] \\
\hline $\mathrm{FeCO}_{2} \mathrm{O}_{4} / \mathrm{CNF}$ & $6 \mathrm{M}$ & 130 & 100 & [177] \\
\hline
\end{tabular}

Mixed Ni-Fe hydroxides were obtained through preferential templating on graphene edges where the edge-rich vertical graphene support provided the unoccupied density of states on the graphene edges, which are able to preferentially template specific valence orbital alignment of the Fe-O entities. This specific interaction of the graphene edge-metal component resulted in the formation of beneficial undersaturated and strained Fe-sites with high valence states, and at the same time, it boosted the formation of redox-activated $\mathrm{Ni}$ species. These two effects resulted in an improved OER reactivity [80]. For the Ni@Pt core-shell nanoplates and $\mathrm{Ni} / \mathrm{rGO}$ composites, the overpotential of $\mathrm{Ni} / \mathrm{rGO}$ is lower than pure $\mathrm{Ni}$ and the enhanced performance of $\mathrm{Ni} / \mathrm{rGO}$ was ascribed to the possible effect of the rGO coatings. The GO was added in the synthesis of the Ni-Al LDH precursor and with the addition of hydrazine hydrate as a reducing agent in the reduction reaction, $\mathrm{GO}$ and $\mathrm{Ni}-\mathrm{Al}$ $\mathrm{LDH}$ are simultaneously reduced. The morphology of obtained product is maintained as hexagonal nanoplates, which further improves the catalytic performance. According to the results of electrochemical impedance spectroscopy, the excellent conductivity of rGO plays a major role in reducing the influence of Ni oxidation in the process of water splitting, and it can effectively improve the electrical conductivity of the anode, facilitating electron extraction and shortening ion transport pathways during OER [100]. A uniformly coated carbon fiber paper with $\mathrm{CoO}_{\mathrm{x}}$ layers was obtained by the atomic layer deposition technique (ALD). It was found that the oxygen evolution is not enhanced after a critical thickness of $\sim 28 \mathrm{~nm}$ and the optimal thickness of the ALD-CoO ${ }_{x}$ film is dependent on two competing effects. The high oxidation state of cobalt ions in thicker $\mathrm{CoO}_{x}$ helps the oxygen evolution, whereas the introduction of a thick oxide coating decelerates the rate of charge transfer at the surface, which exemplifies the limitations of the oxide phases with respect to their low electrical conductivity (Figure 10). The larger Tafel slope for the thicker film could be a result of the inevitable charge transport limitation in the bulk region [109]. 


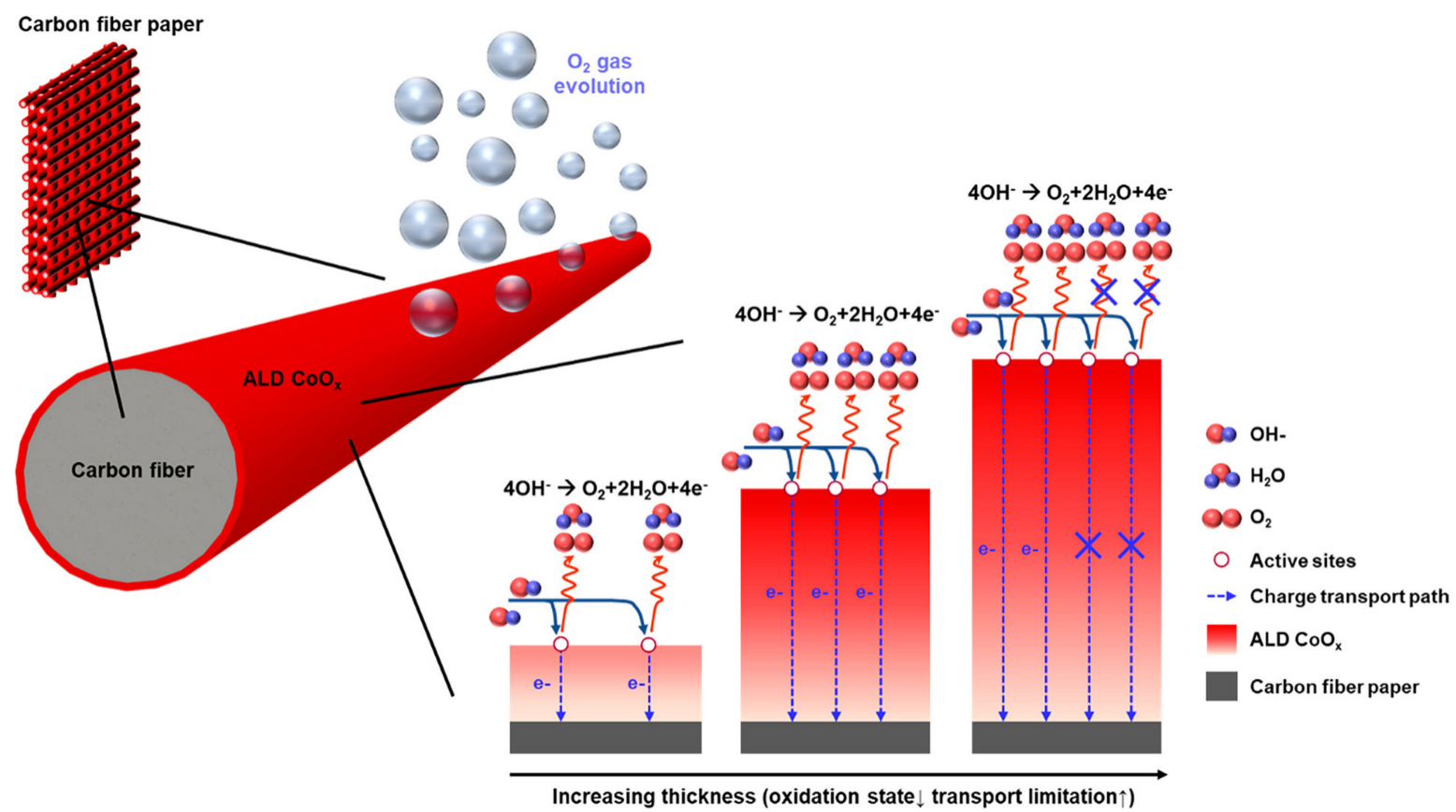

Figure 10. Schematic diagram of the change in oxidation state and charge transport length at various film thicknesses and the consequent OER activity. Reprinted with permission from Choi, H.J.; Han, G.D.; Bae, K.; Shim, J.H. Highly Active Oxygen Evolution on Carbon Fiber Paper Coated with Atomic-Layer-Deposited Cobalt Oxide. ACS Appl. Mater. Interfaces 2019, 11, 10,608-10,615. Copyright 2019, American Chemical Society [109].

The excellent catalytic performance in both OER and ORR of N-rGO/NiCo-NiO-CoO and $\mathrm{N}-\mathrm{rGO} / \mathrm{CoFe}-\mathrm{CoFe}_{2} \mathrm{O}_{4}$ obtained by deposition in an autoclave at $150{ }^{\circ} \mathrm{C}$ for $12 \mathrm{~h}$ was attributed to several factors. Firstly, it was supposed that the graphene matrix can enhance the conductivity and benefit the electron transfer during the catalytic process. Secondly, the nanoparticle with small and uniform size could provide sufficient active sites for electrocatalytic reaction. And finally, the existence of oxygen defects in the prepared composite can enhance the conductivity and accelerate the kinetics of surface redox reactions [96]. Subnanometer cobalt-hydroxide-anchored N-doped carbon nanotube forests, where abundant charge carriers in amorphous $\mathrm{Co}(\mathrm{OH})_{x}$ species, were found to trigger OER activity with a high current density and a low Tafel slope. The unique subnanometer scale morphology along with strong cobalt species-NCNT interaction is ascribed to an increase of the stability of the catalyst during prolonged repeated cycles [102]. One-step calcination of ternary NiFeMn-Prussian blue analogues/polymer hybrid precursors yielded a catalyst wherein a synergy between highly conductive continuous $\mathrm{N}$-doped carbon network and oxidized metal species $\left(\mathrm{Ni}^{2+}, \mathrm{Fe}^{2+}\right.$ and $\left.\mathrm{Mn}^{2+}\right)$ formed at the heterostructured $\mathrm{Ni}_{0.36} \mathrm{Fe}_{0.64} / \mathrm{MnO}_{\mathrm{x}}$ interfaces enabled efficient withdrawing of electrons from $\mathrm{OH}^{-}$and in turn charge transfer during OER [108]. In N-CNT/Ni- $\mathrm{NiFe}_{2} \mathrm{O}_{4}$ composites, the nanoparticles were anchored to the carbon nanotubes, thus greatly preventing agglomeration and achieving excellent structural and electrochemical stability. Moreover, both the N-CNT and the bimetallic spinel oxides contributed to the active sites not only for OER but also for HER and ORR [101]. Composites based on nanostructured iron-doped $\mathrm{CoWO}_{4}$ particles electrically linked to conductive carbon nanotubes, $\mathrm{Co}_{0.5} \mathrm{Fe}_{0.5} \mathrm{WO}_{4} / \mathrm{CNT}$, were obtained using a facile one-pot hydrothermal method and exhibited overpotential at $10 \mathrm{~mA} \mathrm{~cm}^{-2}$ below $300 \mathrm{mV}$ [97]. The OER performance may also be enhanced by combining multiple distinct oxide phases such as hollow $\mathrm{Co}_{3} \mathrm{O}_{4} / \mathrm{CeO}_{2}$ heterostructures and three-dimensional porous $\mathrm{N}$-doped carbon nanofibers N-CNF networks [105]. In addition to graphene-based carbons and carbon nanotubes, other carbon materials are successfully used as supports for the oxide-hydroxide 
phase as in the case of $\mathrm{Ni} / \mathrm{NiO}$ composite with $\mathrm{N}$-doped activated carbon obtained from waste cauliflower leaves [92].

The successful electrocatalytic formulations present enhanced electron transport from the active phase to the current collector thanks to the application of well-conductive carbonbased component $[96,97,100,109]$, which may also provide stabilization of the active metal hydroxides/oxyhydroxides/oxide phase. Various carbon structures are used, such as rGO or CNTs, usually doped with nitrogen to provide the desired electrical properties. Another common trait of the well-performing materials is the ability to stabilize high valence states of the TM cations in the active phase $[80,108,109]$.

\subsection{Carbon-Metal Chalcogenides}

Transition metal chalcogenides (TMCs-sulfides, selenides, tellurides, where TM usually is $\mathrm{Co}, \mathrm{Ni}, \mathrm{Fe}$ ), due to their multivalent oxidation states, abundant defects sites, and structural diversity, exhibit excellent abilities for electrocatalytic water splitting. Such materials are much cheaper than noble metals and exhibit noble-metal-like catalytic properties at the same time. Further, the electronic properties of TMCs can be tunable due to the ion-exchange process and the metal-chalcogen ratio variation in the electrocatalysts [178].

However, TMCs nanomaterials suffer from low stability, easy aggregation of particles, low electronic conductivity, and limited surface area, which can result in poor electrochemical activity. One of the strategies to overcome these obstacles aims at the fabrication of TMC/carbon composites and taking synergistic advantages of both materials. Combining TMCs with carbon materials significantly improves the intrinsic conductivity, facilitates charge transfer of the hybrids, as well as promotes the electroactivity of catalysts. To illustrate the effect of the electron interaction between a chalcogenide phase and the carbon support, density functional theory calculations were performed. It was found that a small increase in the lattice parameter of $\mathrm{Co}_{9} \mathrm{~S}_{8}$, brought about by the different coupling to $\mathrm{N}$-doped carbon, may result in a small but non-negligible charge injection to the sulfide phase, as summarized in Figure 11 [179]. The characteristic reactivity parameters of the carbon-metal chalcogenide electrocatalysts are summarized in Table 4.

Table 4. Selection-comparison of carbon-metal chalcogenide electrocatalysts.

\begin{tabular}{|c|c|c|c|c|}
\hline Catalyst & $\begin{array}{l}\mathrm{KOH} \text { Electrolyte } \\
\text { Concentration }\end{array}$ & $\begin{array}{l}\text { Overpotential at } \\
10 \mathrm{~mA} \mathrm{~cm}-2 / \mathrm{mV}\end{array}$ & $\begin{array}{l}\text { Tafel Slope/ } \\
\text { mV dec }\end{array}$ & Ref. \\
\hline $\mathrm{MoS}_{2}$ wrapped N-doped carbon-coated Co nanospheres & $1 \mathrm{M}$ & 297 & 70 & [110] \\
\hline $\mathrm{CoSe}_{2} / \mathrm{Ni}_{3} \mathrm{Se}_{4} @ \mathrm{~N}$-doped carbon nanosheets/ketjen black carbon & $1 \mathrm{M}$ & 260 & 68 & [114] \\
\hline $\mathrm{NiFe}-\mathrm{Se} /$ carbon fiber paper & $1 \mathrm{M}$ & 281 & 41 & [118] \\
\hline $\mathrm{NiFeCoSe}_{\mathrm{x}} /$ carbon fiber cloth & $1 \mathrm{M}$ & 150 & 85 & [126] \\
\hline $\mathrm{Fe}_{\mathrm{x}} \mathrm{Ni}_{1-\mathrm{x}} \mathrm{S}_{2} / \mathrm{C}$ & $1 \mathrm{M}$ & 248 & 43 & [153] \\
\hline $\mathrm{CoSe}_{2} @ \mathrm{~N}$-doped bamboo-like carbon nanotubes & $1 \mathrm{M}$ & 340 & 103 & [180] \\
\hline Fe-Co $\mathrm{Co}_{1.11} \mathrm{Te}_{2} @ \mathrm{~N}$-doped carbon nanotube & $1 \mathrm{M}$ & 297 & 91 & [181] \\
\hline $\mathrm{NiSe}-\mathrm{Ni}_{3} \mathrm{Se}_{2} / \mathrm{MWCNT}$ & $0.1 \mathrm{M}$ & 325 & 70 & [182] \\
\hline $\mathrm{CoTe}_{2}$ encapsulated in N-doped carbon nanotube frameworks & $1 \mathrm{M}$ & 330 & 83 & [183] \\
\hline NiS@N/S-C & $1 \mathrm{M}$ & 417 & 48 & [184] \\
\hline
\end{tabular}

Recently, great efforts have been taken to develop hybrid structures of carbons and transition metal sulfides, particularly cobalt-based ones [111,123,127,179,185-187]. Cao et al. fabricated $\mathrm{Co}_{9} \mathrm{~S}_{8}$ embedded in a porous nitrogen-doped carbon matrix [187]. For example, a synthesized $\mathrm{Co}_{9} \mathrm{~S}_{8} / \mathrm{N}-\mathrm{C}$ composite reached an OER potential of $0.57 \mathrm{~V}$ at a current density of $5 \mathrm{~mA} \mathrm{~cm}^{-2}$ in $0.1 \mathrm{M} \mathrm{KOH}$ and had a Tafel slope of $75 \mathrm{mV} \mathrm{dec}^{-1}$. The chronoamperometry measurements revealed that after 55,000 s of continuous testing, $\mathrm{Co}_{9} \mathrm{~S}_{8} / \mathrm{N}-\mathrm{C}$ lost $6 \%$ of the initial current density, whereas a decrease of $70 \%$ in current density was observed for a $\mathrm{RuO}_{2} / \mathrm{C}(20 \%$ of an active phase) catalyst. This high electrocatalytic performance with sustained reactivity arises from covalent bonding between $\mathrm{Co}_{9} \mathrm{~S}_{8}$ and $\mathrm{N}$-doped carbon that facilitates the electron transfer. Also, the porous carbon matrix is favorable for the efficient transport of oxygen and electrolyte molecules during 
the OER processes. Ashok et al. designed a hierarchical $\mathrm{Co} / \mathrm{Co}_{9} \mathrm{~S}_{8} / \mathrm{CNT}$ nanostructure that required $1.5 \mathrm{~V}$ to achieve a current density of $10 \mathrm{~mA} \mathrm{~cm}^{-2}$ in $1 \mathrm{M} \mathrm{KOH}$ electrolyte with low Tafel slope $\left(79 \mathrm{mV} \mathrm{dec}^{-1}\right)$ [123]. After $20 \mathrm{~h}$ of the applied constant potential of $1.5 \mathrm{~V}$, the current density was stable with minor variations.
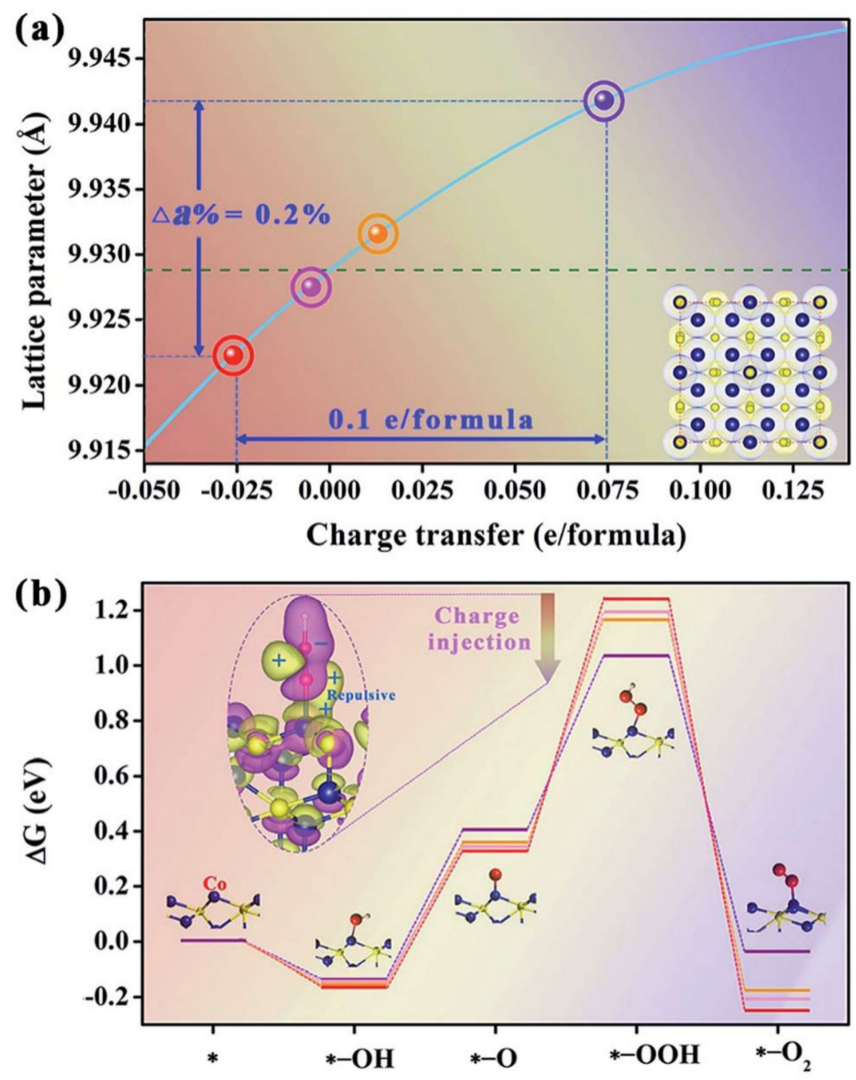

Figure 11. (a) DFT analysis of the dependence of lattice parameter of $\mathrm{Co}_{9} \mathrm{~S}_{8}$ on the variation of injected charge transfer; (b) DFT calculated free energy landscape for the OER at 1.23 V vs. RHE (the standard potential for OER) on the $\mathrm{Cog}_{8} \mathrm{~S}_{8}(100)$ surface at different charging states. Inset in (a): structural model of the $\mathrm{Co}_{9} \mathrm{~S}_{8}$ crystal; (b): absorption structure and charge density redistribution at different charging states (atoms with blue, yellow, red, and white colours represent Co, S, O and $\mathrm{H}$ atoms, respectively). Reproduced from Ref. [179] with permission from the Royal Society of Chemistry.

Besides cobalt sulfides, $\mathrm{Ni}_{7} \mathrm{~S}_{6}$ can be utilized as an OER catalyst, especially when coupled with nitrogen-doped graphene oxide [188]. Such a hierarchical porous nanocomposite (named by authors $\mathrm{NGO} / \mathrm{Ni}_{7} \mathrm{~S}_{6}$ ) has been proven to exhibit improved OER kinetic parameters, in particular a Tafel slope of only of $45.4 \mathrm{mV} \mathrm{dec}^{-1}$, which was lower by $\sim 43.6 \mathrm{mV} \mathrm{dec}^{-1}$ than that for $\mathrm{RuO}_{2}$ measured under similar conditions in alkaline media. Similarly, Yang et al. reported a Tafel slope of $48 \mathrm{mV} \mathrm{dec}^{-1}$ for NiS@N/S-C catalyst. Hybrid material composed of NiS nanoparticles embedded in nitrogen/sulphur co-doped carbon matrix, derived from carbonization of metal-organic framework (MOF), exhibited an overpotential of $417 \mathrm{mV}$, which was delivered at a current density of $10 \mathrm{~mA} \mathrm{~cm}^{-2}$ in $1 \mathrm{M}$ $\mathrm{KOH}$. In addition to adequate OER activity, such composite catalyst exhibited satisfactory long-term durability for water splitting in alkaline media. During the chronopotentiometry measurements, the potential was stable (only insignificant voltage changes occurred)

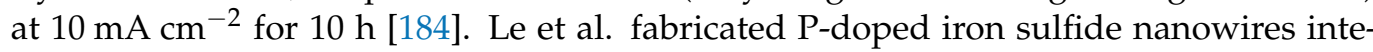
grated within a carbon matrix ( $\left.\mathrm{P}-\mathrm{Fe}_{7} \mathrm{~S}_{8} @ \mathrm{C}\right)$ [189]. The electrocatalyst with the optimized amounts of P dopants exhibited remarkably low overpotential $(210 \mathrm{mV})$ during OER tests 


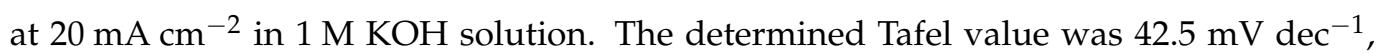
indicating high OER kinetic.

Another approach consists of the fabrication of bimetallic sulfides [84,112,153,190-192]. For instance, $\mathrm{NiCO}_{2} \mathrm{~S}_{4}$ combined with redox couples of $\mathrm{Ni}^{3+} / \mathrm{Ni}^{2+}$ and $\mathrm{Co}^{3+} / \mathrm{Co}^{2+}$ has been recently recognized as a highly efficient bifunctional oxygen electrocatalyst for rechargeable $\mathrm{Zn}$-air batteries. He et al. synthesized nickel-cobalt sulfide nanoparticles confined in cages of carbon-nitrogen nanosheets $\left(\mathrm{NiCO}_{2} \mathrm{~S}_{4} / \mathrm{CNNs}\right.$ composites) [84]. The synergistic effect of both materials provided an overpotential of $360 \mathrm{mV}$ at $10 \mathrm{~mA} \mathrm{~cm}{ }^{-2}$ ) for oxygen evolution reaction in $\mathrm{O}_{2}$-saturated $0.1 \mathrm{M} \mathrm{KOH}$. According to Han et al. $\mathrm{NiCo}_{2} \mathrm{~S}_{4} / \mathrm{N}$-doped CNTs showed excellent performance in the regenerative $\mathrm{Zn}$-air system reaching the chargedischarge polarization of $0.63 \mathrm{~V}$ and a voltaic efficiency of $\sim 67.2 \%$ [112]. Interestingly, after 150 cycles, the polarization decreased only by $0.06 \mathrm{~V}$, reducing an energy efficiency by $\sim 65.1 \%$. As a comparison, standard commercial catalysts $\left(\mathrm{Pt} / \mathrm{C}\right.$ and $\left.\mathrm{RuO}_{2}\right)$ showed larger increments in the voltage gap after $\sim 50$ cycles, indicating their limited rechargeability. Jiang et al. proposed the fabrication of 3D Fe-Ni sulfide nanosheets/reduced graphene oxide catalysts, shortly named $\mathrm{FeNiS}_{2} \mathrm{NS} / \mathrm{rGO}$, and compared OER activity of such material with $\mathrm{RuO}_{2}$ [192]. To reach a current density of $10 \mathrm{~mA} \mathrm{~cm}^{-2}$ in $1 \mathrm{M} \mathrm{KOH}, \mathrm{FeNiS}_{2} \mathrm{NS} / \mathrm{rGO}$ and $\mathrm{RuO}_{2}$ required potentials of $1.43 \mathrm{~V}$ and $1.54 \mathrm{~V}$, respectively. The measured Tafel slope

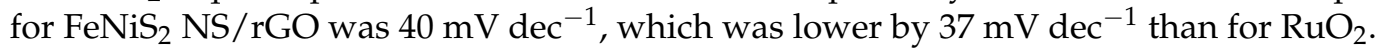
Furthermore, negligible variations in LSV curves for the freshly synthesized sulfide-based catalyst were measured before and after $5000 \mathrm{CV}$ cycles in alkaline electrolyte, suggesting good stability of the catalyst in a long-term test.

Besides sulfides, metal selenides coupled with the carbon matrix have recently been reported as active and stable OER catalysts. Ding et al. presented the catalytic parameters in OER reaction obtained for the hybrid material of $\mathrm{CoSe}_{2}$ nanoparticles with in-situ grown $\mathrm{N}$-doped bamboo-like carbon nanotubes [180]. The $\mathrm{CoSe}_{2} @ \mathrm{~N} / \mathrm{C}-\mathrm{CNT}$ composite required an overpotential of $340 \mathrm{mV}$ vs. RHE to reach a current density of $10 \mathrm{~mA} \mathrm{~cm}{ }^{-2}$ in $1 \mathrm{M}$ $\mathrm{KOH}$, the calculated Tafel slope was $107 \mathrm{mV} \mathrm{dec}^{-1}$. For comparison, carbon nanotubegrafted core-shell structured $\mathrm{CoSe}_{2} @ \mathrm{C}$ hybrids reported by Yuan et al. showed a slightly lower overpotential of $306 \mathrm{mV}$ at $10 \mathrm{~mA} \mathrm{~cm}{ }^{-2}$ in $1 \mathrm{M} \mathrm{KOH}$ and Tafel slope of $26 \mathrm{mV}$ $\operatorname{dec}^{-1}$ [120]. Wang et al. compared the OER catalytic activity of the hybrid consisting of nickel selenide nanoparticles anchored on 2D multilayered graphitic carbon nitride $\left(\mathrm{NiSe}_{2} / \mathrm{g}-\mathrm{C}_{3} \mathrm{~N}_{4}\right.$ ) with its monocomponent counterparts, namely $\mathrm{NiSe}_{2}$ nanoparticles (NPs) and $\mathrm{g}-\mathrm{C}_{3} \mathrm{~N}_{4}$ [113]. NiSe $2 / \mathrm{g}-\mathrm{C}_{3} \mathrm{~N}_{4}$ composite exhibited lower potential and corresponding overpotential $(1.52 \mathrm{~V}, 260 \mathrm{mV})$ than those of $\mathrm{NiSe}_{2} \mathrm{NPs}(1.63 \mathrm{~V}, 400 \mathrm{mV})$ and $\mathrm{g}-\mathrm{C}_{3} \mathrm{~N}_{4}$ $(1.77 \mathrm{~V}, 540 \mathrm{mV})$ at $40 \mathrm{~mA} \mathrm{~cm}{ }^{-2}$. Tafel slopes for $\mathrm{NiSe}_{2} / \mathrm{g}-\mathrm{C}_{3} \mathrm{~N}_{4}, \mathrm{NiSe}_{2}$, and g- $\mathrm{C}_{3} \mathrm{~N}_{4}$ were fitted as 143,299 , and $160 \mathrm{mV} \mathrm{dec}^{-1}$, respectively. Such catalytic parameters suggest faster charge transfer and favorable OER performance of $\mathrm{NiSe}_{2} / \mathrm{g}-\mathrm{C}_{3} \mathrm{~N}_{4}$ as well as point out the synergistic effect of the transition metal chalcogenide nanoparticle coupled with carbon matrix.

In a similar vein to sulfides, bimetallic and multimetallic selenides supported on carbons can generally achieve higher electrocatalytic efficiency during the OER process than monometallic selenides [114,117,118,122,126,182,193,194]. A mixed NiFe selenide supported by carbon fiber paper (NiFe-Se/CFP) required an overpotential of $281 \mathrm{mV}$ at $10 \mathrm{~mA} \mathrm{~cm}^{-2}$ in alkaline media $(1 \mathrm{M} \mathrm{KOH})$, whereas such a value for $\mathrm{FeSe}_{2} / \mathrm{CFP}$ was $395 \mathrm{mV}$ [118]. An enhanced electron-transfer kinetics was observed for NiFe-Se/CFP with

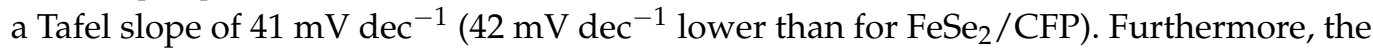
carbon-supported bimetallic chalcogenide catalyst has been proven to show good stability during the long-term $(20 \mathrm{~h})$ OER process. The post-test characterization of the NiFe-Se/CFP test suggests that the surface of the NiFe-Se nanoparticles undergoes a phase transformation from a bimetallic selenide phase to a mixed metal hydroxide/(oxy)hydroxide [118]. To understand the synergistic coupling between individual Co and Ni selenides, Liu et al. designed a hybrid catalyst consisting of heterostructured $\mathrm{CoSe}_{2} / \mathrm{Ni}_{3} \mathrm{Se}_{4}$ bimetallic selenides, $\mathrm{N}$-doped carbon nanosheets, and Ketjen black carbon $\left(\mathrm{CoSe}_{2} / \mathrm{Ni}_{3} \mathrm{Se}_{4} @ \mathrm{NC} / \mathrm{KB}\right)$ [114]. To 
achieve a current density of $10 \mathrm{~mA} \mathrm{~cm}{ }^{-2}$ in $1.0 \mathrm{M} \mathrm{KOH}, \mathrm{CoSe}_{2} / \mathrm{Ni}_{3} \mathrm{Se}_{4} @ \mathrm{NC} / \mathrm{KB}$ needed $260 \mathrm{mV}$, which is lower by 180 and $120 \mathrm{mV}$ than for CoSe $@$ NC/KB and $\mathrm{Ni}_{3} \mathrm{Se}_{4} @ \mathrm{NC} / \mathrm{KB}$, respectively. At the same time, $\mathrm{CoSe}_{2} / \mathrm{Ni}_{3} \mathrm{Se}_{4} @ \mathrm{NC} / \mathrm{KB}$ displayed a Tafel slope of $68 \mathrm{mV} \mathrm{cm}^{-1}$, distinctly lower than those for the corresponding monometallic selenide-based composites. Chi et al. proposed synthesis of trimetallic Ni-Fe-Co selenides anchored on carbon fiber cloth as an efficient electrocatalyst (denoted as $\mathrm{NiFeCoSe}_{\mathrm{x}} / \mathrm{CFC}$ ) for OER in alkaline medium [126]. The synergistic interaction between trimetallic selenides and a selenide-carbon matrix leads to the lower overpotential of $150 \mathrm{mV}$ at $10 \mathrm{~mA} \mathrm{~cm}{ }^{-2}$ in OER tests in $1 \mathrm{M} \mathrm{KOH}$ with a Tafel slope of $85 \mathrm{mV} \mathrm{dec}^{-1}$, a greater double-layer capacitance of $200 \mathrm{mF} \mathrm{cm}^{-2}$, and much smaller charge transfer resistance than a corresponding unary/binary metal selenides.

Apart from transition metal sulfides and selenides, tellurides have also been reported as excellent materials in terms of OER electrocatalysis [181,183,195]. Wang et al. proposed synthesis of cobalt telluride encapsulated in N-doped CNT frameworks ( $\left.\mathrm{CoTe}_{2} @ \mathrm{NCNTFs}\right)$, which exhibited an overpotential of $330 \mathrm{mV}$ toward the OER (at $10 \mathrm{~mA} \mathrm{~cm}^{-2}$ ) in $1.0 \mathrm{M}$ $\mathrm{KOH}$ electrolyte with a Tafel slope of $82.8 \mathrm{mV} \mathrm{dec}^{-1}$ [183]. Similar kinetic parameters were registered by Liu et al. for $\mathrm{CoTe}_{2}$ nanocrystals embedded in an $\mathrm{N}$-doped graphitic carbon matrix (CoTe $\left.{ }_{2} @ \mathrm{~N}-\mathrm{GC}\right)$ [195]. Such a hybrid catalyst required an overpotential of $300 \mathrm{mV}$ to deliver a current density of $10 \mathrm{~mA} \mathrm{~cm}{ }^{-2}$; the value fitted Tafel slope was $90 \mathrm{mV} \mathrm{dec}^{-1}$. After driving a continuous OER test at a fixed potential of $1.55 \mathrm{~V}$ for $20 \mathrm{~h}$, only negligible variations in current density over time were observed, pointing to the great stability of $\mathrm{CoTe}_{2} @ \mathrm{~N}-\mathrm{GC}$.

Sivanantham et al. compared OER activities in an alkaline electrolyte of core-shell cobalt-chalcogenide electrocatalysts with a thin carbon layer coating on each nanoparticle ( $\mathrm{Co}_{9} \mathrm{~S}_{8} @ \mathrm{NC}, \mathrm{CoSe} @ \mathrm{NC}, \mathrm{CoTe} @ \mathrm{NC}$ ) [124]. The nickel foam supported $\mathrm{Co}_{9} \mathrm{~S}_{8} @ \mathrm{NC}$ catalyst required an overpotential of $299 \mathrm{mV}$ to deliver a current density of $10 \mathrm{~mA} \mathrm{~cm}^{-2}$ in $1 \mathrm{M} \mathrm{KOH}$, which is 33 and $68 \mathrm{mV}$ lower than those obtained for CoSe@NC and CoTe@NC composites, respectively. Moreover, the Tafel slope of $\mathrm{Co}_{9} \mathrm{~S}_{8} @ \mathrm{NC}$ was $65 \mathrm{mV} \mathrm{dec}^{-1}$, whereas for CoSe@NC and CoTe@NC calculated values were 76 and $112 \mathrm{dec}^{-1}$, respectively.

\subsection{Carbon-Metal Nitrides and Phosphides}

Other promising electrode materials for water splitting include transition-metal nitrides, in which the electrocatalytic activity, stability, and the number of active sites can be improved by controlling the composition, shape, and morphology of nanoparticles $[90,134-138,144-146,149,152,196-199]$. The presence of nitrogen atoms positively affects the electronic structure of the catalyst, leading to high electron density near the Fermi level and enhanced charge transfer. As illustrated in Figure 11, the strong interaction between $g-\mathrm{C}_{3} \mathrm{~N}_{4}$ support and $\mathrm{CoN}$ may form a region of charge excess and enable electron transport from the cobalt active site to the neighboring $\mathrm{Co}-\mathrm{N}$ bond [197]. Then, the electrons from the OER process could be accepted by the excess regions and accordingly improve the OER activity of the mixed material. To further study the electrical conductivities of all the systems, the densities of states (DOS) were calculated and are illustrated in Figure 12b. Among the samples, CoN shows the most outstanding conductivity, depicted by the highest DOS near the Fermi level, which leads to the excellent conductivity of $\mathrm{Ni}-\mathrm{Co}-\mathrm{CN}$.

Furthermore, the intrinsic conductivity and OER activity of transition-metal nitrides can be modulated by merging the metal active phase with conductive supports such as carbons. Designing composite catalysts, namely transition-metal nitrides/carbon matrix, can also result in better accessibility of active sites and improved stability during electrochemical reactions due to avoiding the aggregation of nanoparticles and improving the corrosion resistance under strongly acidic and basic conditions. To get superior electrocatalytic activity and stability, the optimization of the carbon:TM is required. One of the approaches focuses on encapsulation of metal nanoparticles into an N-doped carbon shell, which may prevent the corrosion and agglomeration of metal NPs in an alkaline electrolyte. The charac- 
teristic reactivity parameters of the carbon-metal nitrides and phosphides electrocatalysts are summarized in Table 5.

(a)

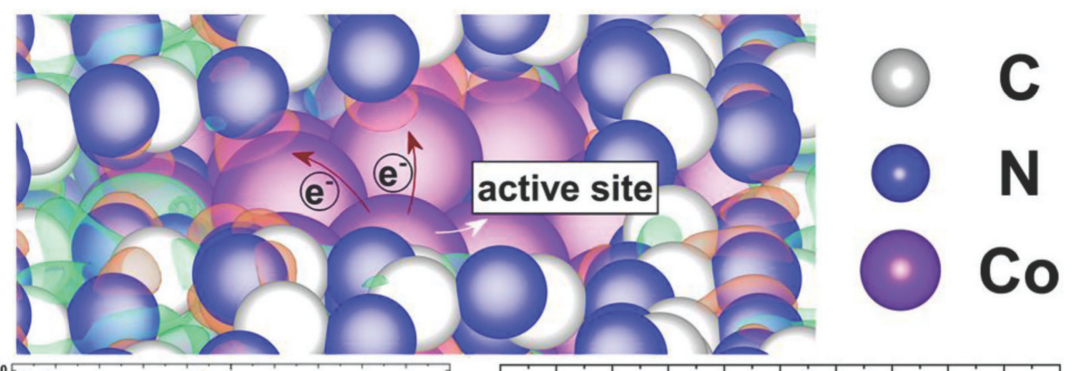

(b)
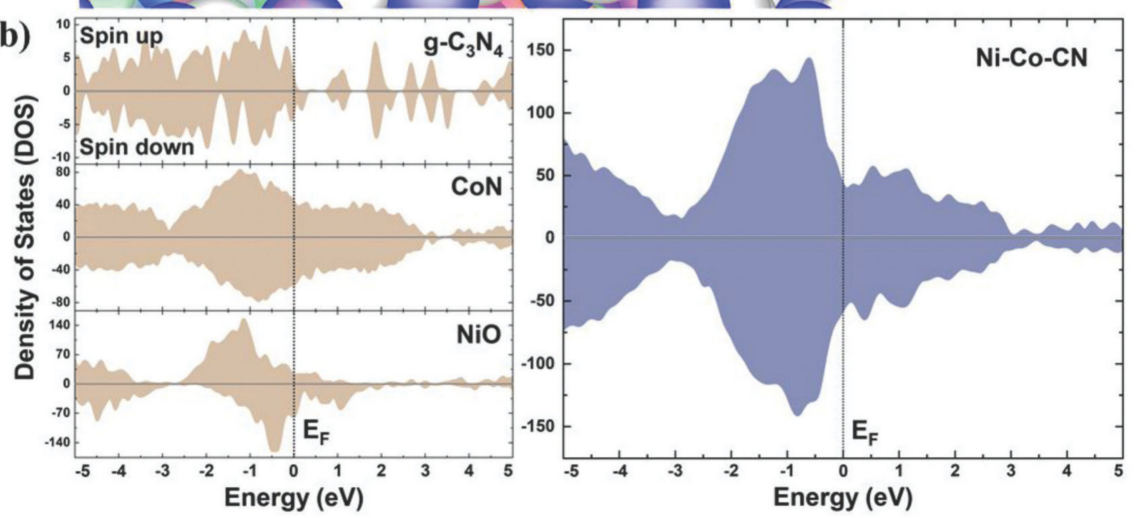

Figure 12. (a) Charge density difference of the $\mathrm{Ni}-\mathrm{Co}-\mathrm{CN}$ surface. Electron excess and deficiency are

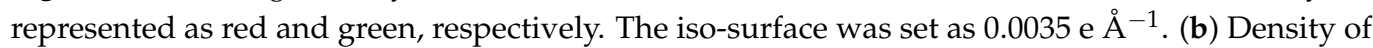
states (DOS) profiles of the partial (left) and ensemble (right) Ni-Co-CN species. Reproduced from Ref. [197] with permission from the Royal Society of Chemistry.

Table 5. Selection-comparison of carbon-metal nitrides and phosphides electrocatalysts.

\begin{tabular}{|c|c|c|c|c|}
\hline Catalyst & $\begin{array}{l}\text { KOH Electrolyte } \\
\text { Concentration }\end{array}$ & $\begin{array}{l}\text { Overpotential at } \\
10 \mathrm{~mA} \mathrm{~cm}^{-2} / \mathrm{mVV}\end{array}$ & Tafel Slope/mV dec -1 & Ref. \\
\hline $\mathrm{Ni}_{3} \mathrm{~N} / \mathrm{B}$-doped graphene oxide & $1 \mathrm{M}$ & 280 & 78 & [90] \\
\hline $\mathrm{Ni}_{12} \mathrm{P}_{5}$ nanosheets coupled with oxidized MWCNTs & $1 \mathrm{M}$ & 280 & 62 & [131] \\
\hline $\mathrm{Co}_{5.47} \mathrm{~N} @ \mathrm{~N}-$ doped rGO & $0.1 \mathrm{M}$ & 350 & 80 & [138] \\
\hline NiFeP@ N-doped carbon sponge & $1 \mathrm{M}$ & 216 & 84 & [139] \\
\hline $\mathrm{Co}_{3} \mathrm{FeN}_{\mathrm{x}} / \mathrm{N}$-doped carbon nanoleaf arrays@carbon cloth & $1 \mathrm{M}$ & 270 & 53 & [144] \\
\hline $\mathrm{Fe}-\mathrm{NiCoP}$ embedded in the amorphous carbon layer & $1 \mathrm{M}$ & 270 & 36 & [147] \\
\hline $\mathrm{S}-\mathrm{Ni}_{3} \mathrm{FeN} / \mathrm{N}, \mathrm{S}$ co-doped grephene & $1 \mathrm{M}$ & 260 & 76 & [152] \\
\hline $\mathrm{NiCO}_{2} \mathrm{P}_{\mathrm{x}} / \mathrm{CNTs}$ & $1 \mathrm{M}$ & 284 & 50 & [200] \\
\hline CoP@N-doped carbon nanotube network & $1 \mathrm{M}$ & 317 & 75 & [201] \\
\hline $\mathrm{FeNi}_{3} @ \mathrm{~N}$-doped carbon & $1 \mathrm{M}$ & 277 & 77 & [202] \\
\hline
\end{tabular}

Choi et al. reported electrochemical activity of composite catalysts consisings of mesoporous $\mathrm{Co}_{3} \mathrm{~N}$ and amorphous $\mathrm{N}$-doped carbon nanocubes (M-Co $3 \mathrm{~N} @ \mathrm{AN}-\mathrm{C}$ ) [149]. The catalyst reached the overpotential of $285 \mathrm{mV} @ 10 \mathrm{~mA} \mathrm{~cm}{ }^{-2}$ during OER measurements in $1 \mathrm{M} \mathrm{KOH}$. Such excellent OER activity together with satisfactory stability results from 3-dimensional mesoporous structures that influence the surface area. Also, N-doped carbon layers improve the charge transfer ability and stability during the water-splitting process. The activity toward oxygen evolution reaction can even be boosted by designing multi-component nitrides, such as porous $\mathrm{Co}_{3} \mathrm{FeN}_{\mathrm{x}} / \mathrm{N}$-doped carbon nanoleaf arrays supported by carbon cloth (named $\mathrm{Co}_{3} \mathrm{FeN}_{\mathrm{x}} / \mathrm{NC}$ LACC) [144]. Hierarchical structure and heterointerfaces between $\mathrm{Co}_{4} \mathrm{~N}$ and $\mathrm{FeN}$ allowed for the reaching of a low overpotential of $270 \mathrm{mV}$ at $10 \mathrm{~mA} \mathrm{~cm}^{-2}$ in $1 \mathrm{M} \mathrm{KOH}$ solution and the Tafel slope of $52.5 \mathrm{mV} \mathrm{dec}^{-1}$. 
Moreover, importantly for commercial electrocatalysts, the $\mathrm{Co}_{3} \mathrm{FeN}_{\mathrm{x}} / \mathrm{NC}$ LACC exhibited outstanding durability during continuous tests, even after $40 \mathrm{~h}$.

Recently, it has been revealed that the incorporation of foreign metal atoms into the crystal lattice of TM-based catalysts changes the local coordination environment and electronic configuration and hence improves the electrocatalytic performance. Lai et al. investigated the influence of S-doping of $\mathrm{Ni}_{3} \mathrm{FeN}$ compounds supported on N/S co-doped graphene, named $\mathrm{S}-\mathrm{Ni}_{3} \mathrm{FeN} / \mathrm{NSG}$, on their electrocatalytic activity [152]. The catalyst required an overpotential of $260 \mathrm{mV}$ to achieve a current density of $10 \mathrm{~mA} \mathrm{~cm}{ }^{-2}$ in $1 \mathrm{M}$ $\mathrm{KOH}$. Such a value is lower by 40 and $67 \mathrm{mV}$ than for $\mathrm{Ni}_{3} \mathrm{FeN} / \mathrm{NG}$ and $\mathrm{Ir} / \mathrm{C}$, respectively. The corresponding Tafel slopes were 76, 100, and $110 \mathrm{mV} \mathrm{dec}^{-1}$ for S-Ni ${ }_{3} \mathrm{FeN} / \mathrm{NSG}, \mathrm{Ir} / \mathrm{C}$, and $\mathrm{Ni}_{3} \mathrm{FeN} / \mathrm{NG}$, respectively. The favorable catalytic reaction kinetics and improved OER activity of $\mathrm{S}-\mathrm{Ni}_{3} \mathrm{FeN} / \mathrm{NSG}$ can be attributed to the decoration of $\mathrm{Ni}_{3} \mathrm{FeN}$ nanoparticles by sulfur atoms. Quantum mechanical modelling pointed out that S-doping enhances the formation of $-\mathrm{OOH}^{*}$ intermediates and noticeably decreases the maximum of change in Gibbs free energy for OER steps.

Most recently, growing interest in terms of carbon-supported OER catalysts is related to transition-metal phosphides (TMPs), mostly due to their relatively low price and earthabundance reserves $[81,131-133,139,141-143,147,148,200,201,203-210]$. The metal phosphides are thermodynamically less stable than corresponding metal hydroxides/oxides under oxidation potentials. Thus, gradually formed metal hydroxide/oxide phases on the TMPs surface during electrochemical reactions are considered to provide the actual active centers for oxygen evolution reaction, while the inner TMPs core acts as the conductive scaffold [61]. Since the morphology and/or structure of metal phosphides may undergo reconstruction upon a redox process, the TMPs do fall entirely under the conventional definition of the term catalyst [211]. Moreover, the transformations of composition and structure of the original catalysts into the final active species are difficult to predict since they may proceed along various paths. Therefore, different electrocatalysts should be extensively studied by experimental and theoretical methods to deeply understand their reaction mechanisms.

Yang et al. reported that cobalt phosphide nanoparticles dispersed within a nitrogendoped carbon nanotube network (CP@NCNT) required an overpotential of $317 \mathrm{mV}$ at $10 \mathrm{~mA} \mathrm{~cm}{ }^{-2}$ with a Tafel slope of $75 \mathrm{mV} \mathrm{dec}^{-1}$ [201]. The achieved overpotential is $25 \mathrm{mV}$ lower than for corresponding undoped composite material (bare CNTs as a carbon matrix), indicating that incorporation of nitrogen atoms promotes charge transfer and consequently enhances the catalytic activity. X-ray photoelectron spectroscopy analysis after $24 \mathrm{~h}$ of the amperometric $i-t$ test revealed surface oxidation of cobalt phosphide nanoparticles proving that formed oxide species of $\mathrm{CoOOH}$ provides new active sites for OER. Tang et al. synthesized a bimetallic composite catalyst consists of $\mathrm{Co}_{2} \mathrm{P}$ nanoparticles coated with a nitrogen-doped carbon matrix and adsorbed at the surface of $\mathrm{Fe}_{2} \mathrm{P}$ microspheres [209]. A designed active $\mathrm{NC}-\mathrm{Fe}_{2} \mathrm{P}$ interface ensured increased charge transfer rate of the catalyst and allowed the researchers to obtain outstanding catalytic parameters toward OER, such as an overpotential of $260 \mathrm{mV}$ at a current density of $10 \mathrm{~mA} \mathrm{~cm}{ }^{-2}$ in $1 \mathrm{M} \mathrm{KOH}$, and

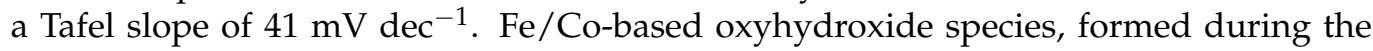
OER process, led to excellent long-term stability. Most recently, the superior performance toward OER of iron-doped nickel-cobalt phosphide embedded in the amorphous carbon layer has been reported [147]. The hybrid material (called Fe-NiCoP@C) reached an overpotential of $270 \mathrm{mV}\left(10 \mathrm{~mA} \mathrm{~cm}^{-2}, 1 \mathrm{M} \mathrm{KOH}\right)$, which is lower by $49 \mathrm{mV}$ than for NiCoP. To get insight into electrode reaction kinetics, electrochemical impedance spectroscopy was conducted. An electrolyte resistance for $\mathrm{Fe}-\mathrm{NiCoP} @ \mathrm{C}$ and $\mathrm{NiCoP}$ were $3.2 \Omega$ and $4.2 \Omega$, respectively, indicating low internal and interfacial resistances between the catalyst surface and the electrolyte for Fe-NiCoP@C. Furthermore, DFT calculations showed that iron dopant affects the electrical property of the composite catalyst as well as plays a role as the active site for the OER process and reduces the free energies of adsorption of the O-containing intermediates. 


\section{Interfaces in OER Electrocatalysts}

The main interface encountered with the OER electrocatalysts is the solid-liquid-gas one, where the material meets the electrolyte and the reaction product, oxygen. Other interfaces include phase boundaries between components of the composite material and phase boundaries created between outermost layers of materials (e.g., oxides, phosphides) and the oxidized/hydroxylated surfaces directly responsible for the catalytic action. The optimization and rational design of three-phase interfaces are of paramount importance in electrocatalytic applications and include the exposure of the active sites, mass diffusion enhancement, and boosting of electron transfer [10]. Improvement in one direction may hinder the overall performance due to a decreased efficiency of another.

At the interfaces between two active components, reconstructed active centers exhibit different chemical properties due to modified bonding and electronic interactions with the neighboring atoms. Moreover, in the vicinity of the interface, materials exhibit structural disorder, increased defects concentration, additional phases, and various molecular components. Therefore, the new active centers located at or in the vicinity of the interfaces can be responsible for the actual catalytic activity and stability rather than the original components $[212,213]$. Typical interfaces present in the electrocatalysts include hydroxide-oxide composites, such as $\mathrm{Ni}(\mathrm{OH})_{2}-\mathrm{CeO}_{2}$, where the improved catalytic activity can be assigned to the strong electronic coupling of the oxide and hydroxide phases, which favorably modulates the interaction between the reaction intermediate and catalyst [214]. Another type involves an in situ formation of the active phase overlayer, especially from materials unstable under reaction conditions, as in $\beta-\mathrm{NiO}(\mathrm{OH}) / \mathrm{Ni}_{2} \mathrm{P} @ \mathrm{NiO}$ catalyst supported on $\mathrm{Mg}_{2} \mathrm{O}(\mathrm{OH})_{2}$-like phase, which is formed during the oxygen evolution reaction, where the $\mathrm{Ni}_{2} \mathrm{P}$ nanoparticles are immediately oxidized forming a core-shell structure. The enhanced performance of the core-shell material is hypothesized to result from the reactivity modulation due to the development of a lattice strain in the interfacial area, and the high surface area of the supported electrocatalyst [215].

Nanocomposites with enhanced electrical conductivities can be created by combining two or more different types of carbon materials. For example, developed for energy storage application, a composite of carbon nanofibers (CNF) with natural graphite microspheres was found to form a continuous conductive network resulting in improved cycling performance. Moreover, improved penetration of the composite surface by the electrolyte resulted in a faster electrode reaction kinetics and the $\mathrm{CNF} /$ graphite network provided mechanical stabilization for the electroactive system by accommodating volume changes and thus preventing its mechanical degradation by cracking [67].

An accurate design, synthesis, modification and detailed characterization of welldefined carbon-carbon or carbon-non carbon materials' interfaces are the basis for the engineering of nanocomposites with tailored properties targeted for specific applications. Every step of the composite preparation will influence the final electrocatalytic activity, notably, heteroatom doping of carbon materials, precursor types of active components, and applied synthetic procedures [213]. The approaches to study composited materials usually lie between two borderline cases. On one hand, a deep understanding of the complex interfacial structures and the interaction of the comprising materials is studied. On the other hand, the preparation of model composites with regulated and optimized interface structure is pursued to gain more fundamental knowledge. Eventually, both approaches mix and should lead to the same goal, which is an improvement in the performance of the electrocatalytic materials.

Interface engineering in carbon-based nanocomposites employs two main types of chemical interactions: covalent and non-covalent. Both types can result in the desired interfacial interactions, however, different synthesis strategies are used for the preparation of the materials. Covalent interactions (chemical bonding) are most often obtained through techniques such as chemical vapor deposition, condensation reaction, radical polymerization, and hydrothermal techniques. Non-covalent interactions, typically achieved by 
self-assembly mixing and in situ polymerization approaches, usually involve $\pi-\pi$ interactions, hydrogen bonding, and van der Waals forces [67].

A brief overview of the recent developments in the heterointerfaces in OER electrocatalysts is presented here. For the $\mathrm{Ni}_{2} \mathrm{P} / \mathrm{Fe}_{2} \mathrm{P}-\mathrm{O}$ system, an occurrence of synergistic effects of $\mathrm{Ni}_{2} \mathrm{P}(\mathrm{O}) / \mathrm{Fe}_{2} \mathrm{P}(\mathrm{O})$ interfaces, formed by active surface layers and metallic phosphide bulk, is proposed. On the surface, phosphates possibly act as a proton-coupled electron transfer mediator, while doped oxyhydroxides could accelerate the formation of $\mathrm{O}-\mathrm{O}$ bonds and lower the activation barrier for OER. The underlying $\mathrm{Ni}_{2} \mathrm{P} / \mathrm{Fe}_{2} \mathrm{P}$ could retain its conductive properties and promote the electron transfer process [216]. A heterojunction within hierarchical CoP-nanowire-FeP-nanorod branched heterostructures endows it with intimate interfacial contact between $\mathrm{CoP}$ and $\mathrm{FeP}$, thus inducing a built-in electric field at the interface, which is said to promote the charge transfer and enhancement of the electrocatalytic activity [217]. In the hierarchical $\mathrm{Co}(\mathrm{OH})_{2} / \mathrm{Ag} / \mathrm{FeP}$ hybrid structure, where the Ag nanoparticles were uniformly distributed on the surface of FeP nanorod arrays, and the latter decorated $\mathrm{Co}(\mathrm{OH})_{2}$ nanosheets, which provided an increased catalytically active area, resulted in a changed electron structure due to the formation of interfaces involved in $\mathrm{Co}(\mathrm{OH})_{2} / \mathrm{Ag} / \mathrm{FeP}$ hybrid, which is considered to be beneficial to generate low-charge state $\mathrm{Fe}^{2+}$ and highly-oxidized $\mathrm{Co}^{3+/ 4+}$ [218]. A heterostructure resulting from a direct combination of $\mathrm{CoP}$ and $\mathrm{CeO}_{2}$ mainly benefits from the abundant interfaces between $\mathrm{CoP}$ nanosheets and $\mathrm{CeO}_{2}$ nanoparticles that generate a high concentration of oxygen vacancies and catalytically active sites, as well as tuning the surface electronic states [219]. Another direct combination of phosphorus-rich and oxygen-rich phases, cobalt hydroxide-black phosphorus nanosheets, resulted in an interface that exhibits small interlayer distance, large interlayer binding energy, and significant charge transfer between $\mathrm{Co}(\mathrm{OH})_{2}$ and black phosphorus, indicating a strong interlayer interaction and metallic interface, resulting in an improved conductivity and fast electron transfer [220].

Sulfide active phases are often investigated for both OER and HER, with potential application as bifunctional catalysts. Introducing $\mathrm{Ni}(\mathrm{OH})_{2}$ to the $\mathrm{Ni}_{3} \mathrm{~S}_{2}$ yielded an electrocatalyst with low ionic and electronic resistances enabled by modulation of the surface atomic configuration of the sulfide phase. This led not only to high OER activity but also accelerated the Volmer step and $\mathrm{OH}-$ adsorption during the HER. Moreover, the obtained loose and interconnected nanoforest-like architecture facilitated the full exposure of active sites with enhanced electrolyte infiltration and bubble escape [221]. Strongly coupled NiS nanoparticles $/ \mathrm{Bi}_{2} \mathrm{WO}_{6}$ nanosheets formed a $0 \mathrm{D} / 2 \mathrm{D}$ heterojunction catalyst with interfacial synergistic effect and a strongly coupled electronic effect. The NiS nanoparticles were evenly distributed on the surface of $\mathrm{Bi}_{2} \mathrm{WO}_{6}$ nanosheets allowing for maximum atom utilization. The re-coordinated nickel and oxygen species act as bridges at the interface, resulting in a novel valence-bond environment of the $\mathrm{O}-\mathrm{Ni}-\mathrm{S}$ bond structure to enhance the charge and mass transfer for the surface reactions [222]. $\mathrm{Cu}_{2} \mathrm{~S}-\mathrm{CoO}_{x} / \mathrm{Cu}$ foam profited from the synergistic effect between $\mathrm{Cu}_{2} \mathrm{~S}$ and $\mathrm{CoO}_{x}$, and electronic coupling between the two components. The catalyst benefits also from the distribution of $\mathrm{CoO}_{x}$ on $\mathrm{Cu}_{2} \mathrm{~S}$ nanowires, which possess good electronic conductivity [223].

The formation of an intimate hydroxide-oxide interface is similarly beneficial for OER. In particular, the addition of $\mathrm{CeO}_{2}$ to hydroxide phases appears to result in strong electronic interaction formed by the intimate hydroxide- $\mathrm{CeO}_{2}$ interfaces, which might favorably modulate the interaction between intermediate and catalyst [214]. The $\mathrm{CeO}_{2}$ addition effect results probably from the enrichment of the electronic distribution near the Fermi level, boosting the electron transfer efficiency from local active centers to adsorbates [224]. Other combinations are also reported, such as dual-interface structure in NiV-LDH@FeOOH on $\mathrm{Ni}$ foam, which brings about improved electrical conductivity and optimized electronic structure [225].

In carbon-based composites, the carbon component provides a high surface area to deposit the active phase or support and active phase. A combination of $\mathrm{Ni}_{2} \mathrm{P}$ nanoparticles and $\mathrm{Mg}_{2} \mathrm{O}(\mathrm{OH})_{2}$-like support grown on carbon paper results in immediate oxidation 
of the $\mathrm{Ni}_{2} \mathrm{P}$ nanoparticles during $\mathrm{OER}$, through the core-shell structuring, eventually forming active and stable $\beta-\mathrm{NiO}(\mathrm{OH}) / \mathrm{Ni}_{2} \mathrm{P} @ \mathrm{NiO}$ catalyst supported on a $\mathrm{Mg}_{2} \mathrm{O}(\mathrm{OH})_{2}-$ like phase. The authors suggest that the high performance of the catalyst results from the development of a substantial degree of lattice strain in the core-shell nanoparticles and the realization of the supported catalyst with a high surface area [215]. Formation of carbon-supported OER catalyst by decomposition of precursors based on the metalorganic framework compounds, like FeHP-ZIF-67, may lead to a durable connection between the carbon and phosphide components, which persists after the oxidation of the phosphide to oxyhydroxide species. These kinds of materials demonstrate increased resistance to aggregation of $\mathrm{Co}_{2} \mathrm{P}$ nanoparticles, while the formation of active interfaces by partially connecting the $\mathrm{Fe}_{2} \mathrm{P}$ microspheres is also observed, which facilitates a rapid charge transfer [209]. N-NiMoO $4 / \mathrm{NiS}_{2}$ catalyst on carbon fiber cloth exhibits enhanced electron transfer from $\mathrm{N}-\mathrm{NiMoO}_{4}$ to $\mathrm{NiS}_{2}$ through abundant epitaxial heterogeneous interfaces at the atomic level. Moreover, this superaerophobic binder-free 3D open electrode with 2D nanosheets provides a large specific surface area that favors gas release from the surface $\left(\mathrm{H}_{2}\right.$ and $\left.\mathrm{O}_{2}\right)$ [226].

\section{Conclusions and Outlook}

The search for active and stable materials for the oxygen evolution reaction has become a field with enormous interest for the development of efficient and cost-effective electrochemical devices like water electrolyzers or aqueous metal-air batteries. In this review, we provide the most recent investigations on the incorporation of carbon-based composite materials and analyze the most relevant advances in activity and stability issues. As a general trend, the use of carbon phases in the OER electrocatalyst formulation aids in increasing the density of active sites, allowing for smaller metallic particles as well as better accessibility of reactants to the catalyst surface.

Carbon-based electrocatalysts were classified in this review according to their composition into four categories: (i) metal-free carbon composites (ii) composites of carbon with metal hydroxides/oxyhydroxides/oxides, (iii) composites of carbon with metal nitrides/phosphides, and (iv) carbon-metal chalcogenides. The graphical summary of the best electrocatalysts reported in this review following the above classification is presented in Figure 13. To date, the lowest OER overpotential and lowest Tafel slope are achieved with carbon-free metal catalysts, with Fe and Ni oxyhydroxides and phosphides presenting the most promising activity within noble metal-free catalysts in an alkaline environment. One of the main problems arising with these materials is that the electrical conductivity of oxide phases could not be improved sufficiently, which causes ohmic resistance and hinders electron transfer within the catalyst layer for practical electrodes, which are usually different from lab-scale ideal conditions.

Carbon-metal oxides and carbon-metal nitrides appear as promising formulations combined with graphitic and other resistant carbon substrates for the OER. The activity for carbon-metal catalysts falls in the range of about $250-350 \mathrm{mV}$ overpotential and the Tafel slope varies between 40 and $80 \mathrm{mV} \mathrm{dec}{ }^{-1}$, with a few exceptions presenting either Tafel or overpotential falling behind those numbers. Meanwhile, metal-free catalysts still present the highest overpotential and Tafel slope values, suggesting that the presence of metallic species is required for proper activity at the current state of knowledge.

Advances in recent years have led to significant improvements in the activity and stability of carbon-based composites and future perspectives are good in terms of the further enhancement of performance by following this strategy. The main positive effects are related to increased catalyst surface area, improved electrical conductivity, and synergistic effects between carbon and metallic sites for enhanced intrinsic activity compared to single phases. However, more effort must be dedicated to the durability and scalability of catalysts. The oxidation of carbon appears as a drawback for the practical application of carbon-based composites that need further and deeper investigation. Experiments in full electrolyzer mode are also required to demonstrate the feasibility of this technology with 
this kind of OER composite catalyst. All this, in parallel with the development of improved anion exchange membranes, will boost the implementation of AEM water electrolyzers for the economic production of hydrogen.

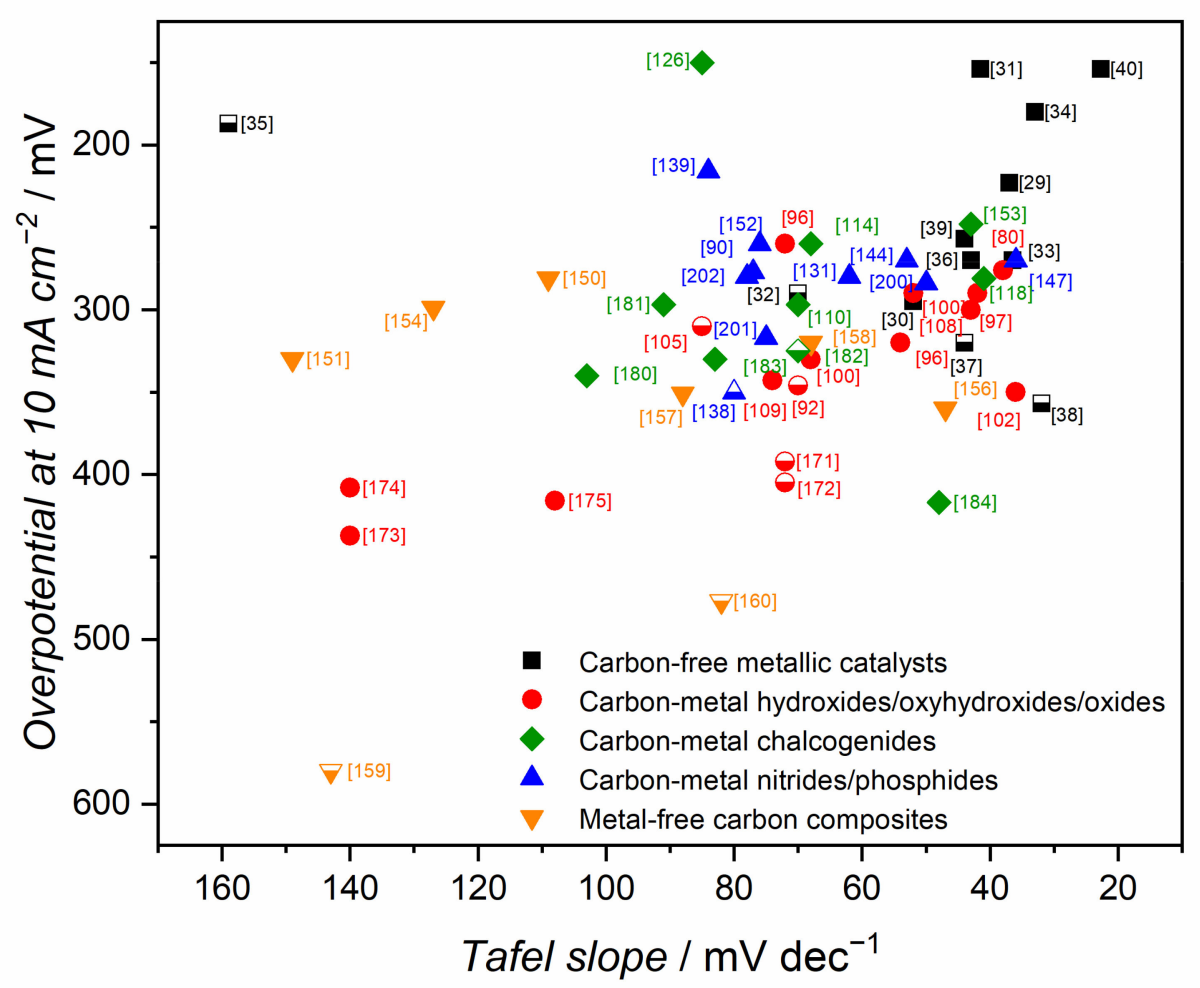

Figure 13. Graphical summary of the best reported electrocatalysts for oxygen evolution reaction divided into different classes of carbon-based composite materials; presented data are for OER process in $1 \mathrm{M}$ (full symbol) and $0.1 \mathrm{M}$ (half-empty symbol) alkaline solution.

Author Contributions: Conceptualization, P.S. and D.S.; investigation, P.S. and J.D.; writingoriginal draft preparation, P.S., J.D. and D.S.; writing-review and editing, D.S., M.J.L. and A.K.; supervision, M.J.L. and A.K.; project administration, P.S.; funding acquisition, P.S. All authors have read and agreed to the published version of the manuscript.

Funding: This study was financially supported by the National Science Center, Poland, project number 2020/37/B/ST5/01876.

Institutional Review Board Statement: Not applicable.

Informed Consent Statement: Not applicable.

Conflicts of Interest: The authors declare no conflict of interest. The funders had no role in the design of the study; in the collection, analyses, or interpretation of data; in the writing of the manuscript; or in the decision to publish the results.

\section{References}

1. Lewis, N.S.; Nocera, D.G. Powering the planet: Chemical challenges in solar energy utilization. Proc. Natl. Acad. Sci. USA 2006, 103, 15729-15735. [CrossRef] [PubMed]

2. Gray, H.B. Powering the planet with solar fuel. Nat. Chem. 2009, 1, 7. [CrossRef] [PubMed]

3. Goodenough, J.B. Electrochemical energy storage in a sustainable modern society. Energy Environ. Sci. 2014, 7, 14-18. [CrossRef]

4. David, M.; Ocampo-Martínez, C.; Sánchez-Peña, R. Advances in alkaline water electrolyzers: A review. J. Energy Storage 2019, 23, 392-403. [CrossRef]

5. Shen, P.K.; Wang, C.-Y.; Jiang, S.P.; Sun, X.J.Z. Electrochemical Energy: Advanced Materials and Technologies; CRC Press: Boca Raton, FL, USA, 2015; ISBN 1482227282. 
6. Nadeem, F.; Hussain, S.M.S.; Tiwari, P.K.; Goswami, A.K.; Ustun, T.S. Comparative review of energy storage systems, their roles, and impacts on future power systems. IEEE Access 2019, 7, 4555-4585. [CrossRef]

7. Bodner, M.; Hofer, A.; Hacker, V. $\mathrm{H}_{2}$ generation from alkaline electrolyzer. Wiley Interdiscip. Rev. Energy Environ. $2015,4,365-381$. [CrossRef]

8. Marchenko, O.V.; Solomin, S.V. The future energy: Hydrogen versus electricity. Int. J. Hydrogen Energy 2015, 40, 3801-3805. [CrossRef]

9. Ayers, K.; Danilovic, N.; Ouimet, R.; Carmo, M.; Pivovar, B.; Bornstein, M. Perspectives on Low-Temperature Electrolysis and Potential for Renewable Hydrogen at Scale. Annu. Rev. Chem. Biomol. Eng. 2019, 10, 219-239. [CrossRef]

10. Wang, Y.; Zou, Y.; Tao, L.; Wang, Y.; Huang, G.; Du, S.; Wang, S. Rational design of three-phase interfaces for electrocatalysis. Nano Res. 2019, 12, 2055-2066. [CrossRef]

11. Reier, T.; Nong, H.N.; Teschner, D.; Schlögl, R.; Strasser, P. Electrocatalytic Oxygen Evolution Reaction in Acidic EnvironmentsReaction Mechanisms and Catalysts. Adv. Energy Mater. 2017, 7, 1601275. [CrossRef]

12. Rossmeisl, J.; Qu, Z.W.; Zhu, H.; Kroes, G.J.; Nørskov, J.K. Electrolysis of water on oxide surfaces. J. Electroanal. Chem. 2007, 607, 83-89. [CrossRef]

13. Pletcher, D.; Li, X. Prospects for alkaline zero gap water electrolysers for hydrogen production. Int. J. Hydrogen Energy 2011, 36, 15089-15104. [CrossRef]

14. Chen, K.; Jiang, S.P. Review-Materials degradation of solid oxide electrolysis cells. J. Electrochem. Soc. 2016, 163, F3070-F3083. [CrossRef]

15. Ding, C.; Shi, J.; Wang, Z.; Li, C. Photoelectrocatalytic Water Splitting: Significance of Cocatalysts, Electrolyte, and Interfaces. ACS Catal. 2017, 7, 675-688. [CrossRef]

16. Tahir, M.; Pan, L.; Idrees, F.; Zhang, X.; Wang, L.; Zou, J.J.; Wang, Z.L. Electrocatalytic oxygen evolution reaction for energy conversion and storage: A comprehensive review; Elsevier: Amsterdam, The Netherlands, 2017; Volume 37, pp. 136-157.

17. Vincent, I.; Bessarabov, D. Low cost hydrogen production by anion exchange membrane electrolysis: A review. Renew. Sustain. Energy Rev. 2018, 81, 1690-1704. [CrossRef]

18. Abbasi, R.; Setzler, B.P.; Lin, S.; Wang, J.; Zhao, Y.; Xu, H.; Pivovar, B.; Tian, B.; Chen, X.; Wu, G.; et al. A Roadmap to Low-Cost Hydrogen with Hydroxide Exchange Membrane Electrolyzers. Adv. Mater. 2019, 31, 1805876. [CrossRef]

19. Qi, J.; Zhang, W.; Cao, R. Solar-to-Hydrogen Energy Conversion Based on Water Splitting. Adv. Energy Mater. 2018, 8, 1701620. [CrossRef]

20. Li, A.; Ooka, H.; Bonnet, N.; Hayashi, T.; Sun, Y.; Jiang, Q.; Li, C.; Han, H.; Nakamura, R. Stable Potential Windows for Long-Term Electrocatalysis by Manganese Oxides Under Acidic Conditions. Angew. Chem. Int. Ed. 2019, 58, 5054-5058. [CrossRef] [PubMed]

21. Hayashi, T.; Bonnet-Mercier, N.; Yamaguchi, A.; Suetsugu, K.; Nakamura, R. Electrochemical characterization of manganese oxides as a water oxidation catalyst in proton exchange membrane electrolysers. R. Soc. Open Sci. 2019, 6, 190122. [CrossRef] [PubMed]

22. Park, Y.S.; Jeong, J.; Noh, Y.; Jang, M.J.; Lee, J.; Lee, K.H.; Lim, D.C.; Seo, M.H.; Kim, W.B.; Yang, J.; et al. Commercial anion exchange membrane water electrolyzer stack through non-precious metal electrocatalysts. Appl. Catal. B Environ. 2021, 292, 120170. [CrossRef]

23. Lindquist, G.A.; Oener, S.Z.; Krivina, R.; Motz, A.R.; Keane, A.; Capuano, C.; Ayers, K.E.; Boettcher, S.W. Performance and Durability of Pure-Water-Fed Anion Exchange Membrane Electrolyzers Using Baseline Materials and Operation. ACS Appl. Mater. Interfaces 2021. [CrossRef]

24. Serov, A.; Kovnir, K.; Shatruk, M.; Kolen'ko, Y.V. Critical review of platinum group metal-free materials for water electrolysis: Transition from the laboratory to the market: Earth-abundant borides and phosphides as catalysts for sustainable hydrogen production. Johnson Matthey Technol. Rev. 2021, 65, 207-226. [CrossRef]

25. Miller, H.A.; Bouzek, K.; Hnat, J.; Loos, S.; Bernäcker, C.I.; Weißgärber, T.; Röntzsch, L.; Meier-Haack, J. Green hydrogen from anion exchange membrane water electrolysis: A review of recent developments in critical materials and operating conditions. Sustain. Energy Fuels 2020, 4, 2114-2133. [CrossRef]

26. Dekel, D.R. Review of Cell Performance in Anion Exchange Membrane Fuel Cells. J. Power Sources 2018, 375, 158-169. [CrossRef]

27. Enapter electrolyser. Available online: https://www.enapter.com (accessed on 21 August 2021).

28. Xu, D.; Stevens, M.B.; Cosby, M.R.; Oener, S.Z.; Smith, A.M.; Enman, L.J.; Ayers, K.E.; Capuano, C.B.; Renner, J.N.; Danilovic, N.; et al. Earth-Abundant Oxygen Electrocatalysts for Alkaline Anion-Exchange-Membrane Water Electrolysis: Effects of Catalyst Conductivity and Comparison with Performance in Three-Electrode Cells. ACS Catal. 2019, 9, 7-15. [CrossRef]

29. Zhang, B.; Zheng, X.; Voznyy, O.; Comin, R.; Bajdich, M.; García-Melchor, M.; Han, L.; Xu, J.; Liu, M.; Zheng, L.; et al. Homogeneously dispersed multimetal oxygen-evolving catalysts. Science 2016, 352, 333-337. [CrossRef]

30. Jin, H.; Mao, S.; Zhan, G.; Xu, F.; Bao, X.; Wang, Y. Fe incorporated $\alpha-\mathrm{Co}(\mathrm{OH})_{2}$ nanosheets with remarkably improved activity towards the oxygen evolution reaction. J. Mater. Chem. A 2017, 5, 1078-1084. [CrossRef]

31. Zhou, H.; Yu, F.; Zhu, Q.; Sun, J.; Qin, F.; Yu, L.; Bao, J.; Yu, Y.; Chen, S.; Ren, Z. Water splitting by electrolysis at high current densities under 1.6 volts. Energy Environ. Sci. 2018, 11, 2858-2864. [CrossRef]

32. Ma, T.Y.; Dai, S.; Jaroniec, M.; Qiao, S.Z. Metal-organic framework derived hybrid $\mathrm{Co}_{3} \mathrm{O}_{4}$-carbon porous nanowire arrays as reversible oxygen evolution electrodes. J. Am. Chem. Soc. 2014, 136, 13925-13931. [CrossRef] 
33. Li, B.B.; Liang, Y.Q.; Yang, X.J.; Cui, Z.D.; Qiao, S.Z.; Zhu, S.L.; Li, Z.Y.; Yin, K. $\mathrm{MoO}_{2}-\mathrm{CoO}$ coupled with a macroporous carbon hybrid electrocatalyst for highly efficient oxygen evolution. Nanoscale 2015, 7, 16704-16714. [CrossRef]

34. Zhang, P.; Li, L.; Nordlund, D.; Chen, H.; Fan, L.; Zhang, B.; Sheng, X.; Daniel, Q.; Sun, L. Dendritic core-shell nickel-iron-copper metal/metal oxide electrode for efficient electrocatalytic water oxidation. Nat. Commun. 2018, 9, 381. [CrossRef]

35. Zhou, W.; Wu, X.J.; Cao, X.; Huang, X.; Tan, C.; Tian, J.; Liu, H.; Wang, J.; Zhang, H. $\mathrm{Ni}_{3} \mathrm{~S}_{2}$ nanorods/Ni foam composite electrode with low overpotential for electrocatalytic oxygen evolution. Energy Environ. Sci. 2013, 6, 2921-2924. [CrossRef]

36. Chen, S.; Kang, Z.; Zhang, X.; Xie, J.; Wang, H.; Shao, W.; Zheng, X.; Yan, W.; Pan, B.; Xie, Y. Highly Active Fe Sites in Ultrathin Pyrrhotite Fe7S8 Nanosheets Realizing Efficient Electrocatalytic Oxygen Evolution. ACS Cent. Sci. 2017, 3, 1221-1227. [CrossRef]

37. Liu, Y.; Cheng, H.; Lyu, M.; Fan, S.; Liu, Q.; Zhang, W.; Zhi, Y.; Wang, C.; Xiao, C.; Wei, S.; et al. Low overpotential in vacancy-rich ultrathin $\mathrm{CoSe}_{2}$ nanosheets for water oxidation. J. Am. Chem. Soc. 2014, 136, 15670-15675. [CrossRef]

38. Gao, Q.; Huang, C.Q.; Ju, Y.M.; Gao, M.R.; Liu, J.W.; An, D.; Cui, C.H.; Zheng, Y.R.; Li, W.X.; Yu, S.H. Phase-Selective Syntheses of Cobalt Telluride Nanofleeces for Efficient Oxygen Evolution Catalysts. Angew. Chem. Int. Ed. 2017, 56, 7769-7773. [CrossRef]

39. Chen, P.; Xu, K.; Fang, Z.; Tong, Y.; Wu, J.; Lu, X.; Peng, X.; Ding, H.; Wu, C.; Xie, Y. Metallic Co4N porous nanowire arrays activated by surface oxidation as electrocatalysts for the oxygen evolution reaction. Angew. Chem. Int. Ed. 2015, 54, 14710-14714. [CrossRef]

40. Yu, F.; Zhou, H.; Huang, Y.; Sun, J.; Qin, F.; Bao, J.; Goddard, W.A.; Chen, S.; Ren, Z. High-performance bifunctional porous non-noble metal phosphide catalyst for overall water splitting. Nat. Commun. 2018, 9, 2551. [CrossRef] [PubMed]

41. Shinagawa, T.; Garcia-Esparza, A.T.; Takanabe, K. Insight on Tafel slopes from a microkinetic analysis of aqueous electrocatalysis for energy conversion. Sci. Rep. 2015, 5, 13801. [CrossRef] [PubMed]

42. Lyu, F.; Wang, Q.; Choi, S.M.; Yin, Y. Noble-Metal-Free Electrocatalysts for Oxygen Evolution. Small 2019, 15, 1804201. [CrossRef] [PubMed]

43. Eftekhari, A. Tuning the electrocatalysts for oxygen evolution reaction. Mater. Today Energy 2017, 5, 37-57. [CrossRef]

44. Gorlin, M.; De Araujo, J.F.; Schmies, H.; Bernsmeier, D.; Dresp, S.; Gliech, M.; Jusys, Z.; Chernev, P.; Kraehnert, R.; Dau, H.; et al. Tracking catalyst redox states and reaction dynamics in ni-fe oxyhydroxide oxygen evolution reaction electrocatalysts: The role of catalyst support and electrolyte pH. J. Am. Chem. Soc. 2017, 139, 2070-2082. [CrossRef]

45. Song, F.; Bai, L.; Moysiadou, A.; Lee, S.; Hu, C.; Liardet, L.; Hu, X. Transition Metal Oxides as Electrocatalysts for the Oxygen Evolution Reaction in Alkaline Solutions: An Application-Inspired Renaissance. J. Am. Chem. Soc. 2018, 140, 7748-7759. [CrossRef]

46. Dette, C.; Hurst, M.R.; Deng, J.; Nellist, M.R.; Boettcher, S.W. Structural Evolution of Metal (Oxy)hydroxide Nanosheets during the Oxygen Evolution Reaction. ACS Appl. Mater. Interfaces 2019, 11, 5590-5594. [CrossRef] [PubMed]

47. Zhu, Y.; Zhou, W.; Shao, Z. Perovskite/Carbon Composites: Applications in Oxygen Electrocatalysis. Small 2017, 13, 1603793. [CrossRef] [PubMed]

48. Zhao, Q.; Yan, Z.; Chen, C.; Chen, J. Spinels: Controlled Preparation, Oxygen Reduction/Evolution Reaction Application, and beyond. Chem. Rev. 2017, 117, 10121-10211. [CrossRef] [PubMed]

49. Wei, C.; Feng, Z.; Scherer, G.G.; Barber, J.; Shao-Horn, Y.; Xu, Z.J. Cations in Octahedral Sites: A Descriptor for Oxygen Electrocatalysis on Transition-Metal Spinels. Adv. Mater. 2017, 29, 1-8. [CrossRef]

50. Jung, J.I.; Risch, M.; Park, S.; Kim, M.G.; Nam, G.; Jeong, H.Y.; Shao-Horn, Y.; Cho, J. Optimizing nanoparticle perovskite for bifunctional oxygen electrocatalysis. Energy Environ. Sci. 2016, 9, 176-183. [CrossRef]

51. Monteverde Videla, A.H.A.; Stelmachowski, P.; Ercolino, G.; Specchia, S. Benchmark comparison of $\mathrm{Co}_{3} \mathrm{O}_{4}$ spinel-structured oxides with different morphologies for oxygen evolution reaction under alkaline conditions. J. Appl. Electrochem. 2017, 47, 295-304. [CrossRef]

52. Stelmachowski, P.; Monteverde Videla, A.H.A.; Ciura, K.; Specchia, S. Oxygen evolution catalysis in alkaline conditions over hard templated nickel-cobalt based spinel oxides. Int. J. Hydrogen Energy 2017, 42, 27910-27918. [CrossRef]

53. Stelmachowski, P.; Monteverde Videla, A.H.A.; Jakubek, T.; Kotarba, A.; Specchia, S. The Effect of Fe, Co, and Ni Structural Promotion of Cryptomelane $\left(\mathrm{KMn}_{8} \mathrm{O}_{16}\right)$ on the Catalytic Activity in Oxygen Evolution Reaction. Electrocatalysis 2018, 9, 762-769. [CrossRef]

54. Moon, G.H.; Yu, M.; Chan, C.K.; Tüysüz, H. Highly Active Cobalt-Based Electrocatalysts with Facile Incorporation of Dopants for the Oxygen Evolution Reaction. Angew. Chem. Int. Ed. 2019, 58, 3491-3495. [CrossRef] [PubMed]

55. Rana, M.; Mondal, S.; Sahoo, L.; Chatterjee, K.; Karthik, P.E.; Gautam, U.K. Emerging Materials in Heterogeneous Electrocatalysis Involving Oxygen for Energy Harvesting. ACS Appl. Mater. Interfaces 2018, 10, 33737-33767. [CrossRef] [PubMed]

56. Bergmann, A.; Jones, T.E.; Martinez Moreno, E.; Teschner, D.; Chernev, P.; Gliech, M.; Reier, T.; Dau, H.; Strasser, P. Unified structural motifs of the catalytically active state of Co(oxyhydr)oxides during the electrochemical oxygen evolution reaction. Nat. Catal. 2018, 1, 711-719. [CrossRef]

57. Suen, N.T.; Hung, S.F.; Quan, Q.; Zhang, N.; Xu, Y.J.; Chen, H.M. Electrocatalysis for the oxygen evolution reaction: Recent development and future perspectives. Chem. Soc. Rev. 2017, 46, 337-365. [CrossRef] [PubMed]

58. Shirotani, I.; Adachi, T.; Tachi, K.; Todo, S.; Nozawa, K.; Yagi, T.; Kinoshita, M. Electrical conductivity and superconductivity of metal phosphides with skutterudite-type structure prepared at high pressure. J. Phys. Chem. Solids 1996, 57, 211-216. [CrossRef]

59. Karaca, E.; Tütüncü, H.M.; Srivastava, G.P.; Uur, S. Electron-phonon superconductivity in the ternary phosphides BaM2P2 (M=Ni,Rh,and Ir). Phys. Rev. B 2016, 94, 054507. [CrossRef] 
60. Shi, Y.; Zhang, B. Recent advances in transition metal phosphide nanomaterials: Synthesis and applications in hydrogen evolution reaction. Chem. Soc. Rev. 2016, 45, 1529-1541. [CrossRef] [PubMed]

61. Jin, S. Are Metal Chalcogenides, Nitrides, and Phosphides Oxygen Evolution Catalysts or Bifunctional Catalysts? ACS Energy Lett. 2017, 2, 1937-1938. [CrossRef]

62. Wang, Y.; Kong, B.; Zhao, D.; Wang, H.; Selomulya, C. Strategies for developing transition metal phosphides as heterogeneous electrocatalysts for water splitting. Nano Today 2017, 15, 26-55. [CrossRef]

63. Xu, K.; Cheng, H.; Liu, L.; Lv, H.; Wu, X.; Wu, C.; Xie, Y. Promoting Active Species Generation by Electrochemical Activation in Alkaline Media for Efficient Electrocatalytic Oxygen Evolution in Neutral Media. Nano Lett. 2017, 17, 578-583. [CrossRef]

64. Tang, C.; Titirici, M.M.; Zhang, Q. A review of nanocarbons in energy electrocatalysis: Multifunctional substrates and highly active sites. J. Energy Chem. 2017, 26, 1077-1093. [CrossRef]

65. Dionigi, F.; Strasser, P. NiFe-Based (Oxy)hydroxide Catalysts for Oxygen Evolution Reaction in Non-Acidic Electrolytes. Adv. Energy Mater. 2016, 6, 1600621. [CrossRef]

66. Hu, Q.; Li, G.; Han, Z.; Wang, Z.; Huang, X.; Yang, H.; Zhang, Q.; Liu, J.; He, C. Recent progress in the hybrids of transition metals/carbon for electrochemical water splitting. J. Mater. Chem. A 2019, 7, 14380-14390. [CrossRef]

67. Liang, Y.; Zhang, W.; Wu, D.; Ni, Q.Q.; Zhang, M.Q. Interface Engineering of Carbon-Based Nanocomposites for Advanced Electrochemical Energy Storage. Adv. Mater. Interfaces 2018, 5, 1800430. [CrossRef]

68. Wang, L.; Fu, L.; Li, J.; Zeng, X.; Xie, H.; Huang, X.; Wang, H.; Tang, Y. On an easy way to prepare highly efficient Fe/N-co-doped carbon nanotube/nanoparticle composite for oxygen reduction reaction in Al-air batteries. J. Mater. Sci. 2018, 53, 10280-10291. [CrossRef]

69. Leonard, D.P.; Stickle, W.F.; Ji, X. Carbon-Supported Iron Phosphides: Highest Intrinsic Oxygen Evolution Activity of the Iron Triad. ACS Appl. Energy Mater. 2018, 1, 3593-3597. [CrossRef]

70. Chung, H.T.; Won, J.H.; Zelenay, P. Active and stable carbon nanotube/nanoparticle composite electrocatalyst for oxygen reduction. Nat. Commun. 2013, 4, 1922. [CrossRef]

71. Youn, D.H.; Han, S.; Kim, J.Y.; Kim, J.Y.; Park, H.; Choi, S.H.; Lee, J.S. Highly active and stable hydrogen evolution electrocatalysts based on molybdenum compounds on carbon nanotube-graphene hybrid support. ACS Nano 2014, 8, 5164-5173. [CrossRef]

72. Ma, T.Y.; Dai, S.; Jaroniec, M.; Qiao, S.Z. Graphitic Carbon Nitride Nanosheet-Carbon Nanotube Three-Dimensional Porous Composites as High-Performance Oxygen Evolution Electrocatalysts. Angew. Chem. 2014, 126, 7409-7413. [CrossRef]

73. Ji, D.; Fan, L.; Li, L.; Mao, N.; Qin, X.; Peng, S.; Ramakrishna, S. Hierarchical catalytic electrodes of cobalt-embedded carbon nanotube/carbon flakes array for flexible solid-state zinc-air batteries. Carbon 2019, 142, 379-387. [CrossRef]

74. Khalid, M.; Honorato, A.M.B.; Pasa, A.A.; Varela, H. A sugar derived carbon-red phosphorus composite for oxygen evolution reaction and supercapacitor activities. Mater. Sci. Energy Technol. 2020, 3, 508-514. [CrossRef]

75. Pérez-Rodríguez, S.; Sebastián, D.; Lázaro, M.J. Electrochemical oxidation of ordered mesoporous carbons and the influence of graphitization. Electrochim. Acta 2019, 303, 167-175. [CrossRef]

76. Pérez-Rodríguez, S.; Sebastián, D.; Lázaro, M.J. Insights on the Electrochemical Oxidation of Ordered Mesoporous Carbons. J. Electrochem. Soc. 2020, 167, 024511. [CrossRef]

77. Zheng, Y.; Chen, S.; Song, H.; Guo, H.; Zhang, K.A.I.; Zhang, C.; Liu, T. Nitrogen-doped hollow carbon nanoflowers from a preformed covalent triazine framework for metal-free bifunctional electrocatalysis. Nanoscale 2020, 12, 14441-14447. [CrossRef]

78. Wahab, M.A.; Joseph, J.; Atanda, L.; Sultana, U.K.; Beltramini, J.N.; Ostrikov, K.; Will, G.; O’Mullane, A.P.; Abdala, A. Nanoconfined Synthesis of Nitrogen-Rich Metal-Free Mesoporous Carbon Nitride Electrocatalyst for the Oxygen Evolution Reaction. ACS Appl. Energy Mater. 2020, 3, 1439-1447. [CrossRef]

79. Li, O.L.; Pham, N.N.T.; Kim, J.; Choi, H.; Lee, D.H.; Yang, Y.; Yao, W.; Cho, Y.R.; Lee, S.G. Insights on boosting oxygen evolution reaction performance via boron incorporation into nitrogen-doped carbon electrocatalysts. Appl. Surf. Sci. 2020, 528, 146979. [CrossRef]

80. Tsounis, C.; Lu, X.; Bedford, N.M.; Subhash, B.; Thomsen, L.; Zhang, Q.; Ma, Z.; Ostrikov, K.; Bendavid, A.; Scott, J.A.; et al. Valence Alignment of Mixed Ni-Fe Hydroxide Electrocatalysts through Preferential Templating on Graphene Edges for Enhanced Oxygen Evolution. ACS Nano 2020, 14, 11327-11340. [CrossRef]

81. Li, R.; Xu, J.; Lu, C.; Huang, Z.; Wu, Q.; Ba, J.; Tang, T.; Meng, D.; Luo, W. Amorphous NiFe phosphides supported on nanoarraystructured nitrogen-doped carbon paper for high-performance overall water splitting. Electrochim. Acta 2020, $357,136873$. [CrossRef]

82. Hummers, W.S. Preparation of Graphitic Acid. U.S. Patent 2,798,878, 9 July 1957.

83. Hummers, W.S.; Offeman, R.E. Preparation of Graphitic Oxide. J. Am. Chem. Soc. 1958, 80, 1339. [CrossRef]

84. He, J.Z.; Niu, W.J.; Wang, Y.P.; Sun, Q.Q.; Liu, M.J.; Wang, K.; Liu, W.W.; Liu, M.C.; Yu, F.C.; Chueh, Y.L. In-situ synthesis of hybrid nickel cobalt sulfide/carbon nitrogen nanosheet composites as highly efficient bifunctional oxygen electrocatalyst for rechargeable Zn-air batteries. Electrochim. Acta 2020, 362, 136968. [CrossRef]

85. Lei, C.; Chen, H.; Cao, J.; Yang, J.; Qiu, M.; Xia, Y.; Yuan, C.; Yang, B.; Li, Z.; Zhang, X.; et al. Fe-N 4 Sites Embedded into Carbon Nanofiber Integrated with Electrochemically Exfoliated Graphene for Oxygen Evolution in Acidic Medium. Adv. Energy Mater. 2018, 8, 1801912. [CrossRef]

86. Rivera-Gavidia, L.M.; Fernández de la Puente, I.; Hernández-Rodríguez, M.A.; Celorrio, V.; Sebastián, D.; Lázaro, M.J.; Pastor, E.; García, G. Bi-functional carbon-based catalysts for unitized regenerative fuel cells. J. Catal. 2020, 387, 138-144. [CrossRef] 
87. Morales, D.M.; Kazakova, M.A.; Dieckhöfer, S.; Selyutin, A.G.; Golubtsov, G.V.; Schuhmann, W.; Masa, J. Trimetallic Mn-Fe-Ni Oxide Nanoparticles Supported on Multi-Walled Carbon Nanotubes as High-Performance Bifunctional ORR/OER Electrocatalyst in Alkaline Media. Adv. Funct. Mater. 2020, 30. [CrossRef]

88. Li, L.; Yang, J.; Yang, H.; Zhang, L.; Shao, J.; Huang, W.; Liu, B.; Dong, X. Anchoring $\mathrm{Mn}_{3} \mathrm{O}_{4}$ Nanoparticles on Oxygen Functionalized Carbon Nanotubes as Bifunctional Catalyst for Rechargeable Zinc-Air Battery. ACS Appl. Energy Mater. 2018, 1, 963-969. [CrossRef]

89. Zhao, T.; Gadipelli, S.; He, G.; Ward, M.J.; Do, D.; Zhang, P.; Guo, Z. Tunable Bifunctional Activity of $\mathrm{Mn}_{\mathrm{x}} \mathrm{Co}_{3-\mathrm{x}} \mathrm{O}_{4} \mathrm{Nanocrystals}$ Decorated on Carbon Nanotubes for Oxygen Electrocatalysis. ChemSusChem 2018, 11, 1248. [CrossRef]

90. Li, B.; Song, F.; Qian, Y.; Shaw, J.; Rao, Y. Boron-doped graphene oxide-supported nickel nitride nanoparticles for electrocatalytic oxygen evolution in alkaline electrolytes. ACS Appl. Nano Mater. 2020, 3, 9924-9930. [CrossRef]

91. Han, X.; Yu, C.; Yang, J.; Song, X.; Zhao, C.; Li, S.; Zhang, Y.; Huang, H.; Liu, Z.; Huang, H.; et al. Electrochemically Driven Coordination Tuning of FeOOH Integrated on Carbon Fiber Paper for Enhanced Oxygen Evolution. Small 2019, 15, 1901015. [CrossRef]

92. Hoang, V.C.; Dinh, K.N.; Gomes, V.G. Hybrid Ni/NiO composite with N-doped activated carbon from waste cauliflower leaves: A sustainable bifunctional electrocatalyst for efficient water splitting. Carbon 2020, 157, 515-524. [CrossRef]

93. Prabu, N.; Kesavan, T.; Maduraiveeran, G.; Sasidharan, M. Bio-derived nanoporous activated carbon sheets as electrocatalyst for enhanced electrochemical water splitting. Int. J. Hydrogen Energy 2019, 44, 19995-20006. [CrossRef]

94. Kordek, K.; Yin, H.; Rutkowski, P.; Zhao, H. Cobalt-based composite films on electrochemically activated carbon cloth as high performance overall water splitting electrodes. Int. J. Hydrogen Energy 2019, 44, 23-33. [CrossRef]

95. Kordek, K.; Jiang, L.; Fan, K.; Zhu, Z.; Xu, L.; Al-Mamun, M.; Dou, Y.; Chen, S.; Liu, P.; Yin, H.; et al. Two-Step Activated Carbon Cloth with Oxygen-Rich Functional Groups as a High-Performance Additive-Free Air Electrode for Flexible Zinc-Air Batteries. Adv. Energy Mater. 2019, 9, 1802936. [CrossRef]

96. Wu, Z.; Li, P.; Qin, Q.; Li, Z.; Liu, X. N-doped graphene combined with alloys (NiCo, CoFe) and their oxides as multifunctional electrocatalysts for oxygen and hydrogen electrode reactions. Carbon 2018, 139, 35-44. [CrossRef]

97. Luo, W.; Wang, J.; Hu, J.; Ji, Y.; Streb, C.; Song, Y.F. Composite Metal Oxide-Carbon Nanotube Electrocatalysts for the Oxygen Evolution and Oxygen Reduction Reactions. ChemElectroChem 2018, 5, 2850-2856. [CrossRef]

98. Oh, T.; Ryu, S.; Oh, H.; Kim, J. $\mathrm{MnCo}_{2} \mathrm{O}_{4}$ nanoparticles supported on nitrogen and sulfur co-doped mesoporous carbon spheres as efficient electrocatalysts for oxygen catalytic reactions. Dalt. Trans. 2019, 48, 945-953. [CrossRef] [PubMed]

99. Wang, J.; Fan, M.; Tu, W.; Chen, K.; Shen, Y.; Zhang, H. In situ growth of $\mathrm{Co}_{3} \mathrm{O}_{4}$ on nitrogen-doped hollow carbon nanospheres as air electrode for lithium-air batteries. J. Alloys Compd. 2019, 777, 944-953. [CrossRef]

100. Wang, F.; Chen, G.; Liu, X.; Chen, F.; Wan, H.; Ni, L.; Zhang, N.; Ma, R.; Qiu, G. Advanced Electrocatalytic Performance of Ni-Based Materials for Oxygen Evolution Reaction. ACS Sustain. Chem. Eng. 2019, 7, 341-349. [CrossRef]

101. Qin, Q.; Chen, L.; Wei, T.; Wang, Y.; Liu, X. Ni/ $\mathrm{NiM}_{2} \mathrm{O}_{4}(\mathrm{M}=\mathrm{Mn}$ or Fe) supported on N-doped carbon nanotubes as trifunctional electrocatalysts for ORR, OER and HER. Catal. Sci. Technol. 2019, 9, 1595-1601. [CrossRef]

102. Kim, J.E.; Lim, J.; Lee, G.Y.; Choi, S.H.; Maiti, U.N.; Lee, W.J.; Lee, H.J.; Kim, S.O. Subnanometer Cobalt-Hydroxide-Anchored N-Doped Carbon Nanotube Forest for Bifunctional Oxygen Catalyst. ACS Appl. Mater. Interfaces 2016, 8, 1571-1577. [CrossRef]

103. Jia, H.; Wang, Z.; Li, C.; Si, X.; Zheng, X.; Cai, Y.; Lin, J.; Liang, H.; Qi, J.; Cao, J.; et al. Designing oxygen bonding between reduced graphene oxide and multishelled $\mathrm{Mn}_{3} \mathrm{O}_{4}$ hollow spheres for enhanced performance of supercapacitors. J. Mater. Chem. A 2019, 7, 6686-6694. [CrossRef]

104. Busacca, C.; Zignani, S.C.; Di Blasi, A.; Di Blasi, O.; Lo Faro, M.; Antonucci, V.; Aricò, A.S. Electrospun $\mathrm{NiMn}_{2} \mathrm{O}_{4}$ and $\mathrm{NiCo}_{2} \mathrm{O}_{4}$ spinel oxides supported on carbon nanofibers as electrocatalysts for the oxygen evolution reaction in an anion exchange membrane-based electrolysis cell. Int. J. Hydrogen Energy 2019. [CrossRef]

105. Li, T.; Li, S.; Liu, Q.; Tian, Y.; Zhang, Y.; Fu, G.; Tang, Y. Hollow $\mathrm{Co}_{3} \mathrm{O}_{4} / \mathrm{CeO}_{2}$ Heterostructures in Situ Embedded in N-Doped Carbon Nanofibers Enable Outstanding Oxygen Evolution. ACS Sustain. Chem. Eng. 2019, 7, 17950-17957. [CrossRef]

106. Kazakova, M.A.; Morales, D.M.; Andronescu, C.; Elumeeva, K.; Selyutin, A.G.; Ishchenko, A.V.; Golubtsov, G.V.; Dieckhöfer, S.; Schuhmann, W.; Masa, J. Fe/Co/Ni mixed oxide nanoparticles supported on oxidized multi-walled carbon nanotubes as electrocatalysts for the oxygen reduction and the oxygen evolution reactions in alkaline media. Catal. Today 2020, 357, 259-268. [CrossRef]

107. Hof, F.; Liu, M.; Valenti, G.; Picheau, E.; Paolucci, F.; Pénicaud, A. Size Control of Nanographene Supported Iron Oxide Nanoparticles Enhances Their Electrocatalytic Performance for the Oxygen Reduction and Oxygen Evolution Reactions. J. Phys. Chem. C 2019, 123, 20774-20780. [CrossRef]

108. Hu, Q.; Liu, X.; Tang, C.; Fan, L.; Chai, X.; Zhang, Q.; Liu, J.; He, C. High efficiency oxygen evolution reaction enabled by 3D network composed of nitrogen-doped graphitic carbon-coated metal/metal oxide heterojunctions. Electrochim. Acta 2018, 265, 620-628. [CrossRef]

109. Choi, H.J.; Han, G.D.; Bae, K.; Shim, J.H. Highly Active Oxygen Evolution on Carbon Fiber Paper Coated with Atomic-LayerDeposited Cobalt Oxide. ACS Appl. Mater. Interfaces 2019, 11, 10608-10615. [CrossRef] [PubMed]

110. Gaur, A.; Sachdeva, P.K.; Kumar, R.; Maruyama, T.; Bera, C.; Bagchi, V. Ultrathin $\mathrm{MoS}_{2}$ wrapped N-doped carbon-coated cobalt nanospheres for OER applications. Sustain. Energy Fuels 2021, 5, 801-807. [CrossRef] 
111. Dou, S.; Tao, L.; Huo, J.; Wang, S.; Dai, L. Etched and doped Co9S8/graphene hybrid for oxygen electrocatalysis. Energy Environ. Sci. 2016, 9, 1320-1326. [CrossRef]

112. Han, X.; Wu, X.; Zhong, C.; Deng, Y.; Zhao, N.; Hu, W. $\mathrm{NiCo}_{2} \mathrm{~S}_{4}$ nanocrystals anchored on nitrogen-doped carbon nanotubes as a highly efficient bifunctional electrocatalyst for rechargeable zinc-air batteries. Nano Energy 2017, 31, 541-550. [CrossRef]

113. Wang, S.; He, P.; Jia, L.; He, M.; Zhang, T.; Dong, F.; Liu, M.; Liu, H.; Zhang, Y.; Li, C.; et al. Nanocoral-like composite of nickel selenide nanoparticles anchored on two-dimensional multi-layered graphitic carbon nitride: A highly efficient electrocatalyst for oxygen evolution reaction. Appl. Catal. B Environ. 2019, 243, 463-469. [CrossRef]

114. Liu, G.; Zhang, Z.; Li, J.; Liu, J.; Long, X.; Chen, H.; Tong, H.; Liu, Z.; Qian, D. Constructing heterostructured CoSe $2 / \mathrm{Ni}_{3} \mathrm{Se}_{4} @ \mathrm{~N}-$ doped carbon nanosheets/ketjen black carbon as a robust oxygen evolution electrocatalyst. Int. J. Hydrogen Energy 2020, 45, 30666-30672. [CrossRef]

115. Ding, J.; Wang, P.; Ji, S.; Wang, H.; Brett, D.J.L.; Wang, R. Mesoporous nickel selenide N-doped carbon as a robust electrocatalyst for overall water splitting. Electrochim. Acta 2019, 300, 93-101. [CrossRef]

116. Sun, J.; Li, G.; Zheng, K.; He, Y.; Guo, Z.; Xu, C. Surface $\mathrm{Co}^{3+}$-rich engineering of $\mathrm{Co}\left(\mathrm{S}_{\mathrm{x}} \mathrm{Se}_{1-\mathrm{x}}\right)_{2}$ nanocrystals coated with ultrathin carbon layer for efficient OER/HER. Appl. Surf. Sci. 2020, 517, 146183. [CrossRef]

117. Feng, Y.; Wang, S.; Wang, H.; Zhong, Y.; Hu, Y. An efficient and stable Ni-Fe selenides/nitrogen-doped carbon nanotubes in situ-derived electrocatalyst for oxygen evolution reaction. J. Mater. Sci. 2020, 55, 13927-13937. [CrossRef]

118. Guo, Y.; Zhang, C.; Zhang, J.; Dastafkan, K.; Wang, K.; Zhao, C.; Shi, Z. Metal-Organic Framework-Derived Bimetallic NiFe Selenide Electrocatalysts with Multiple Phases for Efficient Oxygen Evolution Reaction. ACS Sustain. Chem. Eng. 2021, 9, 2047-2056. [CrossRef]

119. Zou, J.; Luo, Q.; Wu, H.; Liu, S.; Lan, T.; Yao, Y.; Sial, M.A.Z.G.; Zhao, F.; Zhang, Q.; Zeng, X. CoSe 2 /Co nanoheteroparticles embedded in Co, $\mathrm{N}$ co-doped carbon nanopolyhedra/nanotubes as an efficient oxygen bifunctional electrocatalyst for $\mathrm{Zn}$-air batteries. Sustain. Energy Fuels 2020, 4, 4722-4732. [CrossRef]

120. Yuan, M.; Wang, M.; Lu, P.; Sun, Y.; Dipazir, S.; Zhang, J.; Li, S.; Zhang, G. Tuning carbon nanotube-grafted core-shell-structured cobalt selenide@carbon hybrids for efficient oxygen evolution reaction. J. Colloid Interface Sci. 2019, 533, 503-512. [CrossRef] [PubMed]

121. Zhang, S.; Dai, P.; Liu, H.; Yan, L.; Song, H.; Liu, D.; Zhao, X. Metal-organic framework derived porous flakes of cobalt chalcogenides ( $\mathrm{CoX}, \mathrm{X}=\mathrm{O}, \mathrm{S}$, Se and $\mathrm{Te}$ ) rooted in carbon fibers as flexible electrode materials for pseudocapacitive energy storage. Electrochim. Acta 2021, 369, 137681. [CrossRef]

122. Li, W.; Niu, Y.; Wu, X.; Wu, F.; Li, T.; Hu, W. Heterostructured $\mathrm{CoSe}_{2} / \mathrm{FeSe}_{2}$ Nanoparticles with Abundant Vacancies and Strong Electronic Coupling Supported on Carbon Nanorods for Oxygen Evolution Electrocatalysis. ACS Sustain. Chem. Eng. 2020, 8, 4658-4666. [CrossRef]

123. Ashok, A.; Kumar, A.; Ponraj, J.; Mansour, S.A. Development of Co/Cog $\mathrm{S}_{8}$ metallic nanowire anchored on N-doped CNTs through the pyrolysis of melamine for overall water splitting. Electrochim. Acta 2021, 368, 137642. [CrossRef]

124. Sivanantham, A.; Hyun, S.; Son, M.; Shanmugam, S. Nanostructured core-shell cobalt chalcogenides for efficient water oxidation in alkaline electrolyte. Electrochim. Acta 2019, 312, 234-241. [CrossRef]

125. Han, X.; Tong, X.; Wu, G.; Yang, N.; Guo, X.Y. Carbon fibers supported NiSe nanowire arrays as efficient and flexible electrocatalysts for the oxygen evolution reaction. Carbon 2018, 129, 245-251. [CrossRef]

126. Chi, J.Q.; Yan, K.L.; Xiao, Z.; Dong, B.; Shang, X.; Gao, W.K.; Li, X.; Chai, Y.M.; Liu, C.G. Trimetallic Ni-Fe-Co selenides nanoparticles supported on carbon fiber cloth as efficient electrocatalyst for oxygen evolution reaction. Int. J. Hydrogen Energy 2017, 42, 20599-20607. [CrossRef]

127. Wang, J.; Zhong, H.X.; Wang, Z.L.; Meng, F.L.; Zhang, X.B. Integrated Three-Dimensional Carbon Paper/Carbon Tubes/CobaltSulfide Sheets as an Efficient Electrode for Overall Water Splitting. ACS Nano 2016, 10, 2342-2348. [CrossRef] [PubMed]

128. Callejas, J.F.; Read, C.G.; Roske, C.W.; Lewis, N.S.; Schaak, R.E. Synthesis, Characterization, and Properties of Metal Phosphide Catalysts for the Hydrogen-Evolution Reaction. Chem. Mater. 2016, 28, 6017-6044. [CrossRef]

129. Idrees, M.; Mukhtar, A.; Ata-ur-Rehman; Abbas, S.M.; Zhang, Q.; Li, X. Transition metal nitride electrodes as future energy storage devices: A review. Mater. Today Commun. 2021, 27, 102363. [CrossRef]

130. Zheng, J.; Zhang, W.; Zhang, J.; Lv, M.; Li, S.; Song, H.; Cui, Z.; Du, L.; Liao, S. Recent advances in nanostructured transition metal nitrides for fuel cells. J. Mater. Chem. A 2020, 8, 20803-20818. [CrossRef]

131. Aziz, S.T.; Malik, B.; Sadhanala, H.K.; Gedanken, A.; Noked, M.; Nessim, G.D. Nickel-Rich Phosphide (Ni $\left.{ }_{12} \mathrm{P}_{5}\right) \mathrm{Nanosheets}$ Coupled with Oxidized Multiwalled Carbon Nanotubes for Oxygen Evolution. ACS Appl. Nano Mater. 2020, 3, 10914-10921. [CrossRef]

132. Kang, Q.; Li, M.; Shi, J.; Lu, Q.; Gao, F. A Universal Strategy for Carbon-Supported Transition Metal Phosphides as High-Performance Bifunctional Electrocatalysts towards Efficient Overall Water Splitting. ACS Appl. Mater. Interfaces 2020, 12, 19447-19456. [CrossRef]

133. Wu, J.; Li, P.; Parra-Puerto, A.; Wu, S.; Lin, X.; Kramer, D.; Chen, S.; Kucernak, A. Controllable Heteroatom Doping Effects of $\mathrm{Cr}_{\mathrm{x}} \mathrm{Co}_{2-\mathrm{x}} \mathrm{P}$ Nanoparticles: A Robust Electrocatalyst for Overall Water Splitting in Alkaline Solutions. ACS Appl. Mater. Interfaces 2020, 12, 47397-47407. [CrossRef] 
134. Li, H.; Kong, X.; Geng, X.; Gu, C.; Liu, Z.; Wang, J. DNA as template and P-source for synthesis of $\mathrm{Co}_{2} \mathrm{P} / \mathrm{Co}_{2} \mathrm{~N}$ core-shell nanostructure embedded in $\mathrm{N}$-doped carbon nanofiber derived from electrospun precursor for oxygen evolution reaction. Electrochim. Acta 2021, 367, 137562. [CrossRef]

135. Liu, T.; Li, M.; Su, Z.; Bo, X.; Guan, W.; Zhou, M. Monodisperse and Tiny $\mathrm{Co}_{2} \mathrm{~N}_{0.67}$ Nanocrystals Uniformly Embedded over Two Curving Surfaces of Hollow Carbon Microfibers as Efficient Electrocatalyst for Oxygen Evolution Reaction. ACS Appl. Nano Mater. 2018, 1, 4461-4473. [CrossRef]

136. He, G.; Han, X.; Moss, B.; Weng, Z.; Gadipelli, S.; Lai, F.; Kafizas, A.G.; Brett, D.J.L.; Guo, Z.X.; Wang, H.; et al. Solid solution nitride/carbon nanotube hybrids enhance electrocatalysis of oxygen in zinc-air batteries. Energy Storage Mater. 2018, 15, 380-387. [CrossRef]

137. Chen, X.; Gao, P.; Liu, H.; Xu, J.; Zhang, B.; Zhang, Y.; Tang, Y.; Xiao, C. In situ growth of iron-nickel nitrides on carbon nanotubes with enhanced stability and activity for oxygen evolution reaction. Electrochim. Acta 2018, 267, 8-14. [CrossRef]

138. Shu, X.; Chen, S.; Chen, S.; Pan, W.; Zhang, J. Cobalt nitride embedded holey N-doped graphene as advanced bifunctional electrocatalysts for Zn-Air batteries and overall water splitting. Carbon 2020, 157, 234-243. [CrossRef]

139. Hei, J.; Xu, G.; Wei, B.; Zhang, L.; Ding, H.; Liu, D. NiFeP nanosheets on N-doped carbon sponge as a hierarchically structured bifunctional electrocatalyst for efficient overall water splitting. Appl. Surf. Sci. 2021, 549, 149297. [CrossRef]

140. Huang, J.; Li, F.; Liu, B.; Zhang, P. $\mathrm{Ni}_{2} \mathrm{P} / \mathrm{rGO} / \mathrm{NF}$ nanosheets as a bifunctional high-performance electrocatalyst for water splitting. Materials 2020, 13, 744. [CrossRef]

141. Bian, J.; Song, Z.; Li, X.; Zhang, Y.; Cheng, C. Nickel iron phosphide ultrathin nanosheets anchored on nitrogen-doped carbon nanoflake arrays as a bifunctional catalyst for efficient overall water splitting. Nanoscale 2020, 12, 8443-8452. [CrossRef] [PubMed]

142. Ma, B.; Duan, X.; Han, W.; Fan, X.; Li, Y.; Zhang, F.; Zhang, G.; Peng, W. Decorated nickel phosphide nanoparticles with nitrogen and phosphorus co-doped porous carbon for enhanced electrochemical water splitting. J. Colloid Interface Sci. 2020, 567, 393-401. [CrossRef]

143. Li, X.; Qian, X.; Xu, Y.; Duan, F.; Yu, Q.; Wang, J.; Chen, L.; Dan, Y.; Cheng, X. Electrodeposited cobalt phosphides with hierarchical nanostructure on biomass carbon for bifunctional water splitting in alkaline solution. J. Alloys Compd. 2020, 829, 154535. [CrossRef]

144. Zhu, J.; Liu, C.; Sun, J.; Xing, Y.; Quan, B.; Li, D.; Jiang, D. Interfacial engineering of $\mathrm{Co}_{3}$ FeN $\mathrm{x}_{\mathrm{x}}$ embedded N-doped carbon nanoarray derived from metal-organic frameworks for enhanced oxygen evolution reaction. Electrochim. Acta 2020, 354, 136629. [CrossRef]

145. Guan, C.; Sumboja, A.; Zang, W.; Qian, Y.; Zhang, H.; Liu, X.; Liu, Z.; Zhao, D.; Pennycook, S.J.; Wang, J. Decorating Co/CoN nanoparticles in nitrogen-doped carbon nanoarrays for flexible and rechargeable zinc-air batteries. Energy Storage Mater. 2019, 16, 243-250. [CrossRef]

146. Hu, L.; Hu, Y.; Liu, R.; Mao, Y.; Balogun, M.S.; Jie, T.; Tong, Y. Co-based MOF-derived Co/CoN/Co $2 \mathrm{P}$ ternary composite embedded in $\mathrm{N}$ - and P-doped carbon as bifunctional nanocatalysts for efficient overall water splitting. Int. J. Hydrogen Energy 2019, 44, 11402-11410. [CrossRef]

147. Kang, Y.; Wang, S.; Zhu, S.; Gao, H.; Hui, K.S.; Yuan, C.Z.; Yin, H.; Bin, F.; Wu, X.L.; Mai, W.; et al. Iron-modulated nickel cobalt phosphide embedded in carbon to boost power density of hybrid sodium-air battery. Appl. Catal. B Environ. 2021, $285,119786$. [CrossRef]

148. Huo, D.; Song, F.; Hu, J.; Yuan, J.; Niu, L.; Wang, A.-J. One-step synthesis of carbon-encapsulated nickel phosphide nanoparticles with efficient bifunctional catalysis on oxygen evolution and reduction. Int. J. Hydrogen Energy 2021, 46, 8519-8530. [CrossRef]

149. Choi, H.W.; Jeong, D.I.; Woo, S.; Kwon, S.B.; Wu, S.; Kim, J.H.; Yang, W.S.; Kang, B.K.; Lim, B.; Yoon, D.H. Morphology adjustable CoxN with 3D mesoporous structure and amorphous $\mathrm{N}$-doped carbon for overall water splitting. Appl. Surf. Sci. 2020, 529, 147177. [CrossRef]

150. Li, X.; Xu, Y.; Li, Y.; Fan, X.; Zhang, G.; Zhang, F.; Peng, W. Increasing the heteroatoms doping percentages of graphene by porous engineering for enhanced electrocatalytic activities. J. Colloid Interface Sci. 2020, 577, 101-108. [CrossRef]

151. Guo, X.; Duan, X.; Ji, J.; Fan, X.; Li, Y.; Zhang, F.; Zhang, G.; Zhu, Y.A.; Peng, W.; Wang, S. Synthesis of nitrogen and sulfur doped graphene on graphite foam for electro-catalytic phenol degradation and water splitting. J. Colloid Interface Sci. 2021, 583, 139-148. [CrossRef] [PubMed]

152. Lai, C.; Gong, M.; Zhou, Y.; Fang, J.; Huang, L.; Deng, Z.; Liu, X.; Zhao, T.; Lin, R.; Wang, K.; et al. Sulphur modulated Ni 3 FeN supported on N/S co-doped graphene boosts rechargeable/flexible Zn-air battery performance. Appl. Catal. B Environ. 2020, 274, 119086. [CrossRef]

153. Yang, X.; Xie, H.; Zou, Y.; Huang, Y.; Jiang, L.W.; Wang, X.; Tang, D.H.; Si, C.; Wang, J.J. Cost-effective and efficient plum-puddinglike FexNi $\mathrm{Fix}_{1-\mathrm{S}} \mathrm{S}_{2} / \mathrm{C}$ composite electrocatalysts for oxygen evolution reaction. Renew. Energy 2021, 168, 416-423. [CrossRef]

154. Liu, Z.; Wang, M.; Luo, X.; Li, S.; Li, S.; Zhou, Q.; Xu, W.; Wu, R. N-, P-, and O-doped porous carbon: A trifunctional metal-free electrocatalyst. Appl. Surf. Sci. 2021, 544, 148912. [CrossRef]

155. Cheng, Y.; Xu, C.; Jia, L.; Gale, J.D.; Zhang, L.; Liu, C.; Shen, P.K.; Jiang, S.P. Pristine carbon nanotubes as non-metal electrocatalysts for oxygen evolution reaction of water splitting. Appl. Catal. B Environ. 2015, 163, 96-104. [CrossRef]

156. Yang, H.B.; Miao, J.; Hung, S.F.; Chen, J.; Tao, H.B.; Wang, X.; Zhang, L.; Chen, R.; Gao, J.; Chen, H.M.; et al. Identification of catalytic sites for oxygen reduction and oxygen evolution in N-doped graphene materials: Development of highly efficient metal-free bifunctional electrocatalyst. Sci. Adv. 2016, 2, e1501122. [CrossRef] [PubMed] 
157. Zhang, C.; Bhoyate, S.; Hyatt, M.; Neria, B.L.; Siam, K.; Kahol, P.K.; Ghimire, M.; Mishra, S.R.; Perez, F.; Gupta, R.K. Nitrogendoped flexible carbon cloth for durable metal free electrocatalyst for overall water splitting. Surf. Coat. Technol. 2018, 347, 407-413. [CrossRef]

158. Davodi, F.; Tavakkoli, M.; Lahtinen, J.; Kallio, T. Straightforward synthesis of nitrogen-doped carbon nanotubes as highly active bifunctional electrocatalysts for full water splitting. J. Catal. 2017, 353, 19-27. [CrossRef]

159. Paul, R.; Wang, M.; Roy, A. Transparent graphene/BN-graphene stacked nanofilms for electrocatalytic oxygen evolution. ACS Appl. Nano Mater. 2020, 3, 10418-10426. [CrossRef]

160. Cheng, N.; Liu, Q.; Tian, J.; Xue, Y.; Asiri, A.M.; Jiang, H.; He, Y.; Sun, X. Acidically oxidized carbon cloth: A novel metal-free oxygen evolution electrode with high catalytic activity. Chem. Commun. 2015, 51, 1616-1619. [CrossRef]

161. Ali, A.; Akyüz, D.; Asghar, M.A.; Koca, A.; Keskin, B. Free-standing carbon nanotubes as non-metal electrocatalyst for oxygen evolution reaction in water splitting. Int. J. Hydrogen Energy 2018, 43, 1123-1128. [CrossRef]

162. Jiang, H.; Gu, J.; Zheng, X.; Liu, M.; Qiu, X.; Wang, L.; Li, W.; Chen, Z.; Ji, X.; Li, J. Defect-rich and ultrathin N doped carbon nanosheets as advanced trifunctional metal-free electrocatalysts for the ORR, OER and HER. Energy Environ. Sci. 2019, 12, 322-333. [CrossRef]

163. Lu, X.; Yim, W.L.; Suryanto, B.H.R.; Zhao, C. Electrocatalytic oxygen evolution at surface-oxidized multiwall carbon nanotubes. J. Am. Chem. Soc. 2015, 137, 2901-2907. [CrossRef]

164. Li, R.; Wei, Z.; Gou, X. Nitrogen and Phosphorus Dual-Doped Graphene/Carbon Nanosheets as Bifunctional Electrocatalysts for Oxygen Reduction and Evolution. ACS Catal. 2015, 5, 4133-4142. [CrossRef]

165. Zhao, F.; Bae, J.; Zhou, X.; Guo, Y.; Yu, G. Nanostructured Functional Hydrogels as an Emerging Platform for Advanced Energy Technologies. Adv. Mater. 2018, 30, 1801796. [CrossRef]

166. Wang, P.; Zhang, H.; Wang, H.; Li, D.; Xuan, J.; Zhang, L. Hybrid Manufacturing of 3D Hierarchical Porous Carbons for Electrochemical Storage. Adv. Mater. Technol. 2020, 5, 1901030. [CrossRef]

167. Zhu, Y.P.; Jing, Y.; Vasileff, A.; Heine, T.; Qiao, S.Z. 3D Synergistically Active Carbon Nanofibers for Improved Oxygen Evolution. Adv. Energy Mater. 2017, 7, 1602928. [CrossRef]

168. Desalegn, B.Z.; Jadhav, H.S.; Seo, J.G. Highly Efficient g-C3N4 Nanorods with Dual Active Sites as an Electrocatalyst for the Oxygen Evolution Reaction. ChemCatChem 2019, 11, 2870-2878. [CrossRef]

169. Peng, Z.; Yang, S.; Jia, D.; Da, P.; He, P.; Al-Enizi, A.M.; Ding, G.; Xie, X.; Zheng, G. Homologous metal-free electrocatalysts grown on three-dimensional carbon networks for overall water splitting in acidic and alkaline media. J. Mater. Chem. A 2016, 4, 12878-12883. [CrossRef]

170. Ma, T.Y.; Ran, J.; Dai, S.; Jaroniec, M.; Qiao, S.Z. Phosphorus-Doped Graphitic Carbon Nitrides Grown In Situ on Carbon-Fiber Paper: Flexible and Reversible Oxygen Electrodes. Angew. Chem. Int. Ed. 2015, 54, 4646-4650. [CrossRef]

171. Luque-Centeno, J.M.; Martínez-Huerta, M.V.; Sebastián, D.; Lemes, G.; Pastor, E.; Lázaro, M.J. Bifunctional N-doped graphene Ti and Co nanocomposites for the oxygen reduction and evolution reactions. Renew. Energy 2018, 125, 182-192. [CrossRef]

172. Ruiz-Cornejo, J.C.; Vivo-Vilches, J.F.; Sebastián, D.; Martínez-Huerta, M.V.; Lázaro, M.J. Carbon nanofiber-supported tantalum oxides as durable catalyst for the oxygen evolution reaction in alkaline media. Renew. Energy 2021, 178, 307-317. [CrossRef]

173. Alegre, C.; Busacca, C.; Di Blasi, O.; Antonucci, V.; Aricò, A.S.; Di Blasi, A.; Baglio, V. A combination of CoO and Co nanoparticles supported on electrospun carbon nanofibers as highly stable air electrodes. J. Power Sources 2017, 364, 101-109. [CrossRef]

174. Alegre, C.; Modica, E.; Di Blasi, A.; Di Blasi, O.; Busacca, C.; Ferraro, M.; Aricò, A.S.; Antonucci, V.; Baglio, V. NiCo-loaded carbon nanofibers obtained by electrospinning: Bifunctional behavior as air electrodes. Renew. Energy 2018, 125, 250-259. [CrossRef]

175. Alegre, C.; Busacca, C.; Di Blasi, A.; Di Blasi, O.; Aricò, A.S.; Antonucci, V.; Modica, E.; Baglio, V. Electrospun carbon nanofibers loaded with spinel-type cobalt oxide as bifunctional catalysts for enhanced oxygen electrocatalysis. J. Energy Storage 2019, 23, 269-277. [CrossRef]

176. Alegre, C.; Busacca, C.; Di Blasi, A.; Di Blasi, O.; Aricò, A.S.; Antonucci, V.; Baglio, V. Electrocatalysis of Oxygen on Bifunctional Nickel-Cobaltite Spinel. ChemElectroChem 2020, 7, 124-130. [CrossRef]

177. Alegre, C.; Busacca, C.; Di Blasi, A.; Di Blasi, O.; Aricò, A.S.; Antonucci, V.; Baglio, V. Toward more efficient and stable bifunctional electrocatalysts for oxygen electrodes using $\mathrm{FeCO}_{2} \mathrm{O}_{4}$ / carbon nanofiber prepared by electrospinning. Mater. Today Energy 2020, 18, 100508. [CrossRef]

178. Moon, G.D.; Ko, S.; Xia, Y.; Jeong, U. Chemical transformations in ultrathin chalcogenide nanowires. ACS Nano 2010, 4, $2307-2319$. [CrossRef] [PubMed]

179. Chen, Z.; Wu, R.; Liu, M.; Liu, Y.; Xu, S.; Ha, Y.; Guo, Y.; Yu, X.; Sun, D.; Fang, F. Tunable electronic coupling of cobalt sulfide/carbon composites for optimizing oxygen evolution reaction activity. J. Mater. Chem. A 2018, 6, 10304-10312. [CrossRef]

180. Ding, H.; Xu, G.; Zhang, L.; Wei, B.; Hei, J.; Chen, L. A highly effective bifunctional catalyst of cobalt selenide nanoparticles embedded nitrogen-doped bamboo-like carbon nanotubes toward hydrogen and oxygen evolution reactions based on metalorganic framework. J. Colloid Interface Sci. 2020, 566, 296-303. [CrossRef] [PubMed]

181. He, B.; Wang, X.C.; Xia, L.X.; Guo, Y.Q.; Tang, Y.W.; Zhao, Y.; Hao, Q.L.; Yu, T.; Liu, H.K.; Su, Z. Metal-Organic Framework-Derived Fe-Doped $\mathrm{Co}_{1.11} \mathrm{Te}_{2}$ Embedded in Nitrogen-Doped Carbon Nanotube for Water Splitting. ChemSusChem 2020, 13, $5239-5247$. [CrossRef]

182. Oyetade, O.A.; Kriek, R.J. NiSe-Ni $\mathrm{Ne}_{2}$ /Multiwalled Carbon Nanotube Composites as Efficient Electrocatalysts for the Oxygen Evolution Reaction in Alkaline Media. Electrocatalysis 2020, 11, 35-45. [CrossRef] 
183. Wang, X.; Huang, X.; Gao, W.; Tang, Y.; Jiang, P.; Lan, K.; Yang, R.; Wang, B.; Li, R. Metal-organic framework derived CoTe 2 encapsulated in nitrogen-doped carbon nanotube frameworks: A high-efficiency bifunctional electrocatalyst for overall water splitting. J. Mater. Chem. A 2018, 6, 3684-3691. [CrossRef]

184. Yang, L.; Gao, M.; Dai, B.; Guo, X.; Liu, Z.; Peng, B. An efficient NiS@N/S-C hybrid oxygen evolution electrocatalyst derived from metal-organic framework. Electrochim. Acta 2016, 191, 813-820. [CrossRef]

185. Wu, L.L.; Wang, Q.S.; Li, J.; Long, Y.; Liu, Y.; Song, S.Y.; Zhang, H.J. Co9S8 Nanoparticles-Embedded N/S-Codoped Carbon Nanofibers Derived from Metal-Organic Framework-Wrapped CdS Nanowires for Efficient Oxygen Evolution Reaction. Small 2018, 14, 1704035. [CrossRef] [PubMed]

186. Chen, B.; Li, R.; Ma, G.; Gou, X.; Zhu, Y.; Xia, Y. Cobalt sulfide/N,S codoped porous carbon core-shell nanocomposites as superior bifunctional electrocatalysts for oxygen reduction and evolution reactions. Nanoscale 2015, 7, 20674-20684. [CrossRef]

187. Cao, X.; Zheng, X.; Tian, J.; Jin, C.; Ke, K.; Yang, R. Cobalt Sulfide Embedded in Porous Nitrogen-doped Carbon as a Bifunctional Electrocatalyst for Oxygen Reduction and Evolution Reactions. Electrochim. Acta 2016, 191, 776-783. [CrossRef]

188. Jayaramulu, K.; Masa, J.; Tomanec, O.; Peeters, D.; Ranc, V.; Schneemann, A.; Zboril, R.; Schuhmann, W.; Fischer, R.A. Nanoporous Nitrogen-Doped Graphene Oxide/Nickel Sulfide Composite Sheets Derived from a Metal-Organic Framework as an Efficient Electrocatalyst for Hydrogen and Oxygen Evolution. Adv. Funct. Mater. 2017, 27, 1700451. [CrossRef]

189. Le, T.T.; Liu, X.; Xin, P.; Wang, Q.; Gao, C.; Wu, Y.; Jiang, Y.; Hu, Z.; Huang, S.; Chen, Z. Phosphorus-doped Fe $7 S_{8} @$ C nanowires for efficient electrochemical hydrogen and oxygen evolutions: Controlled synthesis and electronic modulation on active sites. $J$. Mater. Sci. Technol. 2021, 74, 168-175. [CrossRef]

190. Ganesan, P.; Staykov, A.; Shu, H.; Uejima, M.; Nakashima, N. Designing an FeIII-doped nickel sulfide/carbon nanotube hybrid catalyst for alkaline electrolyte membrane water electrolyzers and $\mathrm{Zn}$-air battery performances. ACS Appl. Energy Mater. 2020, 3, 10961-10975. [CrossRef]

191. Shen, M.; Ruan, C.; Chen, Y.; Jiang, C.; Ai, K.; Lu, L. Covalent entrapment of cobalt-iron sulfides in N-doped mesoporous carbon: Extraordinary bifunctional electrocatalysts for oxygen reduction and evolution reactions. ACS Appl. Mater. Interfaces 2015, 7, 1207-1218. [CrossRef]

192. Jiang, J.; Lu, S.; Wang, W.K.; Huang, G.X.; Huang, B.C.; Zhang, F.; Zhang, Y.J.; Yu, H.Q. Ultrahigh electrocatalytic oxygen evolution by iron-nickel sulfide nanosheets/reduced graphene oxide nanohybrids with an optimized autoxidation process. Nano Energy 2018, 43, 300-309. [CrossRef]

193. Cao, J.; Wang, K.; Chen, J.; Lei, C.; Yang, B.; Li, Z.; Lei, L.; Hou, Y.; Ostrikov, K. Nitrogen-Doped Carbon-Encased Bimetallic Selenide for High-Performance Water Electrolysis. Nano-Micro Lett. 2019, 11, 67. [CrossRef]

194. Hosseini, H.; Roushani, M. Rational design of hollow core-double shells hybrid nanoboxes and nanopipes composed of hierarchical $\mathrm{Cu}-\mathrm{Ni}$-Co selenides anchored on nitrogen-doped carbon skeletons as efficient and stable bifunctional electrocatalysts for overall water splitting. Chem. Eng. J. 2020, 402, 126174. [CrossRef]

195. Liu, M.; Lu, X.; Guo, C.; Wang, Z.; Li, Y.; Lin, Y.; Zhou, Y.; Wang, S.; Zhang, J. Architecting a Mesoporous N-Doped Graphitic Carbon Framework Encapsulating $\mathrm{CoTe}_{2}$ as an Efficient Oxygen Evolution Electrocatalyst. ACS Appl. Mater. Interfaces 2017, 9, 36146-36153. [CrossRef]

196. Li, G.; Yu, J.; Yu, W.; Yang, L.; Zhang, X.; Liu, X.; Liu, H.; Zhou, W. Phosphorus-Doped Iron Nitride Nanoparticles Encapsulated by Nitrogen-Doped Carbon Nanosheets on Iron Foam In Situ Derived from Saccharomycetes Cerevisiae for Electrocatalytic Overall Water Splitting. Small 2020, 16, 2001980. [CrossRef]

197. Yang, H.; Guo, H.; Pang, K.; Fan, P.; Li, X.; Ren, W.; Song, R. An amorphous carbon nitride/NiO/CoN-based composite: A highly efficient nonprecious electrode for supercapacitors and the oxygen evolution reaction. Nanoscale 2020, 12, 7024-7034. [CrossRef] [PubMed]

198. Zhong, X.; Jiang, Y.; Chen, X.; Wang, L.; Zhuang, G.; Li, X.; Wang, J.G. Integrating cobalt phosphide and cobalt nitride-embedded nitrogen-rich nanocarbons: High-performance bifunctional electrocatalysts for oxygen reduction and evolution. J. Mater. Chem. A 2016, 4, 10575-10584. [CrossRef]

199. Liu, T.; Li, M.; Jiao, C.; Hassan, M.; Bo, X.; Zhou, M.; Wang, H.L. Design and synthesis of integrally structured Ni 3 N nanosheets/carbon microfibers/Ni3N nanosheets for efficient full water splitting catalysis. J. Mater. Chem. A 2017, 5, 9377-9390. [CrossRef]

200. Huang, C.; Ouyang, T.; Zou, Y.; Li, N.; Liu, Z.Q. Ultrathin $\mathrm{NiCo}_{2} \mathrm{P}: \mathrm{X}$ nanosheets strongly coupled with CNTs as efficient and robust electrocatalysts for overall water splitting. J. Mater. Chem. A 2018, 6, 7420-7427. [CrossRef]

201. Yang, D.; Hou, W.; Lu, Y.; Zhang, W.; Chen, Y. Cobalt phosphide nanoparticles supported within network of N-doped carbon nanotubes as a multifunctional and scalable electrocatalyst for water splitting. J. Energy Chem. 2021, 52, 130-138. [CrossRef]

202. Chen, D.; Zhu, J.; Mu, X.; Cheng, R.; Li, W.; Liu, S.; Pu, Z.; Lin, C.; Mu, S. Nitrogen-Doped carbon coupled FeNi 3 intermetallic compound as advanced bifunctional electrocatalyst for OER, ORR and zn-air batteries. Appl. Catal. B Environ. 2020, $268,118729$. [CrossRef]

203. Shi, J.; Qiu, F.; Yuan, W.; Guo, M.; Lu, Z.H. Nitrogen-doped carbon-decorated yolk-shell CoP@FeCoP micro-polyhedra derived from MOF for efficient overall water splitting. Chem. Eng. J. 2021, 403, 126312. [CrossRef]

204. Wang, Z.; Wei, C.; Zhu, X.; Wang, X.; He, J.; Zhao, Y. A hierarchical carbon nanotube forest supported metal phosphide electrode for efficient overall water splitting. J. Mater. Chem. A 2021, 9, 1150-1158. [CrossRef] 
205. Wu, Y.; Xiao, Z.; Jin, Z.; Li, X.; Chen, Y. The cobalt carbide/bimetallic CoFe phosphide dispersed on carbon nanospheres as advanced bifunctional electrocatalysts for the ORR, OER, and rechargeable Zn-air batteries. J. Colloid Interface Sci. 2021, 590, 321-329. [CrossRef]

206. Liu, H.; Guan, J.; Yang, S.; Yu, Y.; Shao, R.; Zhang, Z.; Dou, M.; Wang, F.; Xu, Q. Metal-Organic-Framework-Derived Co 2 P Nanoparticle/Multi-Doped Porous Carbon as a Trifunctional Electrocatalyst. Adv. Mater. 2020, 32, 2003649. [CrossRef] [PubMed]

207. Ma, M.; Zheng, Z.; Song, Z.; Zhang, X.; Han, X.; Chen, H.; Xie, Z.; Kuang, Q.; Zheng, L. In situ construction and post-electrolysis structural study of porous $\mathrm{Ni}_{2} \mathrm{P} @ \mathrm{C}$ nanosheet arrays for efficient water splitting. Inorg. Chem. Front. 2020, 7, 2960-2968. [CrossRef]

208. Yang, D.; Su, Z.; Chen, Y.; Lu, Y.; Yu, B.; Srinivas, K.; Wang, B.; Zhang, W. Double-shelled hollow bimetallic phosphide nanospheres anchored on nitrogen-doped graphene for boosting water electrolysis. J. Mater. Chem. A 2020, 8, 22222-22229. [CrossRef]

209. Tang, Y.J.; You, L.; Zhou, K.; Zhou, K. Enhanced Oxygen Evolution Reaction Activity of a $\mathrm{Co}_{2} \mathrm{P} @ \mathrm{NC}^{-} \mathrm{Fe}_{2} \mathrm{P}$ Composite Boosted by Interfaces between a N-Doped Carbon Matrix and $\mathrm{Fe}_{2} \mathrm{P}$ Microspheres. ACS Appl. Mater. Interfaces 2020, 12, 25884-25894. [CrossRef] [PubMed]

210. He, P.; Yu, X.Y.; Lou, X.W.D. Carbon-Incorporated Nickel-Cobalt Mixed Metal Phosphide Nanoboxes with Enhanced Electrocatalytic Activity for Oxygen Evolution. Angew. Chem. Int. Ed. 2017, 56, 3897-3900. [CrossRef] [PubMed]

211. Pu, Z.; Liu, T.; Amiinu, I.S.; Cheng, R.; Wang, P.; Zhang, C.; Ji, P.; Hu, W.; Liu, J.; Mu, S. Transition-Metal Phosphides: Activity Origin, Energy-Related Electrocatalysis Applications, and Synthetic Strategies. Adv. Funct. Mater. 2020, 30, 2004009. [CrossRef]

212. Zhang, J.; Zhang, Q.; Feng, X. Support and Interface Effects in Water-Splitting Electrocatalysts. Adv. Mater. 2019, $31,1808167$. [CrossRef] [PubMed]

213. Zhu, Y.P.; Guo, C.; Zheng, Y.; Qiao, S.Z. Surface and Interface Engineering of Noble-Metal-Free Electrocatalysts for Efficient Energy Conversion Processes. Acc. Chem. Res. 2017, 50, 915-923. [CrossRef]

214. Zhao, D.; Pi, Y.; Shao, Q.; Feng, Y.; Zhang, Y.; Huang, X. Enhancing Oxygen Evolution Electrocatalysis via the Intimate Hydroxide-Oxide Interface. ACS Nano 2018, 12, 6245-6251. [CrossRef]

215. Xu, J.; Wei, X.K.; Costa, J.D.; Lado, J.L.; Owens-Baird, B.; Gonçalves, L.P.L.; Fernandes, S.P.S.; Heggen, M.; Petrovykh, D.Y.; Dunin-Borkowski, R.E.; et al. Interface Engineering in Nanostructured Nickel Phosphide Catalyst for Efficient and Stable Water Oxidation. ACS Catal. 2017, 7, 5450-5455. [CrossRef]

216. Liu, P.F.; Li, X.; Yang, S.; Zu, M.Y.; Liu, P.; Zhang, B.; Zheng, L.R.; Zhao, H.; Yang, H.G. Ni ${ }_{2} P(O) / F_{2} P(O)$ Interface Can Boost Oxygen Evolution Electrocatalysis. ACS Energy Lett. 2017, 2, 2257-2263. [CrossRef]

217. Niu, Z.; Qiu, C.; Jiang, J.; Ai, L. Hierarchical CoP-FeP Branched Heterostructures for Highly Efficient Electrocatalytic Water Splitting. ACS Sustain. Chem. Eng. 2019, 7, 2335-2342. [CrossRef]

218. Ding, X.; Xia, Y.; Li, Q.; Dong, S.; Jiao, X.; Chen, D. Interface Engineering of $\mathrm{Co}(\mathrm{OH})_{2} / \mathrm{Ag} / \mathrm{FeP}$ Hierarchical Superstructure as Efficient and Robust Electrocatalyst for Overall Water Splitting. ACS Appl. Mater. Interfaces 2019, 11, 7936-7945. [CrossRef]

219. Li, M.; Pan, X.; Jiang, M.; Zhang, Y.; Tang, Y.; Fu, G. Interface engineering of oxygen-vacancy-rich $\mathrm{CoP} / \mathrm{CeO}_{2}$ heterostructure boosts oxygen evolution reaction. Chem. Eng. J. 2020, 395, 125160. [CrossRef]

220. Li, Y.; Liao, C.; Tang, K.; Zhang, N.; Qi, W.; Xie, H.; He, J.; Yin, K.; Gao, Y.; Wang, C. Cobalt hydroxide-black phosphorus nanosheets: A superior electrocatalyst for electrochemical oxygen evolution. Electrochim. Acta 2019, 297, 40-45. [CrossRef]

221. Xu, Q.; Jiang, H.; Zhang, H.; Hu, Y.; Li, C. Heterogeneous interface engineered atomic configuration on ultrathin $\mathrm{Ni}(\mathrm{OH})_{2} / \mathrm{Ni}_{3} \mathrm{~S}_{2}$ nanoforests for efficient water splitting. Appl. Catal. B Environ. 2019, 242, 60-66. [CrossRef]

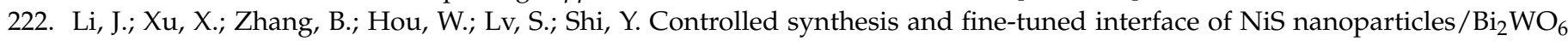
nanosheets heterogeneous as electrocatalyst for oxygen evolution reaction. Appl. Surf. Sci. 2020, 526, 146718. [CrossRef]

223. Guan, X.; Sun, X.; Feng, H.; Zhang, J.; Wen, H.; Tian, W.; Zheng, D.; Yao, Y. Rational interface engineering of $\mathrm{Cu}_{2} \mathrm{~S}-\mathrm{CoO} \mathrm{x}_{\mathrm{x}} / \mathrm{CF}$ enhances oxygen evolution reaction activity. Chem. Commun. 2020, 56, 13571-13574. [CrossRef]

224. Xia, J.; Zhao, H.; Huang, B.; Xu, L.; Luo, M.; Wang, J.; Luo, F.; Du, Y.; Yan, C.H. Efficient Optimization of Electron/Oxygen Pathway by Constructing Ceria/Hydroxide Interface for Highly Active Oxygen Evolution Reaction. Adv. Funct. Mater. 2020, 30, 1908367. [CrossRef]

225. Bao, W.; Xiao, L.; Zhang, J.; Deng, Z.; Yang, C.; Ai, T.; Wei, X. Interface engineering of NiV-LDH@FeOOH heterostructures as high-performance electrocatalysts for oxygen evolution reaction in alkaline conditions. Chem. Commun. 2020, 56, 9360-9363. [CrossRef] [PubMed]

226. An, L.; Feng, J.; Zhang, Y.; Wang, R.; Liu, H.; Wang, G.C.; Cheng, F.; Xi, P. Epitaxial Heterogeneous Interfaces on N-NiMoO 4 / NiS 2 Nanowires/Nanosheets to Boost Hydrogen and Oxygen Production for Overall Water Splitting. Adv. Funct. Mater. 2019, 29, 1805298. [CrossRef] 